\title{
Study the Effect of Ceiling Air Diffuser Blade and Lip Angles Using CFD
}

\author{
By Ahmed Awwad \\ Mohamed H. Mohamed ${ }^{\dagger}$ \\ Mohamed Fatouh
}

\begin{abstract}
The objective of the present work is to investigate the airflow characteristics inside a room through a 5-blade square louver face ceiling air diffuser using CFD to improve occupant's thermal comfort. Several blades angles $\left(45^{\circ}, 60^{\circ}\right.$ and $\left.65^{\circ}\right)$ and lip angles $\left(0^{\circ}, 5^{\circ}, 10^{\circ}\right.$, and $\left.15^{\circ}\right)$ were installed inside the room model. The realizable $k-\varepsilon$ turbulence model was used to simulate all the $3 D$ cases. In the paper, the results of 5 blade louver face diffuser with $60^{\circ}$ blade angle and horizontal lip are compared with 5-blade louver face diffuser with $45^{\circ}$ and $65^{\circ}$ blade angles with horizontal lip. Then, the effect of lip angle is investigated and compared with the results from a diffuser with a $60^{\circ}$ and horizontal lip. The results showed that the diffuser with a $65^{\circ}$ blade angle provides jet air velocity higher than $60^{\circ}$ beside air patterns cling with room ceiling, which enhances the surface (Coanda) effect and provides lower temperature gradients than $60^{\circ}$. Therefore, it is suitable to install in larger spaces in order to reduce drafts on space occupants and reduce installation costs. On the other hand, the results indicated that the diffuser model with a $45^{\circ}$ blade angle and $0^{\circ}$ lip angle provides cone-shaped air patterns without any being attached to the room ceiling, therefore this type is preferable for installation in rooms with larger height or inside areas that require relatively low noise levels. Moreover, increasing the diffuser lip angle to $15^{\circ}$ allows air patterns relatively to leave the room ceiling, and reach thermal comfort conditions without draft faster than the $0^{\circ}$ lip angle.
\end{abstract}

Keywords: Blade angle, Ceiling air diffusers, CFD, Comfort criteria, Lip angle, Surface (Coanda) effect.

\section{Introduction}

Air terminal devices (inlets and outlets) represent one of the important factors that affect the in-room air diffusion process. ASHRAE stated that the proper air distribution process inside the room is required to provide comfort criteria for space occupants with minimize energy consumption (ASHRAE, 2013). Therefore, studying the characteristics of supply air outlets is necessary to understanding their effects on airflow distribution inside rooms. Mohammed revealed that ceiling air diffusers serve many purposes inside a room (Mohammed, 2013):

- To deliver required supply airflow to the desired space.

\footnotetext{
${ }^{*}$ Helwan University, Egypt.

†Umm Al-Qura University, Saudi Arabia.

${ }^{\ddagger}$ Helwan University, Egypt.
} 
- To return or exhaust airflow from the desired space.

- To provide a stable and uniform air diffusion patterns to any desired directions.

- To reinforce and ensure mixing of primary supply air and entrained (secondary) room air effectively.

- Controlled air distribution to create low velocity movement to minimize noise level in the desired space.

There are many types of ceiling mounted air outlets used in various air distribution applications with different shapes such as round, square, rectangular, swirl, jet, and linear slot. Each of them has a particular function to provide thermal comfort conditions for the space occupant as well as good air distribution (PRICE, 2016; ZAMZAM, 2016; GAMMA LINE INTERNATIONAL, 2016; AIR MASTER, 2016).

Studying the airflow characteristics from ceiling air diffusers is required in order to achieve good design and comfort conditions for human occupants and to relate this factor to energy consumption using numerical and experimental techniques. Sun and Smith studied airflow patterns and temperature distribution from a 2D square cone ceiling diffuser model with and without the offset and lips of a diffuser using CFD simulation (Sun and Smith, 2005). The results from the simulation study were compared with the results from infrared visualization methodology for verification purposes. The results showed that the offset and lips of the diffuser model work to determine the airflow distribution quality in the room. The example without the offset but with the lip (NO/WL) indicated that the airflow pattern clings to the ceiling, which enhances the surface effect and minimizes draft phenomena. However, the arrangement with offset and without lip lead to a forced airflow pattern directed to the lower part of the room. The CFD simulation results were consistent with the infrared visualization results for the case with offset and lip (WO/WL).

Aziz et al. applied both experimental and numerical methods to determine airflow characteristics of different ceiling diffuser types (vortex, round, and square cone) and identified their effects on comfort criteria, indoor air quality, and energy consumption (Aziz et al., 2012). The conservation equations and standard k- $\varepsilon$ turbulence model were solved to simulate all cases. The results showed that the airflow with highest value came from the square cone diffuser. The highest values of the pressure coefficient or energy consumption of round and vortex diffusers amounted to the same inlet velocity. In addition, the square cone diffuser has small ventilation effectiveness (E) while the round diffuser has a high value. The highest value of effective draft temperature (EDT) occurred from vortex diffusers, and the lowest value from round diffusers. The simplified method was proposed by Mohammed for air inlet opening to speed up the ceiling air diffusers simulation process (Mohammed, 2013). Both experimental and numerical methods were applied to measure and record the room air velocity and temperature distributions for non-simplified round and square cone diffusers (with inlet neck). These results were compared with those of simplified round and square cone diffusers (without inlet neck) by replacing the square ceiling 
diffuser with a rectangular and the round ceiling diffuser with a cylindrical. The results showed that the airflow characteristics of a vertical plane at the center of the room for both non-simplified and simplified diffusers were similar.

Djunaedy and Cheong used CFD simulation techniques to study the influence of five different simplified models of square four-way air supply ceiling diffusers on airflow characteristics inside three different room sizes (Djunaedy and Cheong, 2002). Validations of five simplified models were done by comparing the results from each one with the measurements from experimental work. The standard $\mathrm{k}-\varepsilon$ and RNG k- $\varepsilon$ turbulence models were solved to simulate airflow distributions. The results presented the throw pattern profile of the different diffuser models inside different rooms. The results from the diffuser model (D) presented more consistent results with experimental work than the other models.

Abanto et al. studied the characteristics of airflow from four-way air supply ceiling diffusers in a computer room using computational fluid dynamic analysis (Abanto et al., 2004). That work identified the effects of object distribution, sources of energy, air inlets, outlets, and position in space on airflow patterns. The conservation equations including mass, momentum, and energy were solved; RNG $\mathrm{k}-\varepsilon$ turbulence model and radiation model was selected to simulate airflow distributions inside the room. The results introduced the maximum values for relative humidity and temperature inside the room, which are recommended for thermal comfort. In addition, identification of the effect of changing the shape of industrial air supply ceiling diffusers with planar diffuser in airflow characteristic was carried out.

Fontanini et al. studied the characteristics of airflow from conventional air ceiling diffusers and compared the results with new simplified diffusers based on ductwork fabrication to improve energy efficiency inside buildings (Fontanini et al., 2011). The CFD simulation methodology at 3D and unsteady state were established to identify the airflow behaviors and thermal distribution patterns inside the room. The energy equations and standard $k-\varepsilon$ turbulence model were solved. The results show that new fabric ductwork diffusers heat the desired space faster than conventional ceiling diffusers with high performance, and therefore enhance energy saving.

Other studies explain the effect of obstruction walls inside the room on airflow distribution. Posner et al. used CFD simulation analysis to explain and identify the effect of geometric room parameters such as obstruction walls on the characteristics of airflow patterns inside the room, and compare the results with experimental measurements using Laser Doppler Anemometry and Particle Image Velocimetry techniques (Posner et al., 2003). In this study, energy equation,

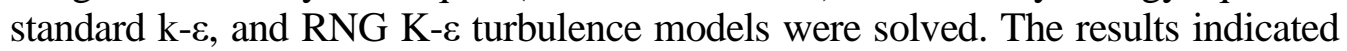
that the obstruction walls have a strong effect on airflow distribution inside the room and must take into consideration the ventilation design system. Tina et al. used RNG-large eddy simulation (LES) technique to study the airflow behaviors inside the room with and without contaminant particles (Tina et al., 2007). The results in the case of the room without contaminant particles present strong agreements with Posner and with the experimental data presented by Weizhen 
$\mathrm{Lu}$ et al. in the case with contaminant particles (Posner et al., 2003; Lu et al., 1996).

Tina et al. used three turbulence standard k- $\varepsilon$, RNG k- $\varepsilon$ and RNG-based LES models to study and simulate dispersion and concentration of contaminant particles inside the room, then compared the results with the experimental data presented by Posner (Tina et al., 2006; Posner et al., 2003). The results indicated that the RNG-based LES model has the best agreement with the experimental data of all the other turbulence models, and RNG-based LES model is a better turbulence model in unsteady low Reynolds number turbulent flow. In addition, the standard k- $\varepsilon$ model predicated higher normalized turbulent kinetic energy (k) and turbulent viscosity values than RNG k- $\varepsilon$.

Heschl et al. used various linear and non-linear RANS turbulence models $\mathrm{k}-\varepsilon, \mathrm{k}-\omega$ and $\mathrm{v}^{2}-f$ in several test cases such as linear free jet, plane wall jet, 2D room geometry and 3D room geometry with partition to improve the prediction of linear diffuser airflow patterns inside the room (Heschl et al., 2013). Generally, the results indicated that all turbulence models show good agreement with the experimental data and the proposed non-linear turbulence model can improve the prediction of the airflow patterns inside the room. In addition, Zhao et al. presented a simplified system for a new air supply model called N-point air supply opening model and a new numerical method called error pre-treatment method with a zero equation turbulence model to simulate airflow distribution inside the room faster than conventional turbulence models. Displacement diffusers, square diffusers and grille diffusers were used for this study (Zhao et al., 2003). The results indicated that the simplified system could be used to simulate and predict airflow characteristics inside a room in less time than conventional simulation methods with acceptable results.

Fan et al. applied both experimental and numerical methods to identify the performance of diffuse ceiling ventilation systems (downward ventilation) as a new design in a typical office room and determine the airflow characteristics inside the room at different air change rates (Fan et al., 2013). The energy equation and RNG k- $\varepsilon$ turbulence model were applied to simulate the characteristics of airflow inside the room. The results showed that both the experiment and CFD simulation meet the acceptable comfort criteria without draft risk in the occupied zone. Moreover, other studies explained the effect of different ventilation methods on the airflow and temperature distribution. Wang and Lin applied experimental techniques with several ventilation systems to determine the required time (pull-down period) to achieve thermal comfort conditions for humans before the space is ready for occupation (Wang and Lin, 2015). The results from the mixed ventilation system were compared with displacement and stratum ventilation methods. The stratum ventilation method requires shorter time and lower energy consumption than the other ventilation systems.

Rees and Haves used the experimental method to study the influence of displacement ventilation systems with chilled ceiling panel system in airflow and temperature distribution inside the room. Air velocity data are presented and compared with CFD results reported by Rees et al. (Rees and Haves, 2013; Rees et al., 2001). The results from the displacement ventilation system show 
that good agreement with the other studies and the temperature profiles are not affected by internal heat gain. On the other hand, the presence of the chilled ceiling system produces a good mixing in the upper part of the room, which reduced the temperature gradients.

Despite these aforementioned studies, the previous work in determining the effect of changing the ceiling diffuser geometry shape on indoor air quality is limited. Therefore, the goal of the present study is to determine the effect of changing the blade and lip angles of 5-blade square louver face ceiling diffusers on airflow velocity and temperature distributions inside a room, comparing the results from each model with the standard diffuser, which has a $60^{\circ}$ blade angle and $0^{\circ}$ lip angle.

\section{Methodology}

ANSYS FLUENT software packages are used to study and simulate the airflow characteristics and temperature distribution patterns from the different models of louver face ceiling diffusers inside the room (ANSYS, 2013). The air fluid used in the simulation is assumed to be steady. The governing equations are solved, and the realizable $\mathrm{k}-\varepsilon$ turbulent model is used to represent the best common turbulence models that have eddies.

Conservation of mass:

$\frac{\partial u}{\partial x}+\frac{\partial v}{\partial y}+\frac{\partial w}{\partial z}=0$

$\nabla . V=0$

Conservation of momentum:

The momentum equation (Navier-Stokes equation) is derived throughout flow domain as,

$\rho V \cdot \nabla V=-\nabla P+\mu \nabla^{2} V+\rho g$

At neglect body forces, $\rho g=0$

$$
\begin{aligned}
& (V \cdot \nabla) V=-\frac{1}{\rho}(\nabla P)+\frac{\mu}{\rho} \nabla^{2} V \\
& \rho V \cdot \nabla V=-\nabla P+\mu \nabla^{2} V+\rho g \beta(\Delta T)
\end{aligned}
$$

Where $\Delta \mathrm{T}=$ temperature deviation from reference temperature.

Conservation of energy:

The energy equation is derived based on the temperature distribution throughout non-isothermal flow domain

$\rho C_{p} V \cdot \nabla T=\lambda_{e f f} \nabla^{2} T$ 
Where $\lambda_{\text {eff }}$ is the effective thermal conductivity that can be described as,

$\lambda_{\text {eff }}=\lambda_{l}+\lambda_{t}$

Where, $\lambda_{\mathrm{l}}$ is the laminar thermal conductivity and $\lambda_{\mathrm{t}}$ is the turbulent thermal conductivity.

\section{Geometry Model Configuration}

Figure 1 shows the 3D airflow domain of the louver face ceiling diffuser at the center of the ceiling of the room with dimensions $(2 \mathrm{~m}$ length $\times 2 \mathrm{~m}$ width $\times 2 \mathrm{~m}$ height $)$, the square supply inlet air duct with dimensions $(0.6 \mathrm{~m}$ length $\times$ $0.6 \mathrm{~m}$ width $\times 0.6 \mathrm{~m}$ height$)$, and the single outlet air duct with dimensions (0.6 $\mathrm{m}$ length $\times 0.6 \mathrm{~m}$ width $\times 0.6 \mathrm{~m}$ height) $0.1 \mathrm{~m}$ distance above the room flooring, which represents the computational fluid domain.

\section{Figure 1. The 3D Geometry Model}

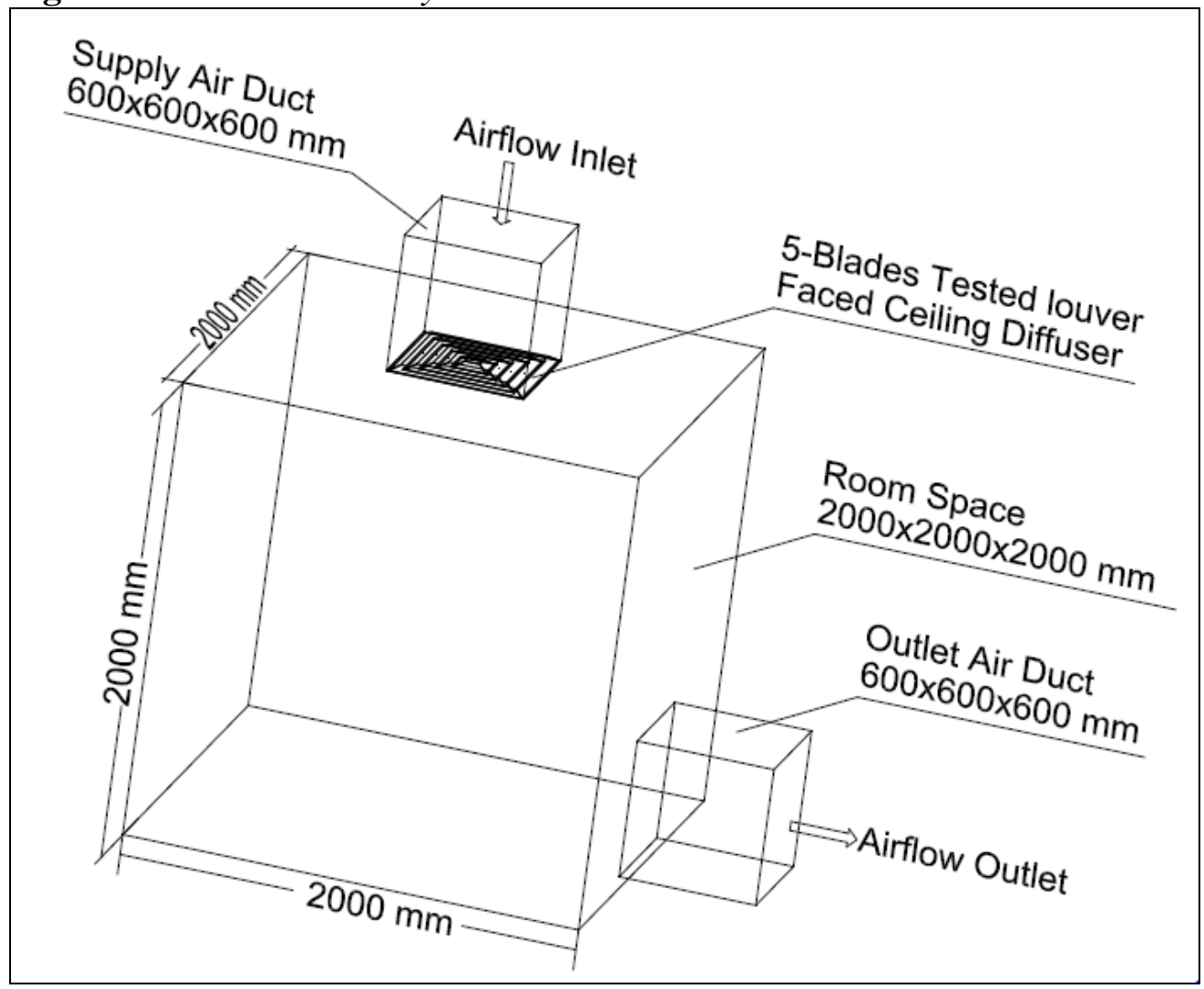

The thickness of a standard or conventional 5-blade louver face diffuser is very small, approximately $1.6 \mathrm{~mm}$ with horizontal lip length $6 \mathrm{~mm}$ and blade angle $60^{\circ}$ as shown in Figure 2. This will lead to the production of a large number of mesh elements, and therefore the simulation process will be complicated and time consuming. To overcome this problem, a 5-blade louver face diffuser with 
thickness $1 \mathrm{~cm}$ and $1 \mathrm{~cm}$ lip length is proposed to accelerate the simulation process with the same passage distance between blades as shown in Figure 3.

Figure 2. The Sectional View of Standard 5-Blades Louver Face Ceiling Diffuser with $60^{\circ}$ Blade Angle and $0^{\circ}$ Lip Angle

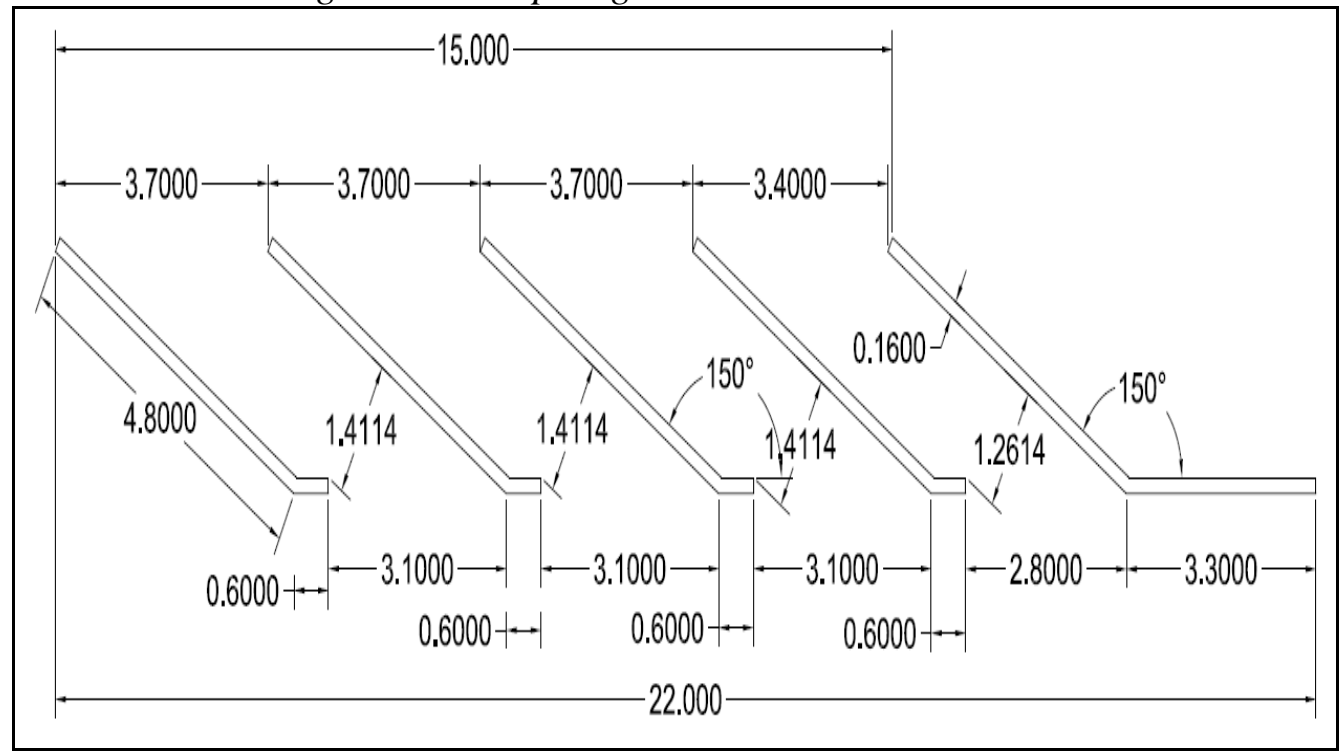

Figure 3. The Sectional View of Proposed 5-Blades Louver Face Ceiling Diffuser with $60^{\circ}$ Blade Angle and $0^{\circ}$ Lip Angle

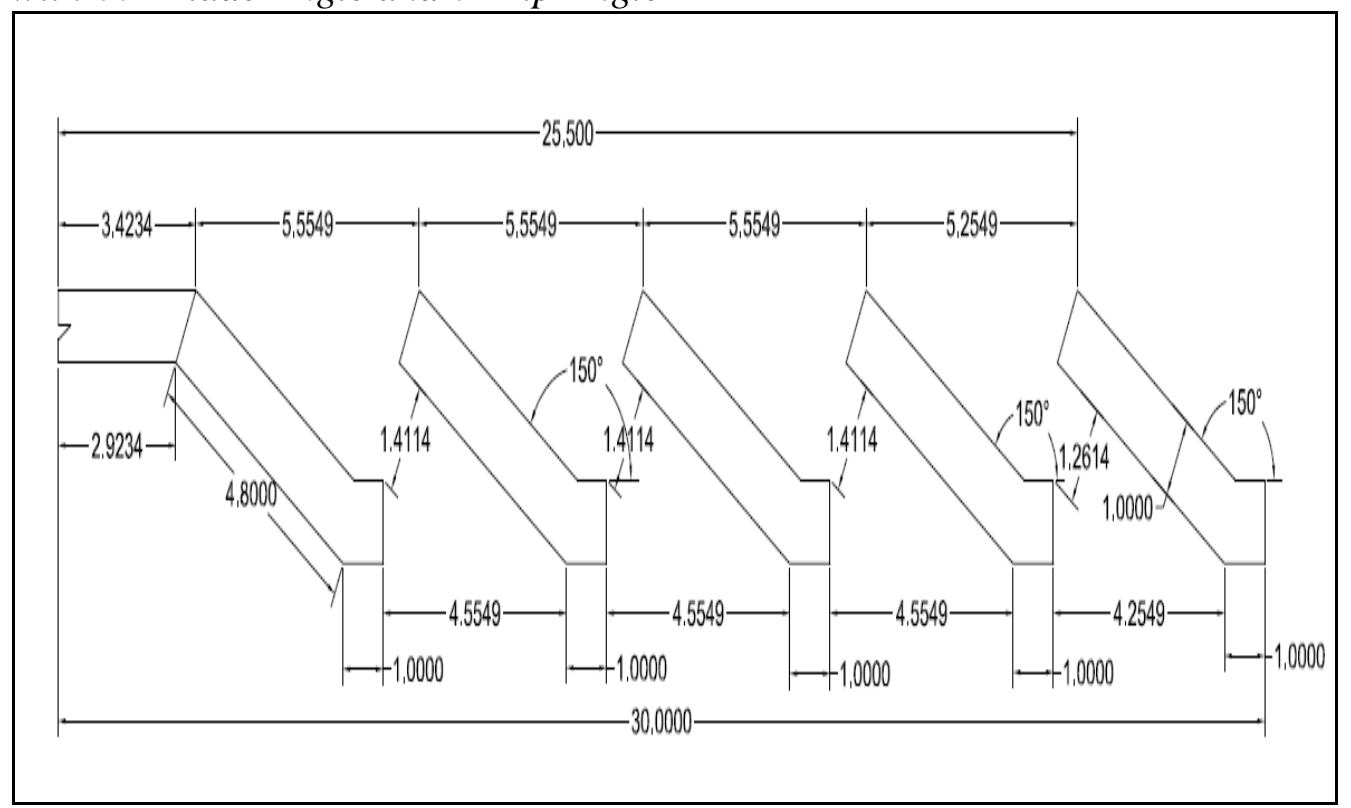

\section{Mesh Generation and Mesh Independence Study}

In the present study, the choice of mesh details depends on the geometry model. The mesh advanced size function was selected based on proximity to the medium as a relevance center, and the proximity to the minimum grid size, 
maximum face size, and maximum grid size in order to achieve acceptable mesh quality. Boundary conditions are created for inlet, outlet, room walls, supply duct walls, exit duct walls, and diffuser blades.

In order to get accurate results from the CFD simulation, several grid sizes $(0.01 \mathrm{~m}, 0.0095 \mathrm{~m}, 0.009 \mathrm{~m}, 0.0085 \mathrm{~m}$, and $0.00825 \mathrm{~m})$ with various numbers of mesh elements $(5886000,10769458,12687692,13999599$, and 14703726) respectively are used to study the mesh independence, where the mean velocity magnitude at a line located from the center of the diffuser to the left and right vertical walls was determined.

The results from 12687692 to 14703726 number of grid elements are approximately identical as shown in Figure 4 with a maximum percentage error of about $1.015 \%$. Therefore, the CFD simulation results are considered to show mesh independence, and the grid size of $0.00825 \mathrm{~m}$ was used for all simulated cases in this study.

Figure 4. The Mean Velocity Magnitude at Different Mesh Sizes

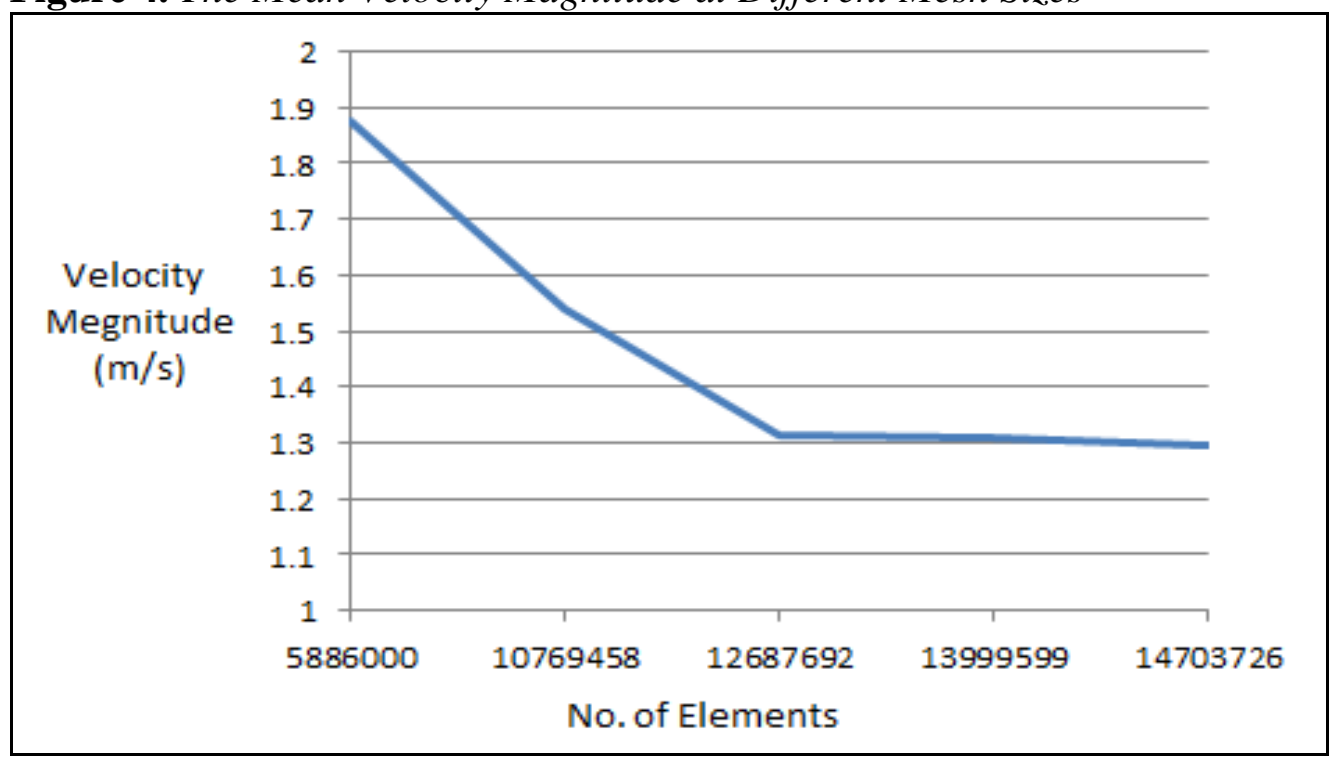

\section{Setup and Solution Processes}

The FLUENT setup process is prepared by selecting pressure-based as a solver type at steady state and 3D dimensions; the energy equation is defined, realizable; $\mathrm{k}-\varepsilon$ turbulent model is used as the best common turbulence model and the working fluid for this study was defined as air with constant properties.

Motion at the smallest eddies of turbulence depends on the turbulent dissipation rate $(\varepsilon)$ and turbulent kinetic energy $(\mathrm{k})$.

$$
\begin{aligned}
& \varepsilon=\frac{-\mathrm{dK}}{\mathrm{dt}} \\
& \mathrm{k}=0.5\left(\overline{\mathrm{u}^{\prime 2}}+\overline{\mathrm{v}^{\prime 2}}+\overline{\mathrm{w}^{\prime 2}}\right)
\end{aligned}
$$

where, $(\mathrm{k})$ is the summation of the three fluctuating velocity component. 
Reynolds Averaged Navier-Stokes (RANS) is one of the different approaches to make turbulence computationally by solve Time Averaged Navier-Stokes equations.

$\rho\left(\frac{\partial \bar{U}_{i}}{\partial \mathrm{t}}+\bar{U}_{k} \frac{\partial \bar{U}_{i}}{\partial \mathrm{x}_{\mathrm{k}}}\right)=\frac{-\partial \mathrm{P}}{\partial x_{i}}+\frac{\partial}{\partial \mathrm{x}_{\mathrm{j}}}\left(\mu \frac{\partial \bar{U}_{i}}{\partial \mathrm{x}_{\mathrm{j}}}\right)-\frac{\partial\left(\rho \overline{u_{l}^{\prime} u_{j}^{\prime}}\right)}{\partial \mathrm{x}_{\mathrm{j}}}$

K-transport equation:

$\rho \frac{D k}{D t}=\frac{\partial}{\partial \mathrm{x}_{\mathrm{j}}}\left[\left(\mu+\frac{\mu_{t}}{\sigma_{k}}\right) \frac{\partial \mathrm{k}}{\partial \mathrm{x}_{\mathrm{j}}}\right]+\mu_{t} S^{2}-\rho \varepsilon$

where, strain rate tensor

$S=\sqrt{2 S_{i j} S_{i j}}$

$\varepsilon$-transport equation

$\rho \frac{D \varepsilon}{D t}=\frac{\partial}{\partial \mathrm{x}_{\mathrm{j}}}\left[\left(\mu+\frac{\mu_{t}}{\sigma_{\varepsilon}}\right) \frac{\partial \varepsilon}{\partial \mathrm{x}_{\mathrm{j}}}\right]+\frac{\varepsilon}{k}\left(\mu_{t} C_{1 \varepsilon} S^{2}-\rho \varepsilon C_{2 \varepsilon}\right)$

Turbulent viscosity

$\mu_{t}=\frac{\rho c_{\mu} k^{2}}{\varepsilon}$

The coefficients $\sigma_{\mathrm{k}}, \sigma_{\varepsilon}, \mathrm{C}_{1 \varepsilon}, \mathrm{C}_{2 \varepsilon}, \mathrm{C}_{\mu}$ are empirical constants determined from benchmark experiments of simple flows using air and water.

The boundary conditions are set at each zone as shown in Table 1, at the inlet boundary zone with velocity inlet $0.6 \mathrm{~m} / \mathrm{s}$ in a direction normal to inlet boundary zone with a negative Y-coordinate direction with temperature $287 \mathrm{~K}$ $\left(14^{\circ} \mathrm{C}\right), 5 \%$ turbulent intensity, and 10 turbulent viscosity ratio. All room, supply duct, exit duct, and diffuser blades are set as wall boundary condition types with isothermal temperature $296 \mathrm{~K}\left(23^{\circ} \mathrm{C}\right)$.

Table 1. Boundary Conditions

\begin{tabular}{|c|c|c|c|}
\hline $\begin{array}{c}\text { Boundary Zone } \\
\text { Name }\end{array}$ & Boundary Type & Velocity (m/s) & Temperature (K) \\
\hline Inlet & Velocity inlet & 0.6 & 287 \\
\hline Outlet & Pressure outlet & Will calculated & Will calculated \\
\hline Room walls & wall & 0 & 296 \\
\hline Supply duct walls & wall & 0 & 296 \\
\hline Exit duct walls & wall & 0 & 296 \\
\hline Diffuser blades & wall & 0 & 296 \\
\hline
\end{tabular}


The solution methods are identified in this study using a SIMPLE pressurevelocity coupling algorithm with least-squares cell-based as a gradient of solution with a second order upwind for higher-order discretization schemes. Convergence was reached and the calculation completed when the residual monitor values were less than $10^{-3}$ for all parameters except energy, which was less than $10^{-6}$.

\section{Wall Y-plus Value $\left(Y^{+}\right)$}

The $\mathrm{k}-\varepsilon$ turbulence model is valid away from the walls and the flow commonly affected by the walls. Therefore, determining the wall unit $\mathrm{y}^{+}$value is important to making the $\mathrm{k}-\varepsilon$ turbulence model valid near the walls, which can be calculated based on different factors such as friction velocity at the wall, distance to the wall, and kinematic viscosity of the fluid. It may be noted that ANSYS user's guide provides upper and lower limits on the acceptable wall $\mathrm{y}^{+}$ value (ANSYS, 2013). However, $\mathrm{y}^{+}$value close to the lower bound $\left(\mathrm{y}^{+}=30\right)$ is most desirable. Figure 5 reveals wall $\mathrm{y}^{+}$values within the acceptable values.

Figure 5. Wall $Y^{+}$Value

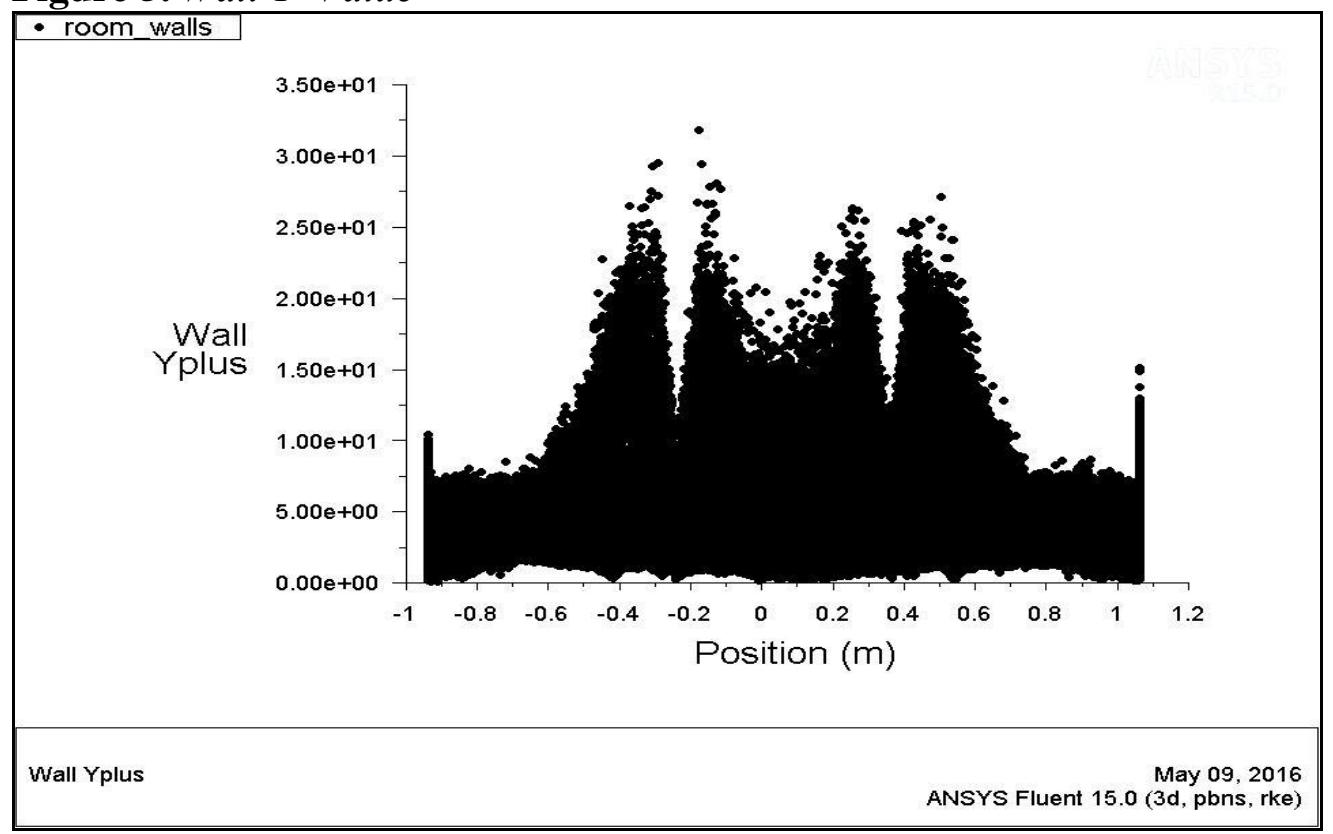

\section{Model Validation}

In the present work, the experimental and numerical results given by Posner et al. [12] are selected to establish the validation process (Posner et al., 2003). Simulation analysis was used to explain and identify the effect of geometric room parameters, such as partition, on the characteristics of airflow patterns inside the room and to compare the results with experimental measurements. As shown in Figure 6, the geometry of the model room $91.4 \mathrm{~cm}$ width, $45.7 \mathrm{~cm}$ depth and $30.5 \mathrm{~cm}$ height. A partition in the middle of the room with height 15 
$\mathrm{cm}$ and the inlet and outlet with the same cross sectional area $10 \mathrm{~cm} \times 10 \mathrm{~cm}$. The inlet velocity was $0.235 \mathrm{~m} / \mathrm{s}$ and the Reynolds number of the inlet velocity was determined to be 1500 . The present CFD results as shown in Figure 7 and Figure 8, the CFD based on RNG k- $\varepsilon$ turbulence and laminar flow, provide good agreement with the results given by Posner et al. (Posner et al., 2003), where the experimental peak airflow speed is $0.249 \mathrm{~m} / \mathrm{s}$ and the calculated peak speed is $0.243 \mathrm{~m} / \mathrm{s}$ from RNG K-epsilon and laminar models. However, the calculated peak speed from the present work is $0.24 \mathrm{~m} / \mathrm{s}$. Therefore, the largest discrepancy is about $3 \%$.

Figure 6. Drawing of Model Room Showing the Partition and its Location, and Showing the Vertical Inlet Jet Axis (Red Color) for Comparison about Vertical Velocity Magnitude between Experimental and CFD Simulation

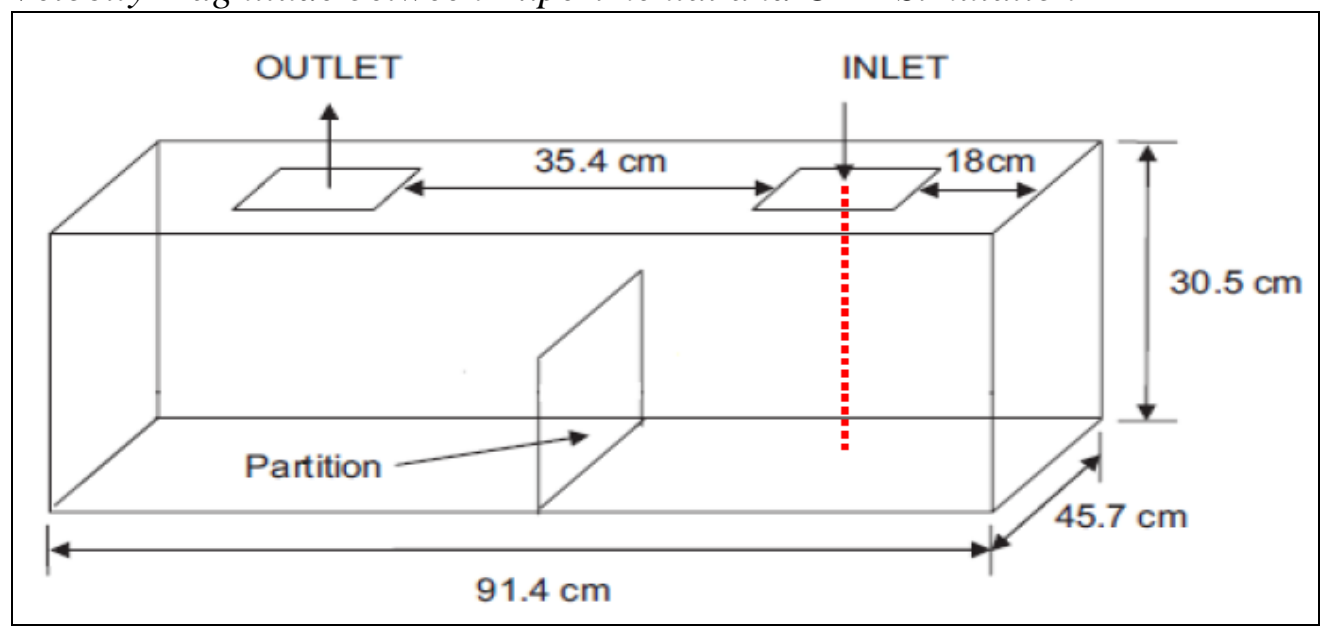

Figure 7. Comparison between Experimental and CFD Simulation with RNG K-epsilon Turbulence Model of Posner et al. (2003) and Present Work of the Vertical Velocity Magnitude along the Vertical Inlet Jet Axis

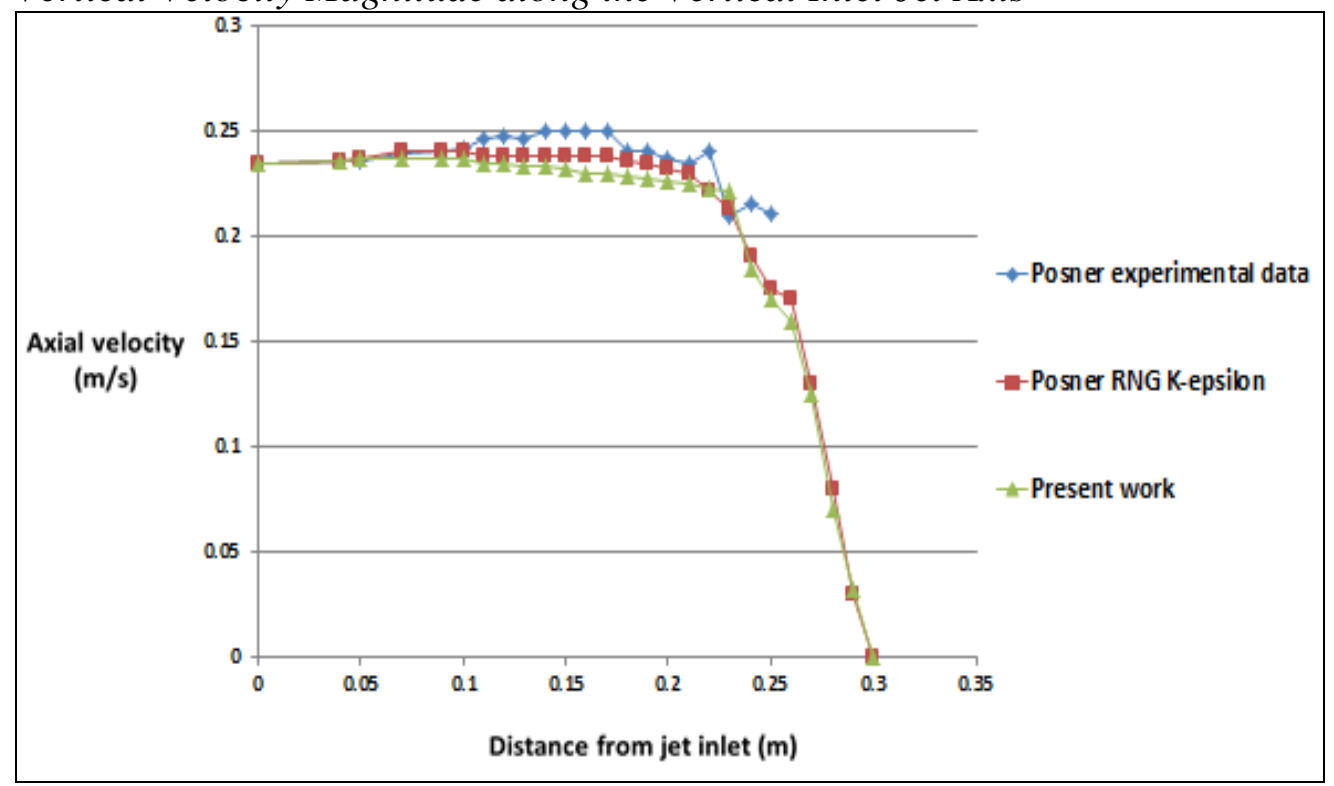


Figure 8. Comparison between Experimental and CFD Simulation with Laminar Flow of Posner et al. (2003) and Present Work of the Vertical Velocity Magnitude along the Vertical Inlet Jet Axis

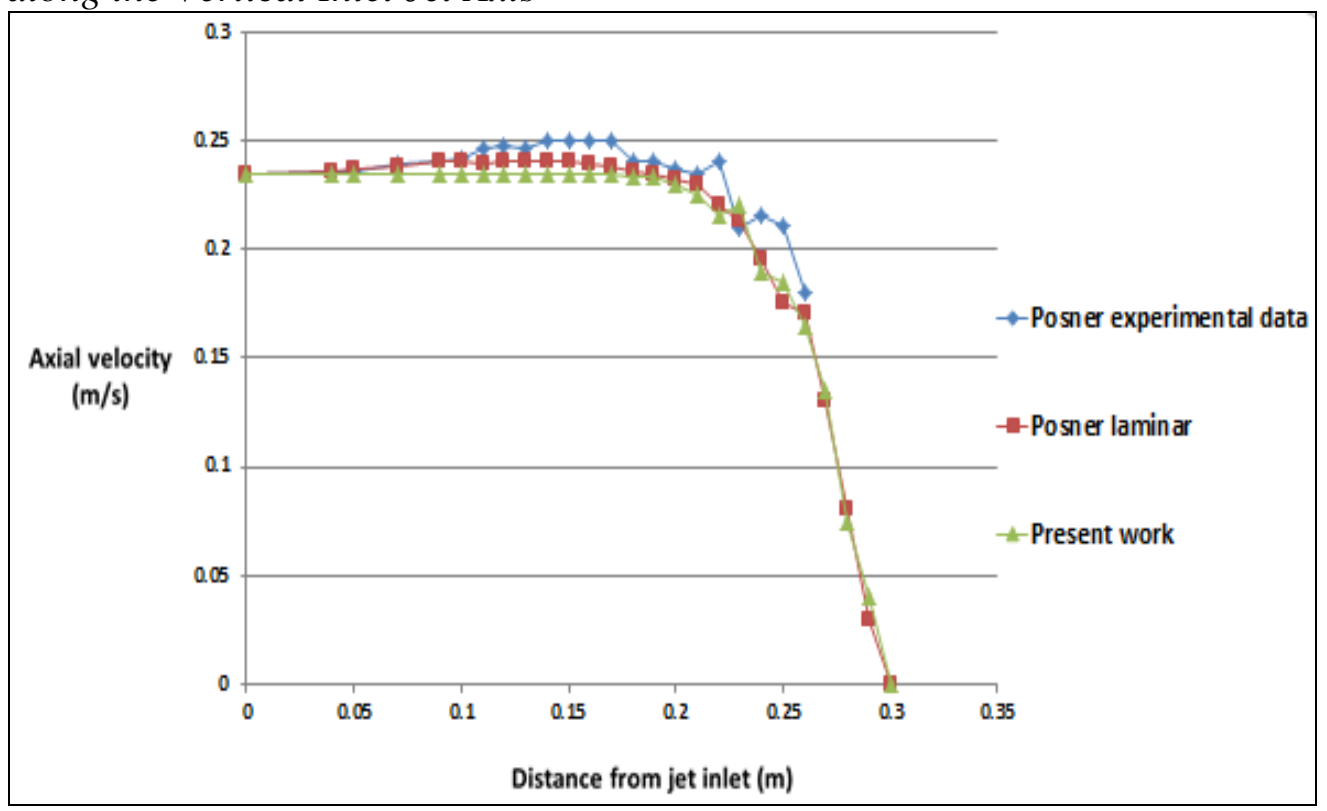

\section{Results and Discussion}

This section shows and discusses the CFD simulation results of airflow velocity and temperature distributions from several geometric models of louverface square ceiling diffusers inside of a room. The contours of velocity magnitude, $Y$ velocity, and static temperature, besides the solution XY plot at different lines in the opposite direction of (Y) axis for each case are illustrated in this part.

\section{Louver Face Ceiling Diffuser with $60^{\circ}$ Blade Angle and $0^{\circ}$ Lip Angle}

As shown in Figure 9, contours of airflow velocity distribution from the louver-face ceiling diffuser with $60^{\circ}$ blade angle and $0^{\circ}$ lip angle with maximum jet velocity $(4.205-4.672 \mathrm{~m} / \mathrm{s})$ and the airflow terminal velocity throughout the room were noticed uniformly $(0-0.467 \mathrm{~m} / \mathrm{s})$, as shown in Table 2 . Moreover, the airflow patterns out from the diffuser cling to the ceiling, then turned downward before approaching the walls. This indication about the surface (Coanda) effect is noticed.

In order to determine the terminal velocity in the occupied zone affecting comfort criteria, Figure 10 shows that the XY plot for velocity magnitude at different lines (line 1 to 4 ) appeared in a small figure beside the XY plot figure, where these lines located in the opposite direction of vertical $\mathrm{Y}$ axis and away $0 \mathrm{~m},-0.5 \mathrm{~m},-1 \mathrm{~m}$, and $-1.6 \mathrm{~m}$ respectively from the room ceiling level. This figure proves that at lines 2 to 4, which are located within the height of the occupied zone, the airflow velocity magnitude was higher near the walls 
(maximum $0.467 \mathrm{~m} / \mathrm{s}$ ) than the area away from the wall (average $0.25 \mathrm{~m} / \mathrm{s}$ ). Therefore, the occupants away from the walls will feel comfortable.

Figure 9. Contour of Velocity Magnitude of the Diffuser with $60^{\circ}$ Blade Angle and $0^{\circ}$ Lip Angle

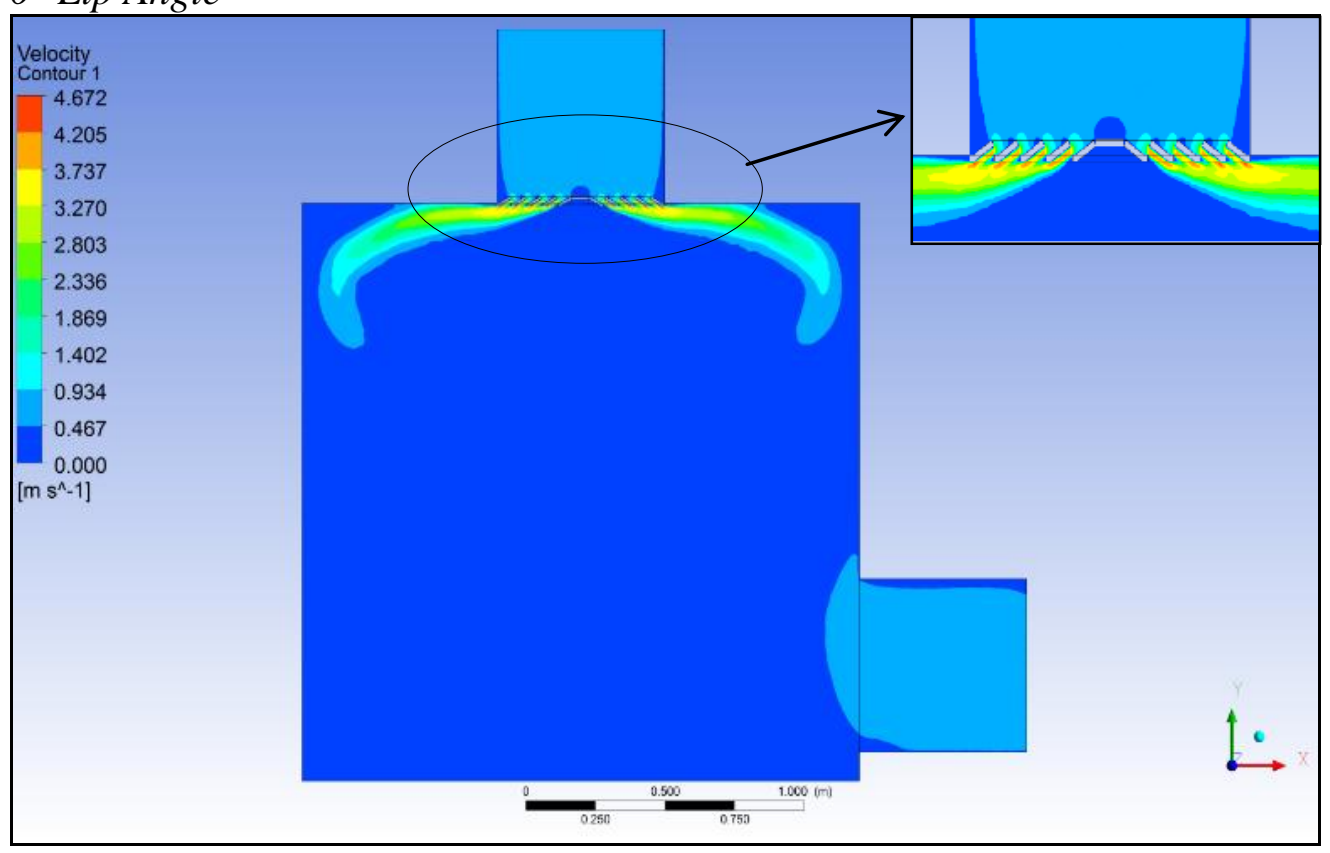

Figure 10. The XY Plot of Velocity Magnitude from the Diffuser with $60^{\circ}$ Blade Angle and $0^{\circ}$ Lip Angle

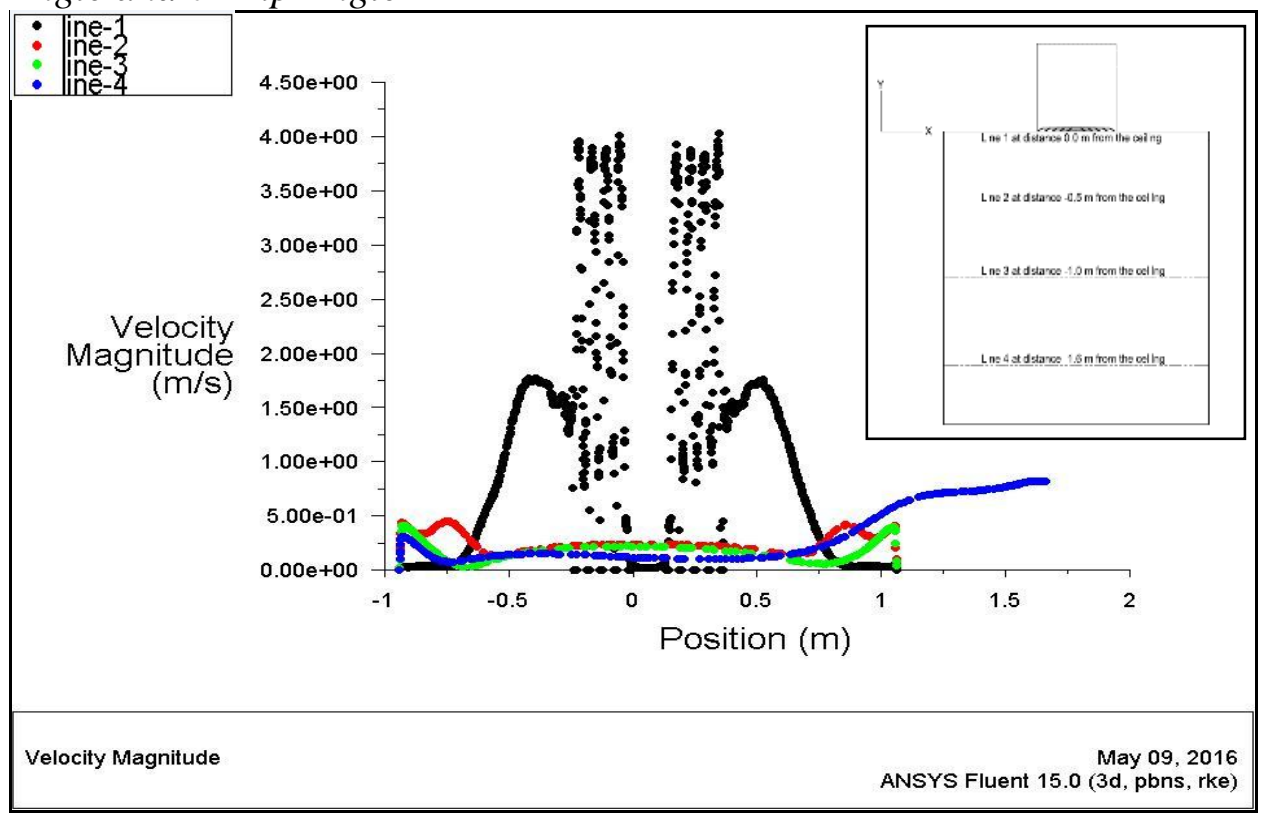

To validate the results from Figures 9 and 10, Figure 11 shows that the contours of $Y$ velocity were uniform $(-0.042-0.412 \mathrm{~m} / \mathrm{s})$ throughout the room, which is consistent with the results from Fig. 9 and indicates that the occupants 
feel comfortable. This value is acceptable according to ASHRAE standard 552013 and SMACNA standard, which indicates that the maximum air speed in occupied zone to be $(0.25 \mathrm{~m} / \mathrm{s})$ and the minimum to be $(0.1 \mathrm{~m} / \mathrm{s})($ ASHRAE, 2013; SMACNA HVAC). In addition, Figure 12 shows that the XY plot for Y velocity at different lines (line 1 to 4 ), where the airflow velocity inside the room for the lines 2 to 4 was around $0.25 \mathrm{~m} / \mathrm{s}$ and this consistent with the results from Figure 10.

Table 2. Range of Velocity Magnitude, Y Velocity and Static Temperature Distribution from Various Diffuser Models

\begin{tabular}{|c|c|c|c|}
\hline \multirow{2}{*}{$\begin{array}{c}\text { DIFFUSER } \\
\text { MODEL }\end{array}$} & $\begin{array}{c}\text { VELOCITY } \\
\text { MANITUDE } \\
(\mathrm{m} / \mathrm{s})\end{array}$ & $\begin{array}{c}\text { Y VELOCITY } \\
(\mathrm{m} / \mathrm{s})\end{array}$ & $\begin{array}{c}\text { STATIC } \\
\text { TEMPERATURE (K) }\end{array}$ \\
\hline $\begin{array}{c}60^{\circ} \text { blade angle } \\
\& 0^{\circ} \text { lip angle }\end{array}$ & $0-0.467$ & $-0.042-0.412$ & $291.489-293.294$ \\
\hline $\begin{array}{c}65^{\circ} \text { blade angle } \\
\& 0^{\circ} \text { lip angle }\end{array}$ & $0-0.569$ & $-0.019-0.555$ & $291.486-293.292$ \\
\hline $\begin{array}{c}45^{\circ} \text { blade angle } \\
\& 0^{\circ} \text { lip angle }\end{array}$ & $0-0.247$ & $-0.477-0.409$ & $291.495-293.297$ \\
\hline $\begin{array}{c}60^{\circ} \text { blade angle } \\
\& 5^{\circ} \text { lip angle }\end{array}$ & $0-0.485$ & $-0.003-0.488$ & $291.486-293.292$ \\
\hline $\begin{array}{c}60^{\circ} \text { blade angle } \\
\& 10^{\circ} \text { lip angle }\end{array}$ & $0-0.426$ & $-0.351-0.570$ & $291.482-293.289$ \\
\hline $\begin{array}{c}60^{\circ} \text { blade angle } \\
\& 15^{\circ} \text { lip angle }\end{array}$ & $0-0.405$ & $-0.298-0.583$ & $291.493-293.296$ \\
\hline
\end{tabular}

Figure 11. Contour of $Y$ Velocity from the Diffuser with $60^{\circ}$ Blade Angle and $0^{\circ}$ Lip Angle

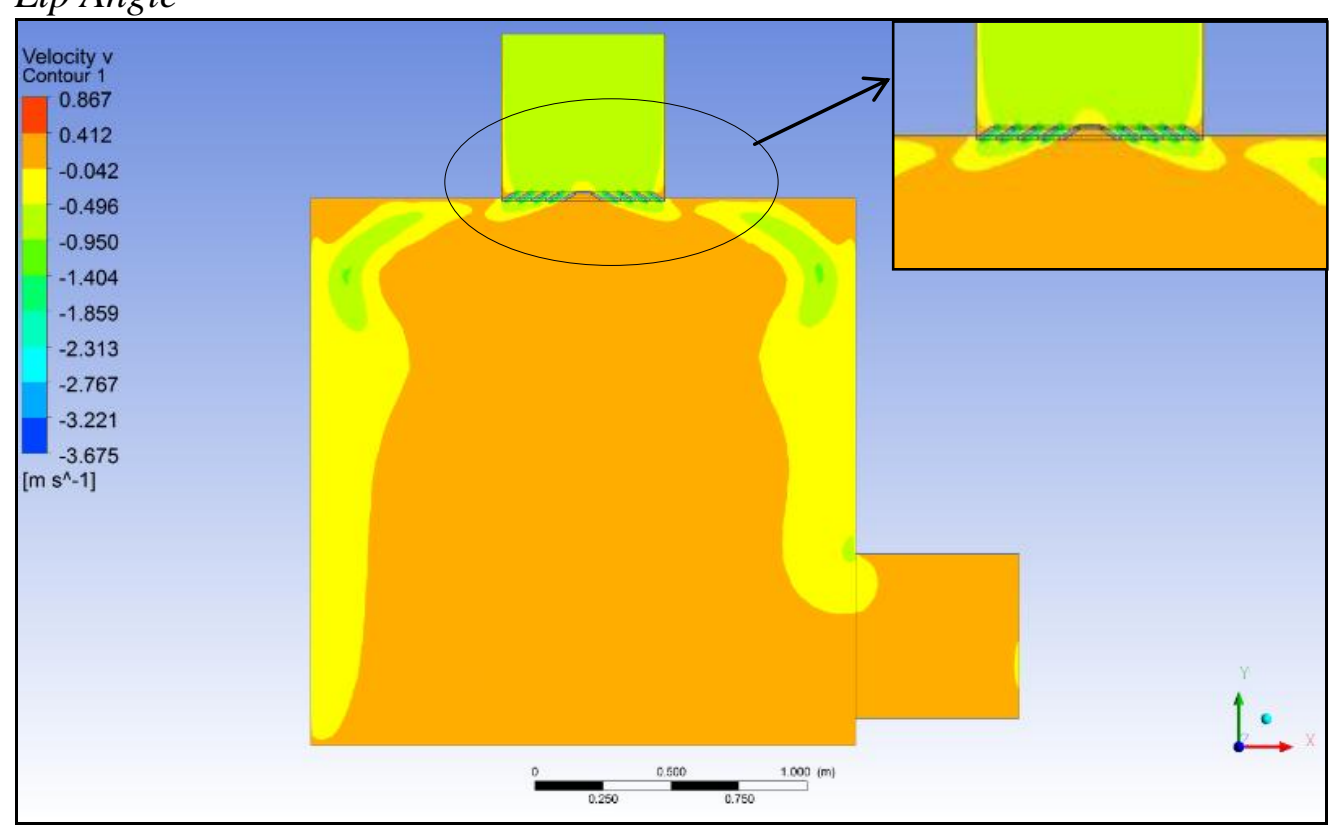


Figure 12. The $X Y$ Plot of $Y$ Velocity at Section Lines from the Diffuser with $60^{\circ}$ Blade Angle and $0^{\circ}$ Lip Angle

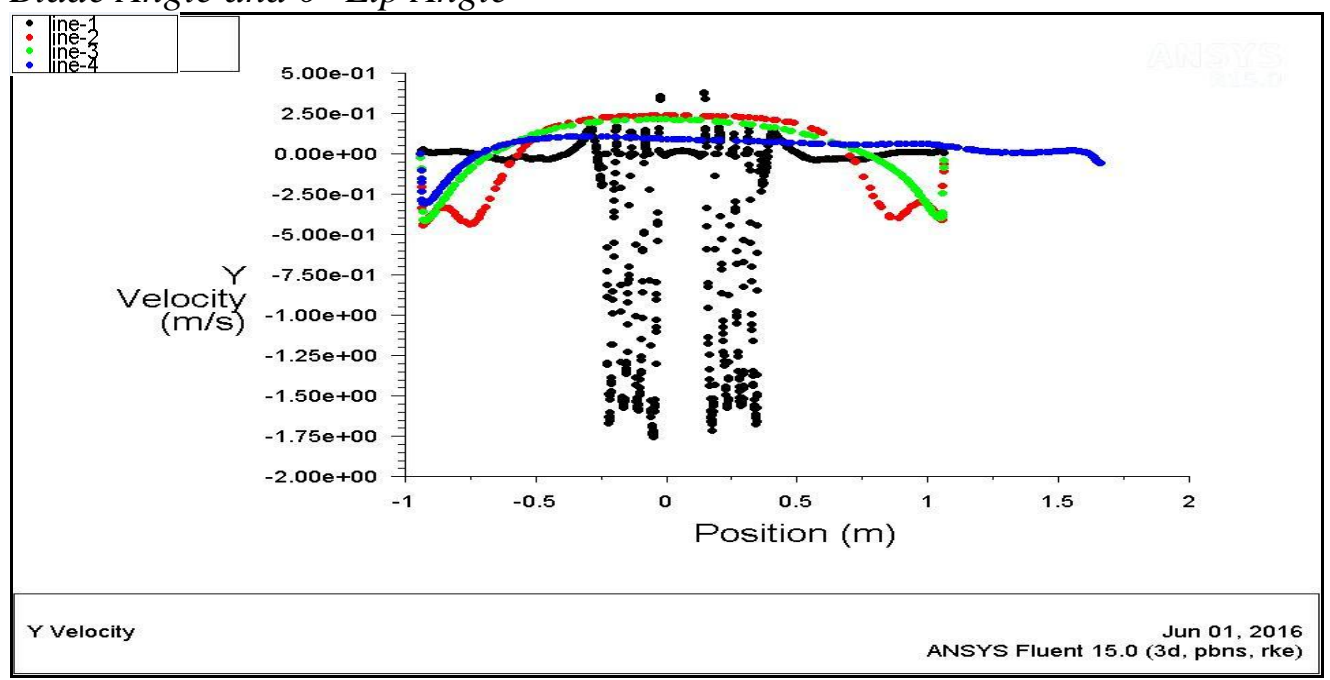

From Figure 13, contours of the airflow temperature distribution from the ceiling diffuser are $(291.489-293.294 \mathrm{~K})$ throughout the room. In addition, Figure 14 shows the XY plot for static temperature at different lines, which validates and is consistent with the results from Figure 13. Table 3 shows the average static temperature values at different lines, which indicate that the temperature gradients inside the occupied zone from line 2 to 4 were $1.641^{\circ} \mathrm{C}$. This value is acceptable according to the ASHRAE standard 55-2013, which indicates that air temperature difference between head level and ankle level shall not exceed $3{ }^{\circ} \mathrm{C}$ for seated occupants or $4^{\circ} \mathrm{C}$ for standing occupants. In addition, the SMACNA standard indicates that the maximum temperature gradients value should be $2^{\circ} \mathrm{C}$ (ASHRAE, 2013; SMACNA HVAC).

Figure 13. Contour of Temperature from the Diffuser with $60^{\circ}$ Blade Angle and $0^{\circ}$ Lip Angle

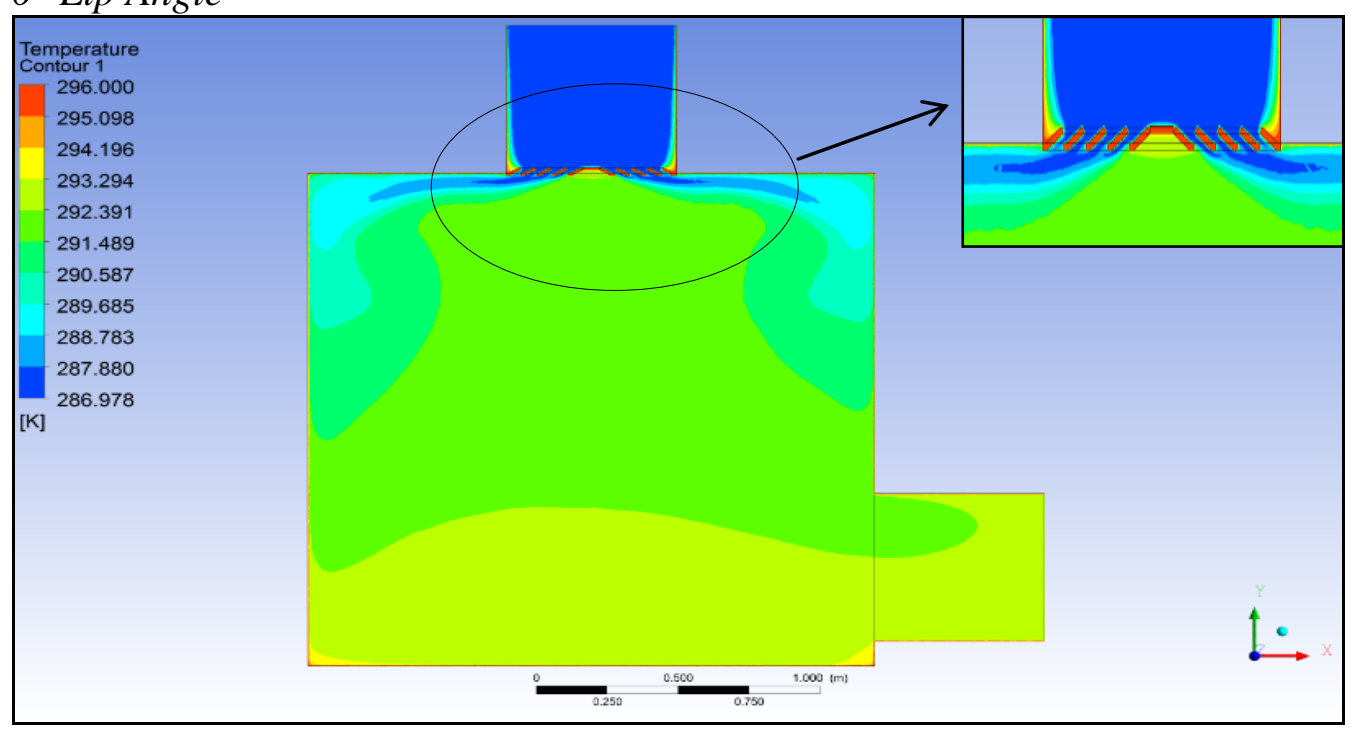


Figure 14. The XY Plot of Static Temperature from the Diffuser with $60^{\circ}$ Blade Angle and $0^{\circ}$ Lip Angle

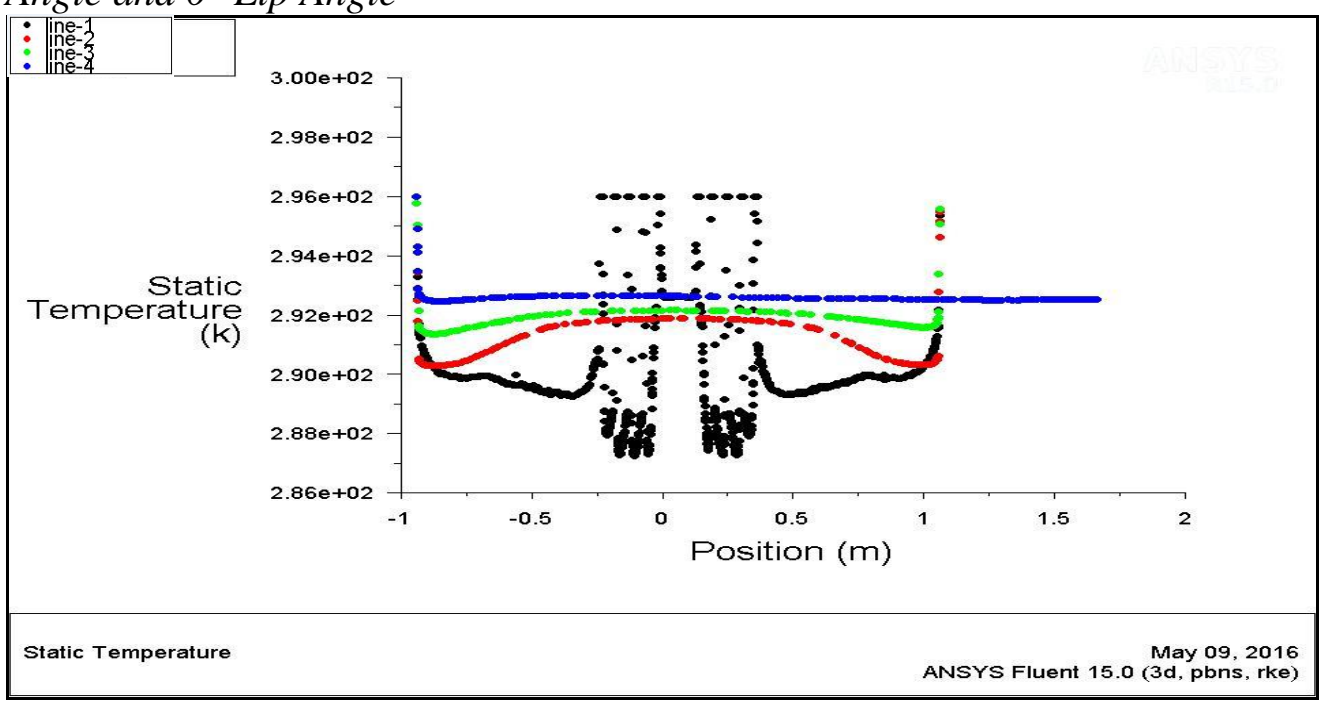

Table 3. Average Velocity Magnitude, Average Y Velocity and Average Static Temperature Distribution from Various Diffuser Models within the Room with One Outlet near Wall Bottom at Different Lines Location

\begin{tabular}{|c|c|c|c|c|}
\hline $\begin{array}{c}\text { CASE } \\
\text { STUDY }\end{array}$ & $\begin{array}{l}\text { LINE } \\
\text { NAME }\end{array}$ & $\begin{array}{c}\text { AVERAGE } \\
\text { VELOCITY } \\
\text { MAGNITUDE } \\
(\mathrm{m} / \mathrm{s})\end{array}$ & $\begin{array}{c}\text { AVERAGE Y } \\
\text { VELOCITY } \\
(\mathrm{m} / \mathrm{s})\end{array}$ & $\begin{array}{c}\text { AVERAGE } \\
\text { STATIC } \\
\text { TEMPERATURE } \\
(\mathrm{K})\end{array}$ \\
\hline \multirow{4}{*}{$\begin{array}{l}60^{\circ} \text { blade } \\
\text { angle and } 0^{\circ} \\
\text { lip angle }\end{array}$} & LINE (1) & 1.301 & -0.293 & 289.681 \\
\hline & LINE (2) & 0.306 & -0.152 & 290.925 \\
\hline & LINE (3) & 0.220 & -0.097 & 291.778 \\
\hline & LINE (4) & 0.381 & 0.006 & 292.566 \\
\hline \multirow{4}{*}{$\begin{array}{l}65^{\circ} \text { blade } \\
\text { angle and } 0^{\circ} \\
\text { lip angle }\end{array}$} & LINE (1) & 2.018 & -0.300 & 289.635 \\
\hline & LINE (2) & 0.342 & -0.179 & 291.162 \\
\hline & LINE (3) & 0.263 & -0.114 & 291.920 \\
\hline & LINE (4) & 0.429 & -0.009 & 292.589 \\
\hline \multirow{4}{*}{$\begin{array}{l}45^{\circ} \text { blade } \\
\text { angle and } 0^{\circ} \\
\text { lip angle }\end{array}$} & LINE (1) & 0.546 & -0.257 & 290.565 \\
\hline & LINE (2) & 0.298 & -0.170 & 290.273 \\
\hline & LINE (3) & 0.204 & -0.088 & 291.309 \\
\hline & LINE (4) & 0.404 & -0.010 & 292.228 \\
\hline \multirow{4}{*}{$\begin{array}{l}60^{\circ} \text { blade } \\
\text { angle and } 5^{\circ} \\
\text { lip angle }\end{array}$} & LINE (1) & 1.523 & -0.575 & 291.991 \\
\hline & LINE (2) & 0.298 & -0.159 & 291.049 \\
\hline & LINE (3) & 0.241 & -0.099 & 291.914 \\
\hline & LINE (4) & 0.419 & -0.007 & 292.586 \\
\hline \multirow{4}{*}{$\begin{array}{c}60^{\circ} \text { blade } \\
\text { angle and } \\
10^{\circ} \text { lip angle }\end{array}$} & LINE (1) & 1.417 & -0.556 & 292.007 \\
\hline & LINE (2) & 0.285 & -0.129 & 291.015 \\
\hline & LINE (3) & 0.218 & -0.093 & 291.875 \\
\hline & LINE (4) & 0.401 & -0.017 & 292.577 \\
\hline \multirow{4}{*}{$\begin{array}{c}60^{\circ} \text { blade } \\
\text { angle and } \\
15^{\circ} \text { lip angle }\end{array}$} & LINE (1) & 1.423 & -0.583 & 291.809 \\
\hline & LINE (2) & 0.305 & -0.162 & 290.928 \\
\hline & LINE (3) & 0.200 & -0.087 & 291.757 \\
\hline & LINE (4) & 0.412 & -0.021 & 292.517 \\
\hline
\end{tabular}




\section{Louver Face Ceiling Diffuser with $65^{\circ}$ Blade Angle and $0^{\circ}$ Lip Angle}

As shown in Figure 15, increasing the diffuser blade angle to $65^{\circ}$ leads to decreasing the passage distance. Furthermore, this increases the jet velocity out from the diffuser (maximum $5.119-5.688 \mathrm{~m} / \mathrm{s}$ ) more than the jet velocity from the $60^{\circ}$ blade angle. Therefore, the airflow distribution patterns throughout the room are noticed uniformly $(0-0.569 \mathrm{~m} / \mathrm{s})$ and are higher than the diffuser with a $60^{\circ}$ blade angle $(0-0.467 \mathrm{~m} / \mathrm{s})$ as shown in Table 2 . In addition, the surface (Coanda) effect of air distribution is noticed where the airflow patterns cling to the ceiling more than in the case of the $60^{\circ}$ blade angle.

In order to determine the terminal velocity in the occupied zone and to check the comfort criteria, Figure 16 shows the XY plot for velocity magnitude at different lines (line 1 to 4 ). As shown in line 1, increasing the blade angle also leads to increasing the jet and terminal velocities, more than diffusers with $60^{\circ}$ blade angles. In addition, this figure proves that at lines 2 to 4 , which are located within the height of occupied zone, the airflow velocity magnitude was higher near the walls (maximum $0.5 \mathrm{~m} / \mathrm{s}$ ) than the area away from the wall (average $0.26 \mathrm{~m} / \mathrm{s}$ ) at lines 2 and 3. Near the floor at line 4, the average airflow velocity was above $0.15 \mathrm{~m} / \mathrm{s}$. Therefore, the occupants inside the occupied zone will feel uncomfortable (coolness). Thus we recommend using this model in the larger space due to high jet velocity out from the diffuser.

Figure 15. Contour of Velocity Magnitude of the Diffuser with $65^{\circ}$ Blade Angle and $0^{\circ}$ Lip Angle

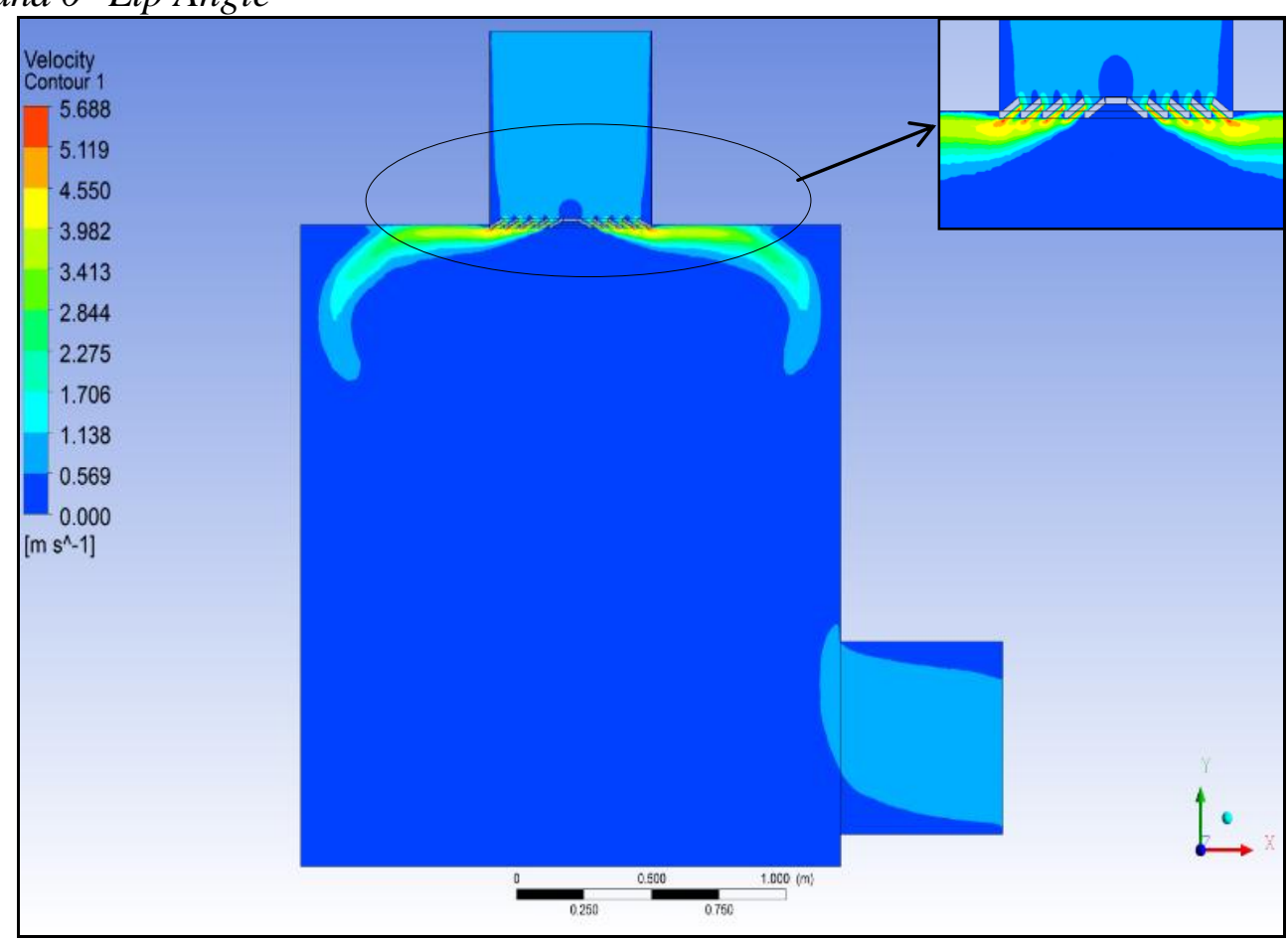


Figure 16. The XY Plot of Velocity Magnitude from the Diffuser with $65^{\circ}$ Blade Angle and $0^{\circ}$ Lip Angle

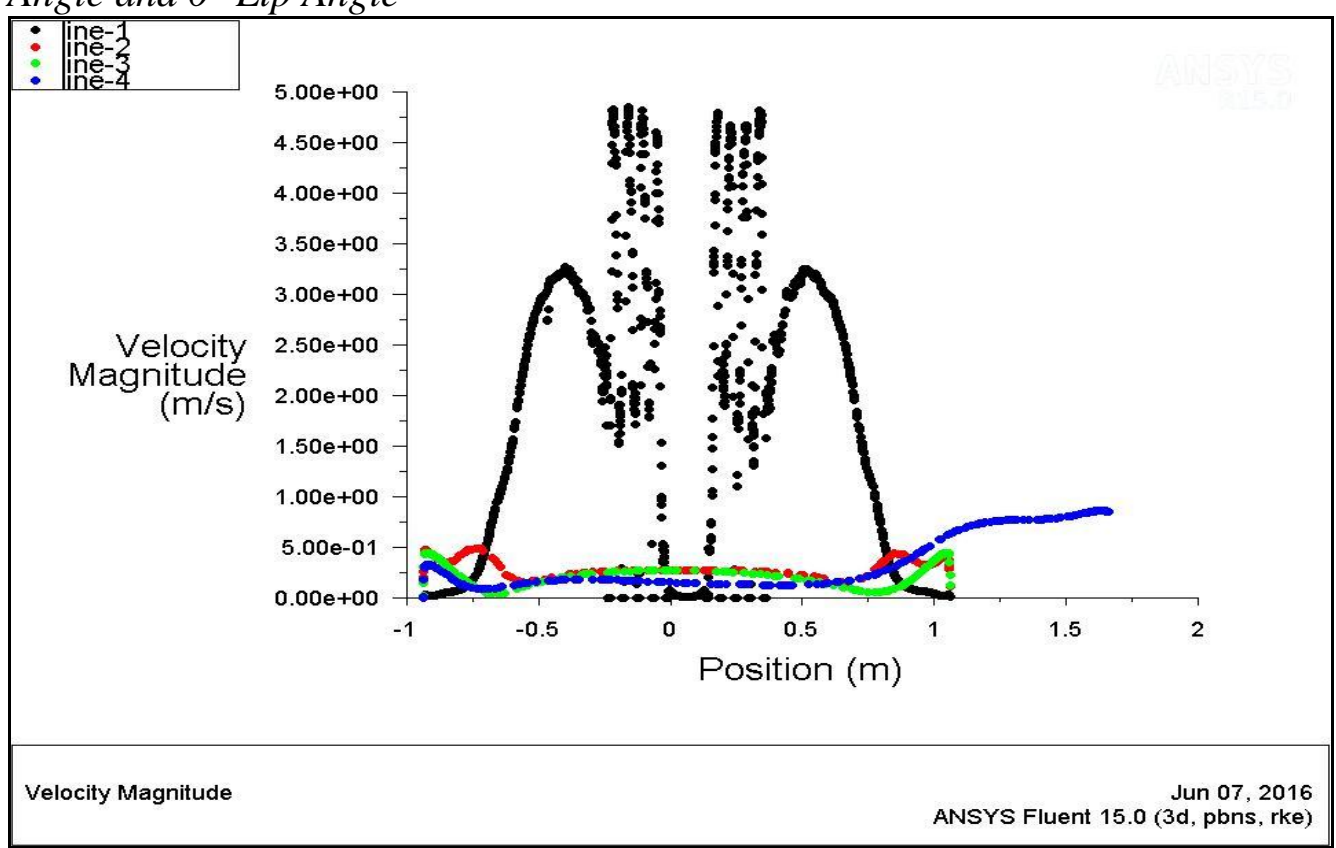

Figure 17 shows that the contour of $\mathrm{Y}$ velocity was uniform $(-0.019$ $0.555 \mathrm{~m} / \mathrm{s}$ ) throughout the room, which is consistent with the results from Figure 15. This related to increasing the jet velocity and thereby increasing the airflow recirculation inside the room, which produces contours of $\mathrm{Y}$ velocity higher than the diffuser with $60^{\circ}$ blade angle $(-0.042-0.412 \mathrm{~m} / \mathrm{s})$. In addition, Figure 18 proves the $\mathrm{XY}$ plot for $\mathrm{Y}$ velocity at different lines, where the airflow velocity inside the room (away from the walls) for the lines 2 to 4 was within $0.26 \mathrm{~m} / \mathrm{s}$ and consistent with the results from Figure 16.

Figure 17. Contour of $Y$ Velocity from the Diffuser with $65^{\circ}$ Blade Angle and $0^{\circ}$ Lip Angle

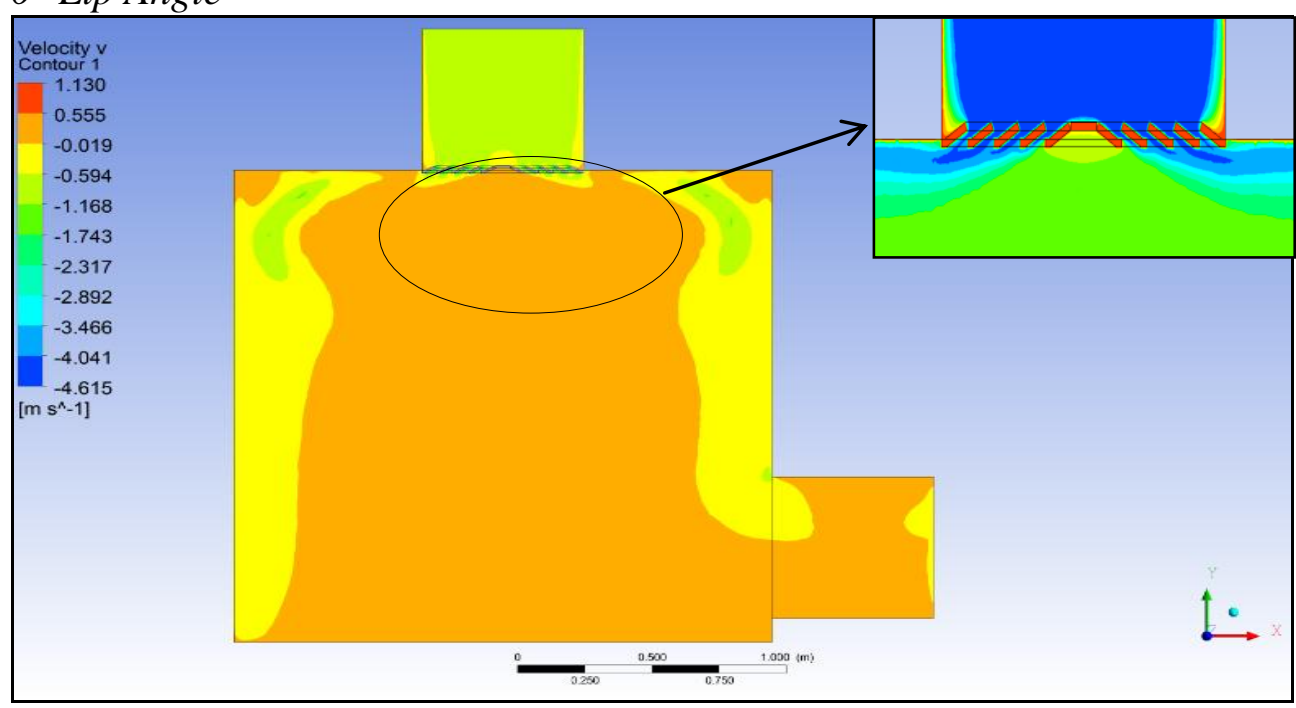


Figure 18. The XY Plot of $Y$ Velocity from the Diffuser with $65^{\circ}$ Blade Angle and $0^{\circ}$ Lip Angle

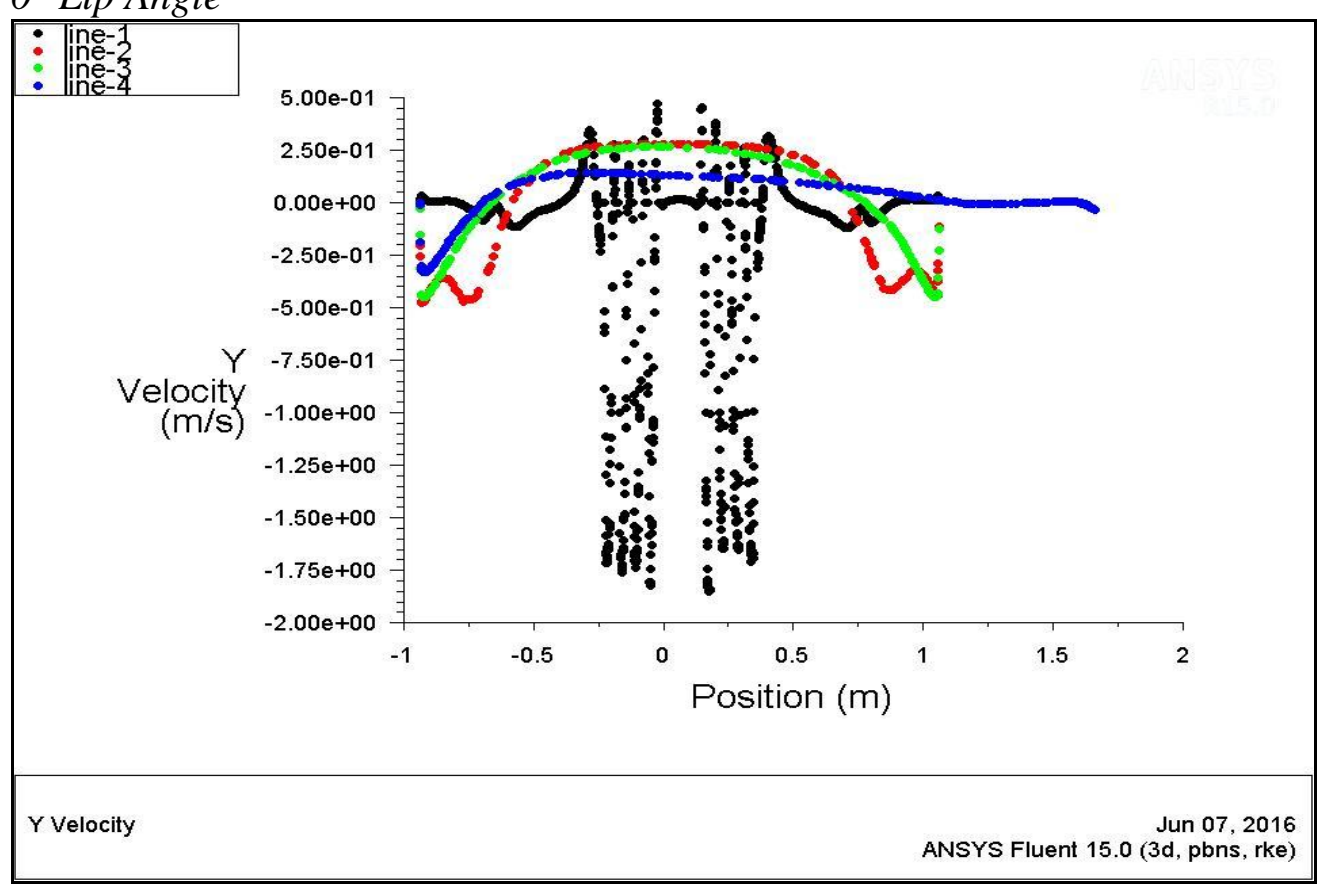

From Figure 19, the airflow temperature distribution from the ceiling diffuser is (291.486 - 293.292 K). In addition, Figure 20 shows the XY plot for static temperature at different lines, which validates the results from Figure 19. Table 3 shows the average static temperature value at different lines, which indicates that the temperature gradients from line 2 to 4 was $1.427^{\circ} \mathrm{C}$, which is lower than the value with $60^{\circ}$ blade angle, and this value acceptable according to ASHRAE standard 55-2013 and SMACNA standard (ASHRAE, 2013; SMACNA HVAC).

Figure 19. Contour of Temperature from the Diffuser with $65^{\circ}$ Blade Angle and $0^{\circ}$ Lip Angle

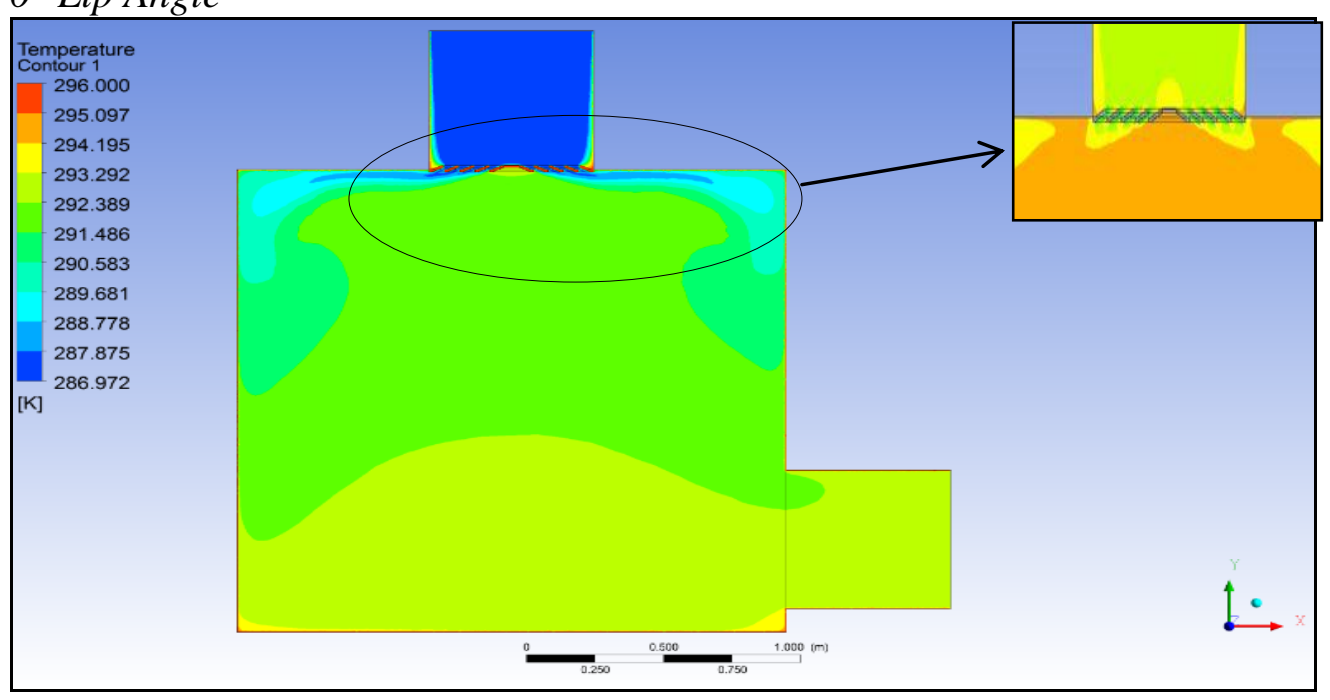


Figure 20. The XY Plot of Static Temperature from the Diffuser with $65^{\circ}$ Blade Angle and $0^{\circ}$ Lip Angle

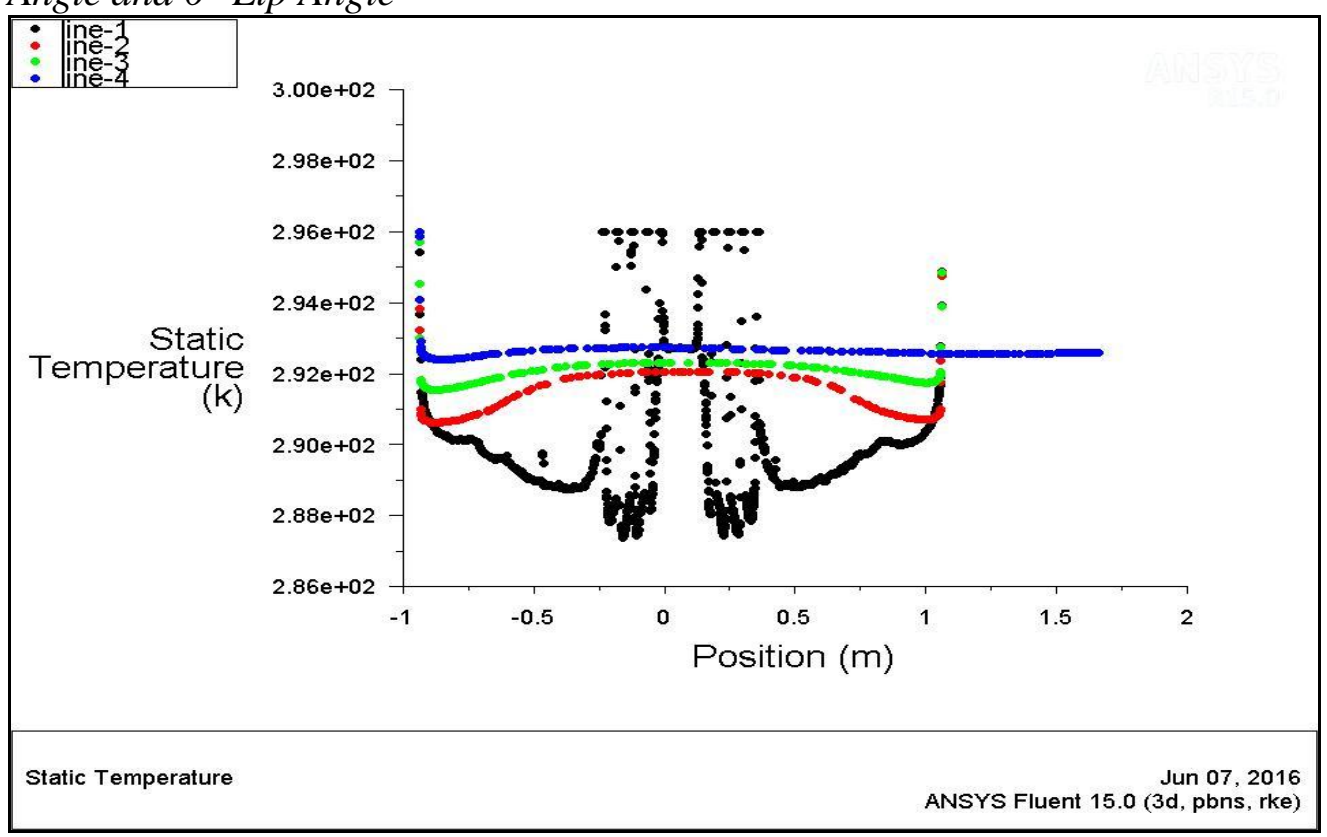

Since the jet and terminal velocities out from the diffuser model with $65^{\circ}$ blade angle are more than the velocities from the standard diffuser with $60^{\circ}$ blade angle, there are low vertical temperature gradients throughout the room. Therefore, we can use this diffuser model in rooms with larger size.

Figure 21 shows the diffuser shape with $65^{\circ}$ blade angle and $0^{\circ}$ lip angle inside the new room model with larger dimensions $(2.75 \mathrm{~m}$ length $\times 2.75 \mathrm{~m}$ width $\times 2.5 \mathrm{~m}$ height). On the other hand, the supply and outlet air ducts are still the same dimensions as the previous work $(0.6 \mathrm{~m}$ length $\times 0.6 \mathrm{~m}$ width $\times 0.6 \mathrm{~m}$ height).

Figure 21. The 3D New Larger Room Geometry View with One Outlet near Right Hand Side Wall Bottom

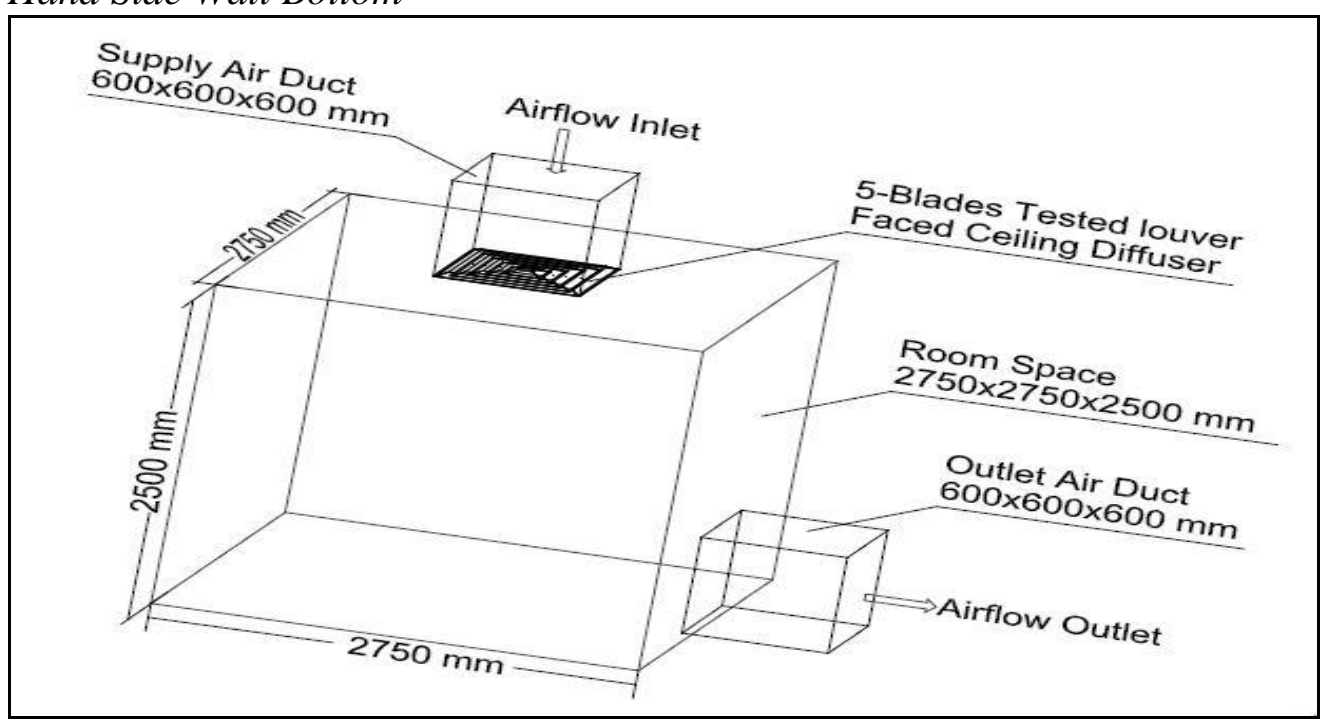


The airflow velocity contours from the diffuser with $65^{\circ}$ blade angle and with $0^{\circ}$ (horizontal) lip angle inside the new room model are shown in Figure 22 . The jet velocity out from the diffuser within the range $(5.081-5.645 \mathrm{~m} / \mathrm{s})$ and the terminal velocity inside the room were consistent $(0-0.565 \mathrm{~m} / \mathrm{s})$. These values are relatively identical to the diffuser inside the small room, which recorded $(5.119-5.688 \mathrm{~m} / \mathrm{s})$ jet velocity and $(0-0.569 \mathrm{~m} / \mathrm{s})$ terminal velocity.

In order to make comparisons regarding the effect of room size on diffuser performance, Figure 23 shows the velocity magnitude at different levels located inside the occupied zone.

It is expected that increasing the room dimensions leads to decreasing the airflow velocity values throughout the room as shown in Figure 23. Table 4 presents the average values for velocity magnitude at different levels inside both small and large rooms. Inside the large room, the average values appeared within the range $(0.15-0.24 \mathrm{~m} / \mathrm{s})$ that represents the thermal comfort conditions inside the occupied zone recommended by the ASHRAE standard 55-2013 (ASHRAE, 2013). However, near the room floor at lines 5 and 6 as shown in Figure 24, the average velocity value was close to $0.1 \mathrm{~m} / \mathrm{s}$, which represents a minimum value recommended by SMACNA (SMACNA HVAC).

Figure 22. Contours of Airflow Velocity Distribution from the Diffuser with $65^{\circ}$ Blade Angle and $0^{\circ}$ Lip Angle Inside the New Room Model

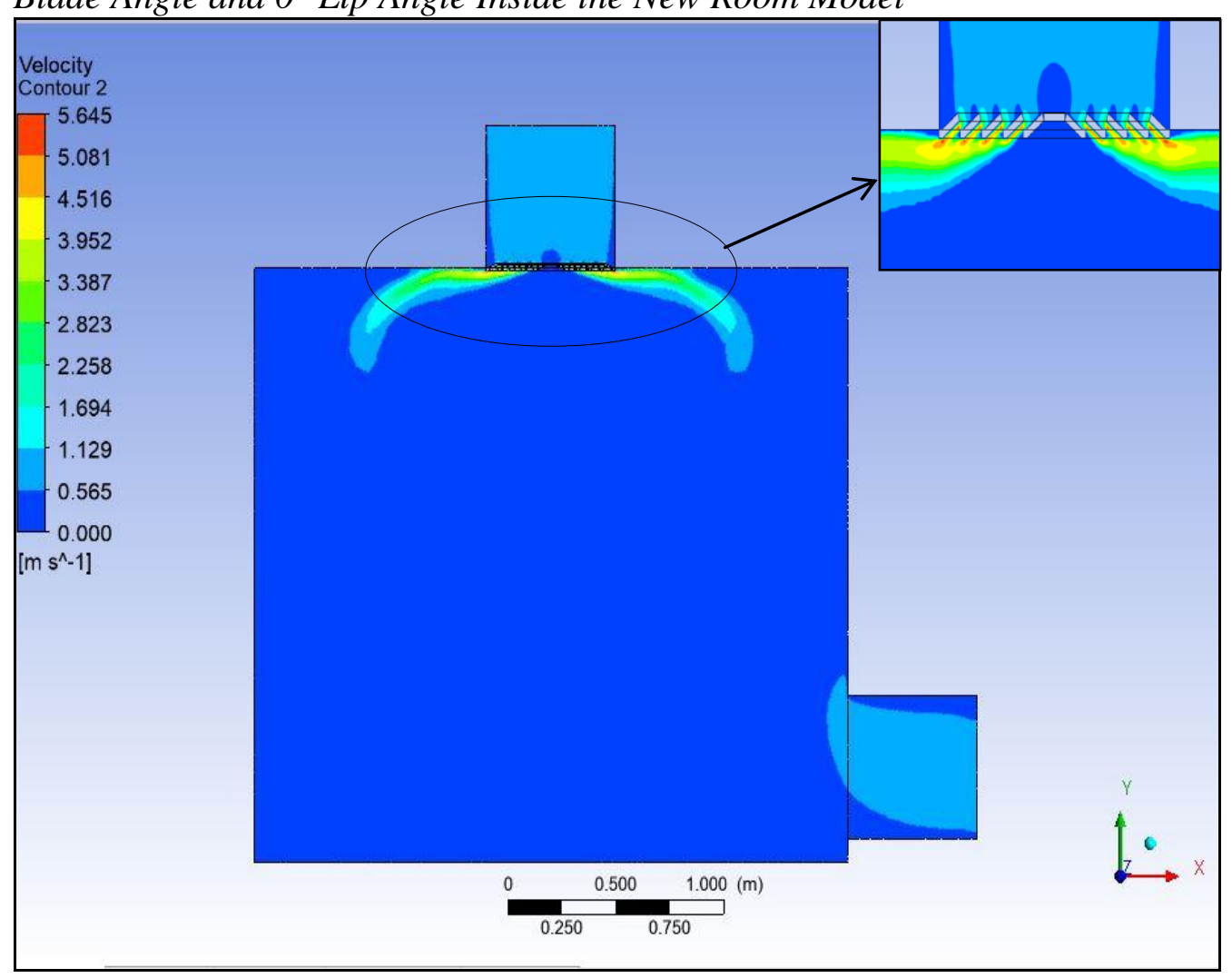


Figure 23. Velocity Magnitude from Louver Face Ceiling Diffuser with $65^{\circ}$ Blade Angle and $0^{\circ}$ Lip Angles at Different Lines inside the Two Room Models

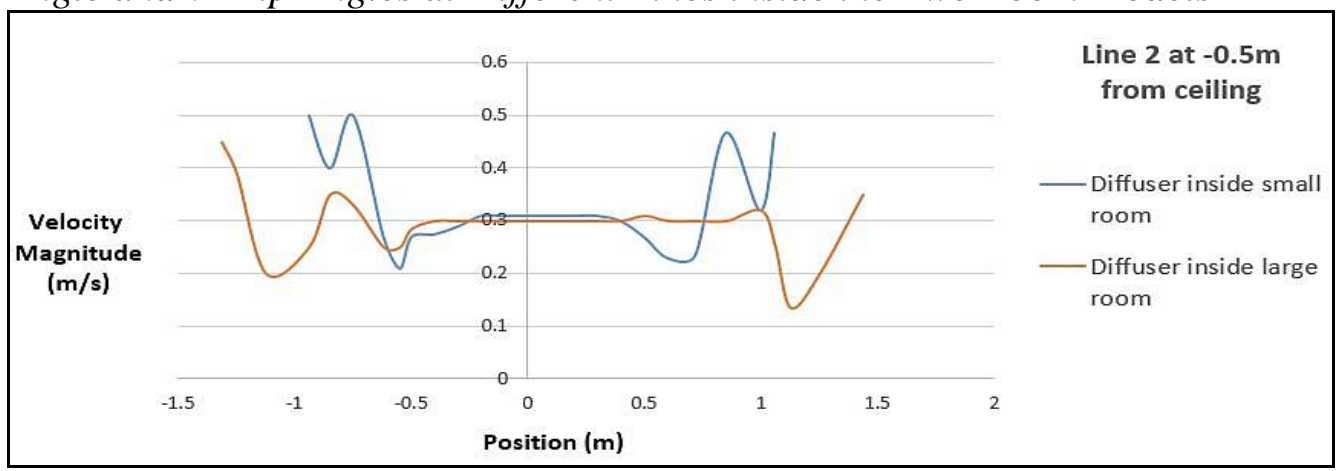

(a)

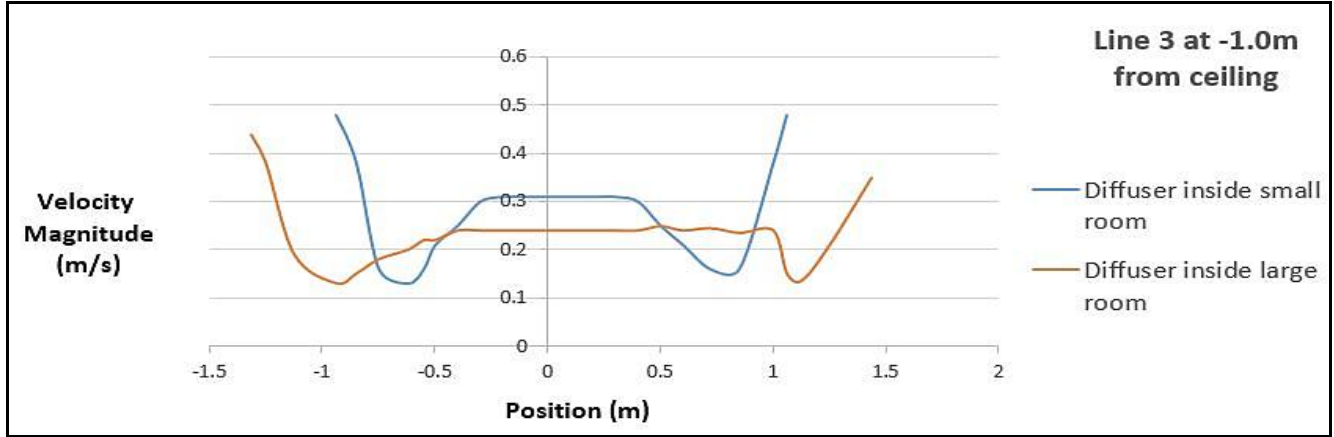

(b)

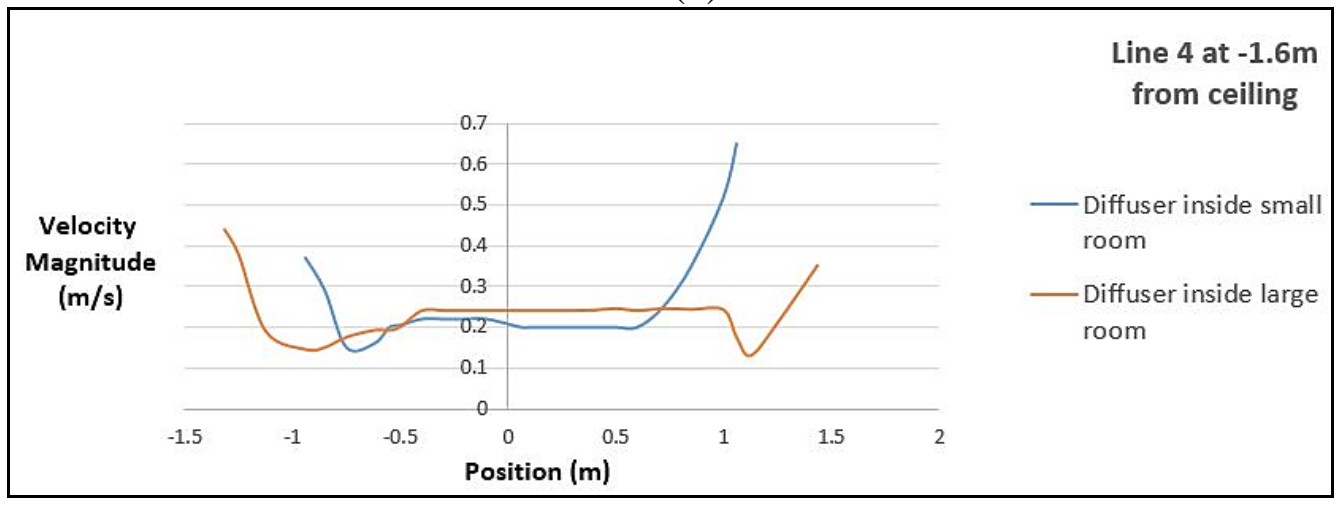

(c)

Figure 24. Velocity Magnitude from Louver Face Ceiling Diffuser with $65^{\circ}$ Blade Angle and $0^{\circ}$ Lip Angles Near the Floor inside the New Room Model

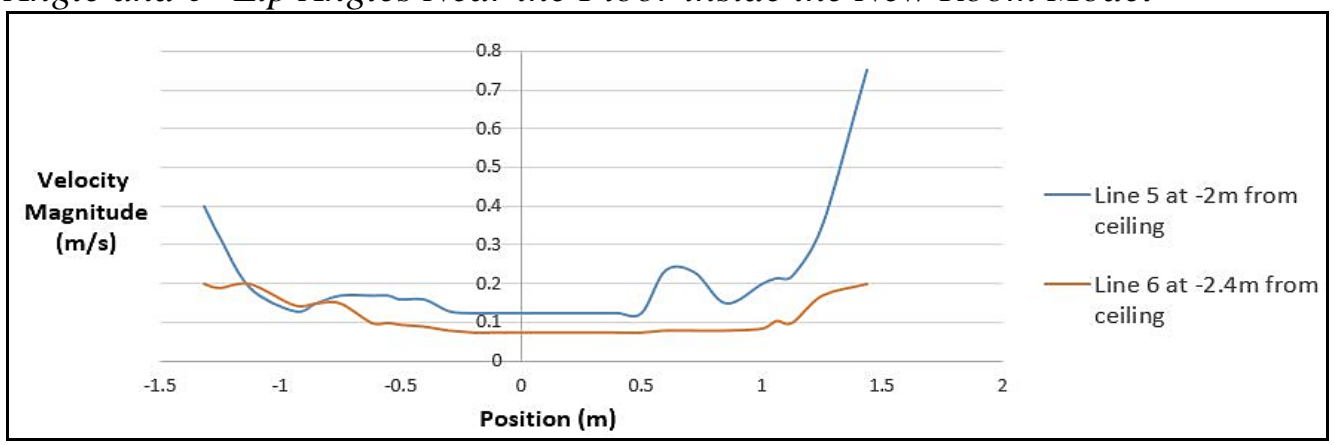


Table 4. Average Velocity Magnitude and Average Static Temperature Distribution from the Diffuser with $65^{\circ}$ Blade Angle and $0^{\circ}$ Lip Angle at Different Lines Location Inside the Two Room Models

\begin{tabular}{|c|c|c|c|}
\hline Item & Line number & $\begin{array}{l}\text { Diffuser with } 65^{\circ} \\
\text { blade angle and } 0^{\circ} \text { lip } \\
\text { within the small room }\end{array}$ & $\begin{array}{l}\text { Diffuser with } 65^{\circ} \\
\text { blade angle and } 0^{\circ} \text { lip } \\
\text { within the large room }\end{array}$ \\
\hline \multirow{5}{*}{$\begin{array}{l}\text { Average velocity } \\
\text { magnitude }(\mathrm{m} / \mathrm{s})\end{array}$} & Line (2) & 0.342 & 0.245 \\
\hline & Line (3) & 0.263 & 0.156 \\
\hline & Line (4) & 0.429 & 0.152 \\
\hline & Line (5) & 0 & 0.209 \\
\hline & Line (6) & 0 & 0.095 \\
\hline \multirow{5}{*}{$\begin{array}{l}\text { Average static } \\
\text { temperature }(\mathrm{K})\end{array}$} & Line (2) & 291.162 & 292.752 \\
\hline & Line (3) & 291.920 & 293.300 \\
\hline & Line (4) & 292.589 & 293.582 \\
\hline & Line (5) & 0 & 293.673 \\
\hline & Line (6) & 0 & 293.915 \\
\hline
\end{tabular}

The temperature distribution from the diffuser with $65^{\circ}$ blade angle inside the large room model (Figure 25) is [293.007 - $294.015 \mathrm{~K}]$. Relatively, it is higher than the temperature distribution from the diffuser with $65^{\circ}$ blade angle [291.486 - 293.292 K] inside the small room model, due to increasing the friction and heat transfer between airflow and room ceiling.

Increasing the room dimensions leads to an increasing in the static temperature values throughout the room as shown in Figure 26. Table 4 presented the average values for temperature at different levels inside small and large rooms, which indicated that the temperature gradients between lines from the diffuser model inside the large room was $1.163^{\circ} \mathrm{C}$ and less than that indicated from diffusers inside the small room $1.427^{\circ} \mathrm{C}$.

Figure 25. Contours of Airflow Temperature Distribution from the Diffuser with $65^{\circ}$ Blade Angle and $0^{\circ}$ Lip Angle inside the New Room Model

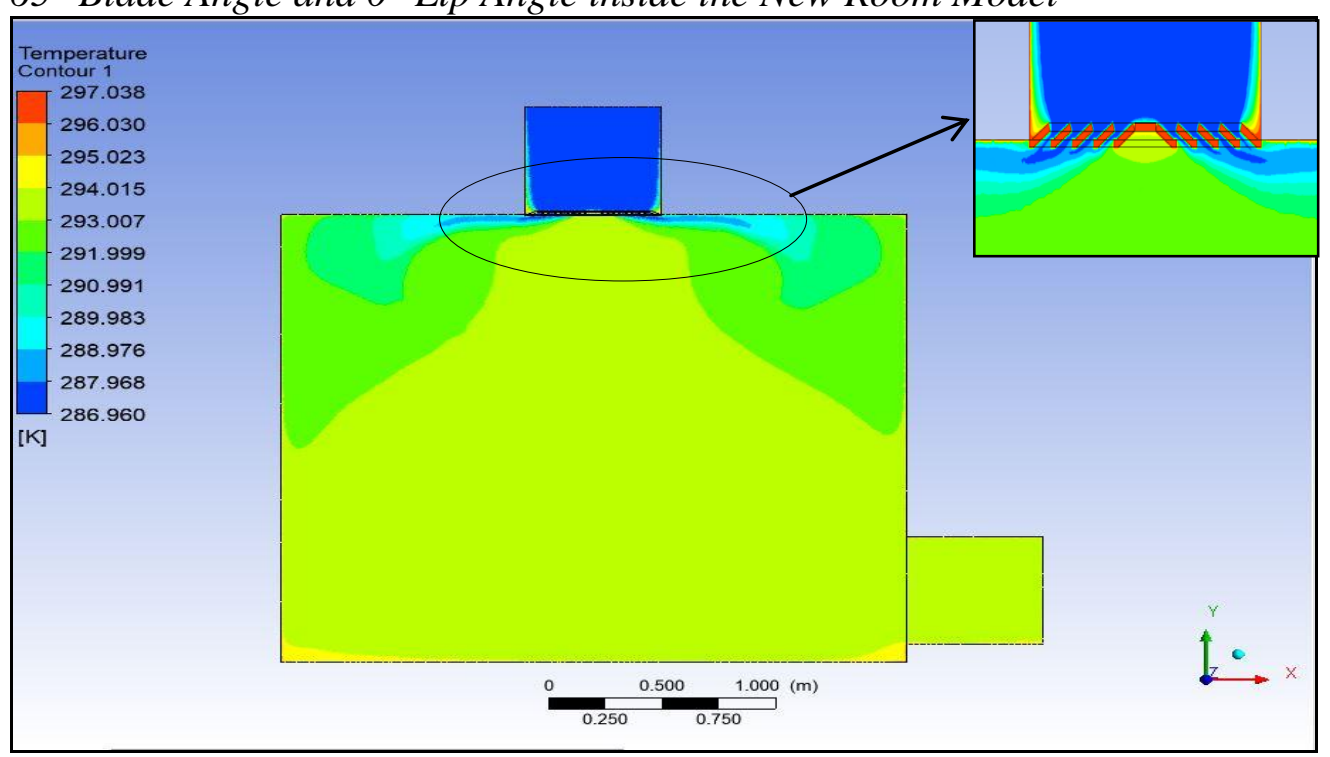


Figure 26. Static Temperature Distribution from Louver Face Ceiling Diffuser with $65^{\circ}$ Blade Angle and $0^{\circ}$ Lip Angles at Different Lines inside the Two Room Models

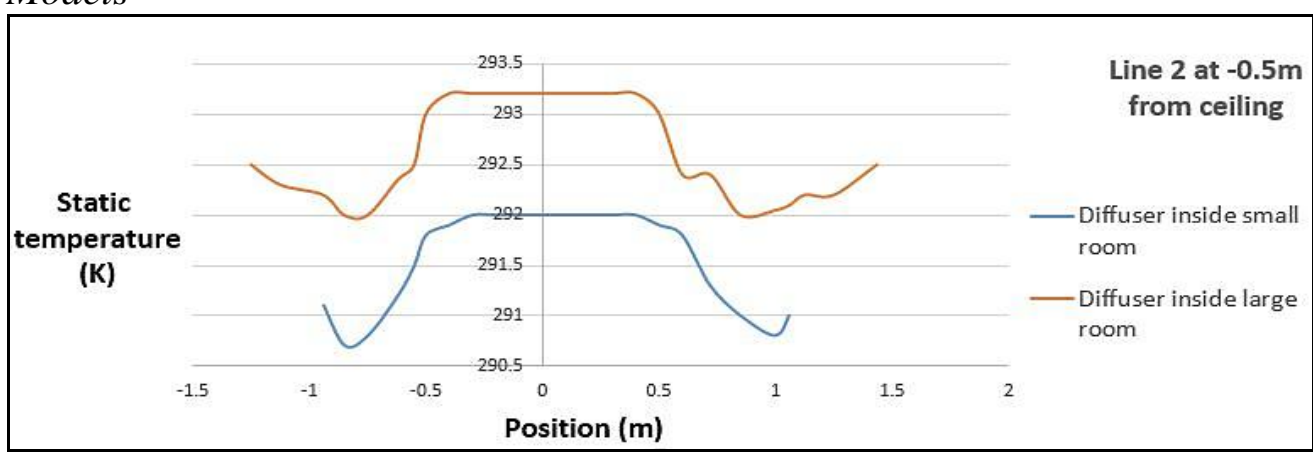

(a)

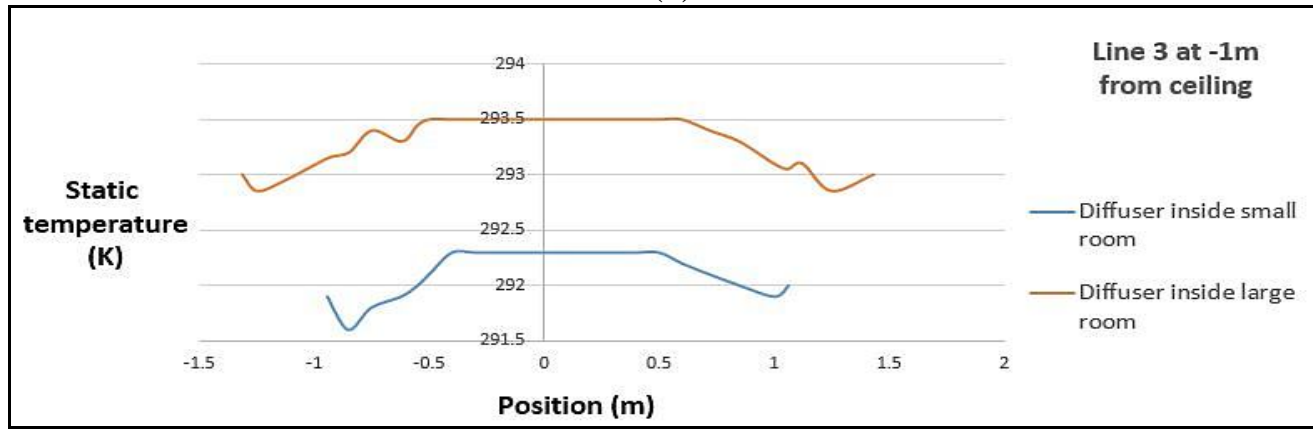

(b)

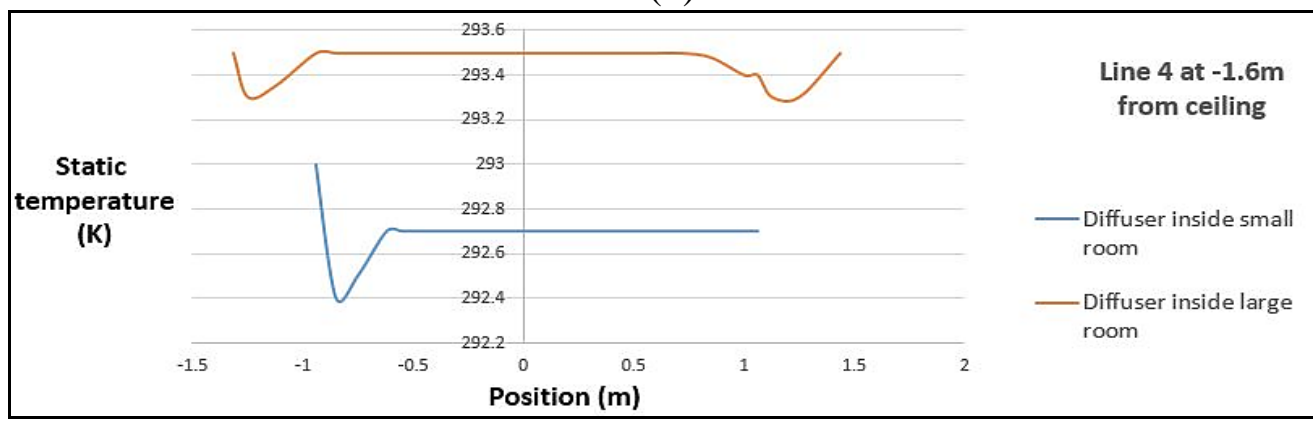

(c)

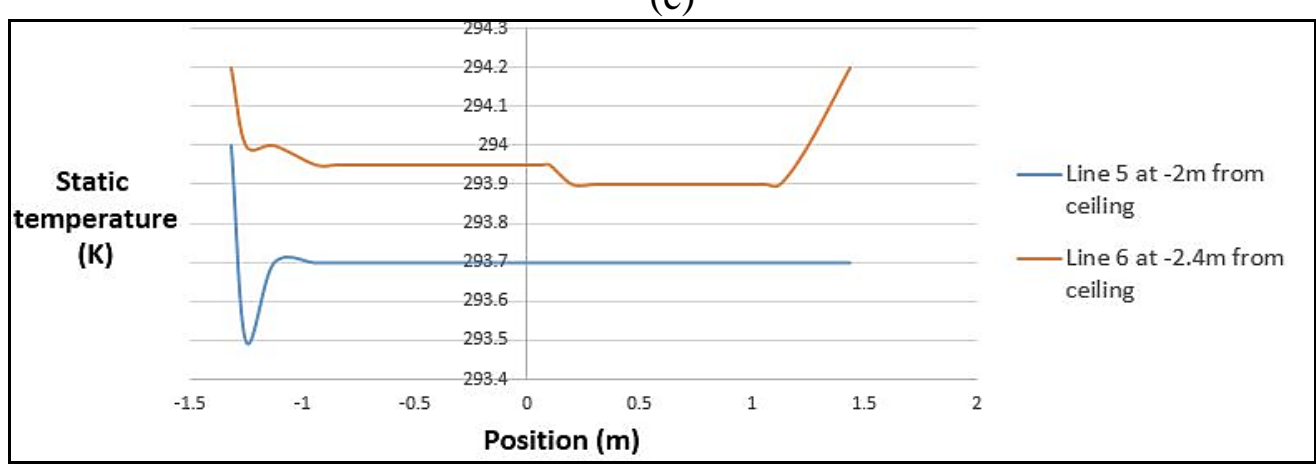

(d) 


\section{Louver Face Ceiling Diffuser with $45^{\circ}$ Blade Angle and $0^{\circ}$ Lip Angle}

As shown in Figure 27, decreasing the diffuser blade angle leads to increasing the passage distance and decreasing the jet velocity out from the diffuser (maximum $2.219-2.465 \mathrm{~m} / \mathrm{s}$ ) less than the jet velocity from $60^{\circ}$ blade angle $(4.205-4.672 \mathrm{~m} / \mathrm{s})$. The airflow distribution patterns throughout the room are shown to be relatively uniform $(0-0.247 \mathrm{~m} / \mathrm{s})$ and less than the diffuser with $60^{\circ}$ blade angle $(0-0.467 \mathrm{~m} / \mathrm{s})$. The surface (Coanda) effect of air distribution is not noticed where the airflow distribution patterns are cone-shaped without any attachment to the room ceiling. Thus, the airflow turned downward when approaching the vertical walls. Therefore, a $45^{\circ}$ blade angle increases the airflow velocity at the walls inside the occupied zone.

Figure 28 shows the XY plot for velocity magnitude at different lines (line 1 to 4 ). The airflow velocity magnitude is higher near the walls (maximum $0.59 \mathrm{~m} / \mathrm{s}$ ) for line 2 due to cone shape of flow distribution than the lines 3 and 4 within the range $0.4 \mathrm{~m} / \mathrm{s}$ and $0.3 \mathrm{~m} / \mathrm{s}$ respectively, while the area away from the wall (average $0.20 \mathrm{~m} / \mathrm{s}$ ). Therefore, the occupants will feel comfortable and we can use this diffuser model in the room with larger height due to the airflow's cone shape producing high velocity on vertical walls and neglecting the surface (Coanda) effect.

Figure 27. Contour of Velocity Magnitude of the Diffuser with $45^{\circ}$ Blade Angle and $0^{\circ}$ Lip Angle

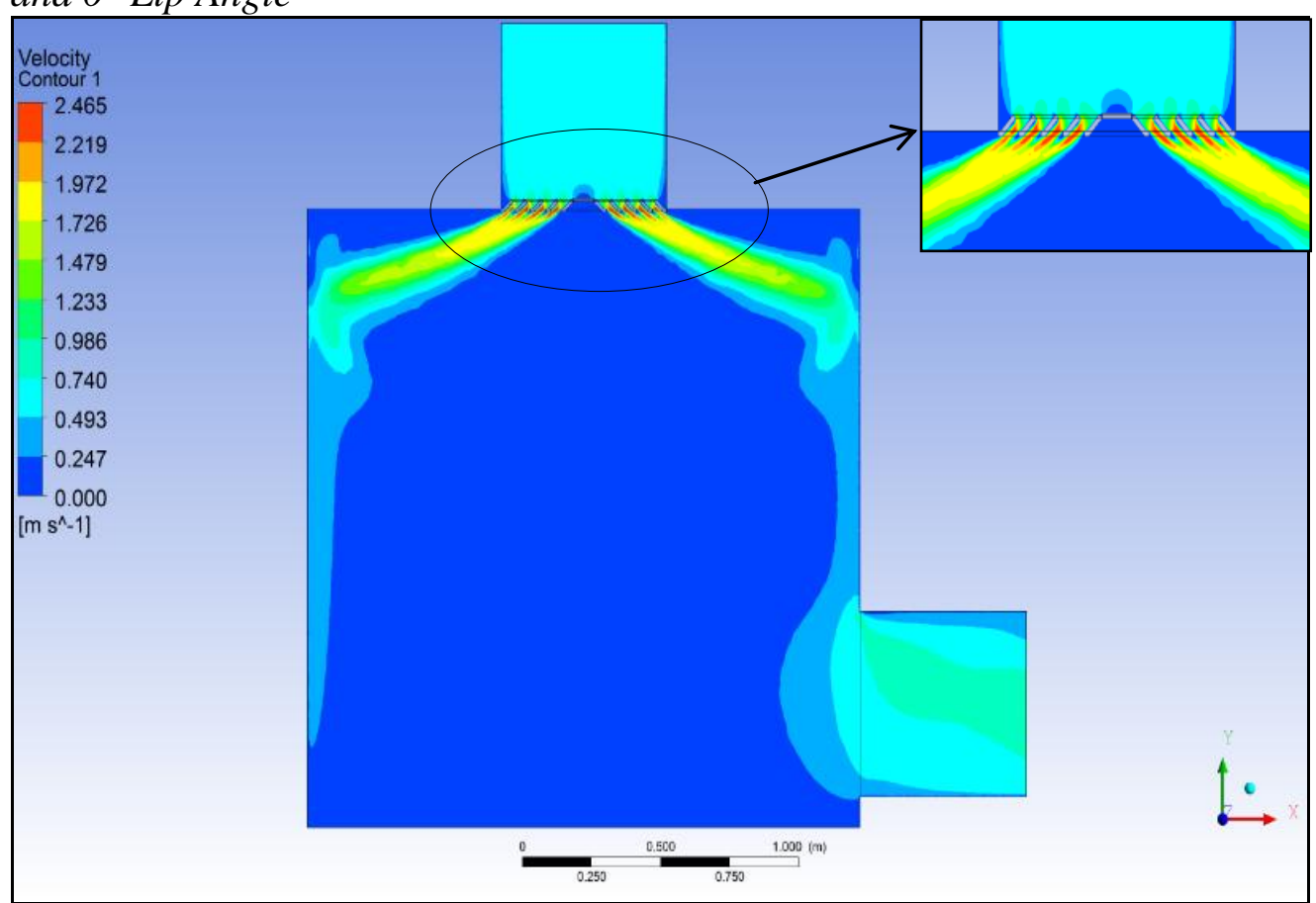


Figure 28. The XY Plot of Velocity Magnitude from the Diffuser with $45^{\circ}$ Blade Angle and $0^{\circ}$ Lip Angle

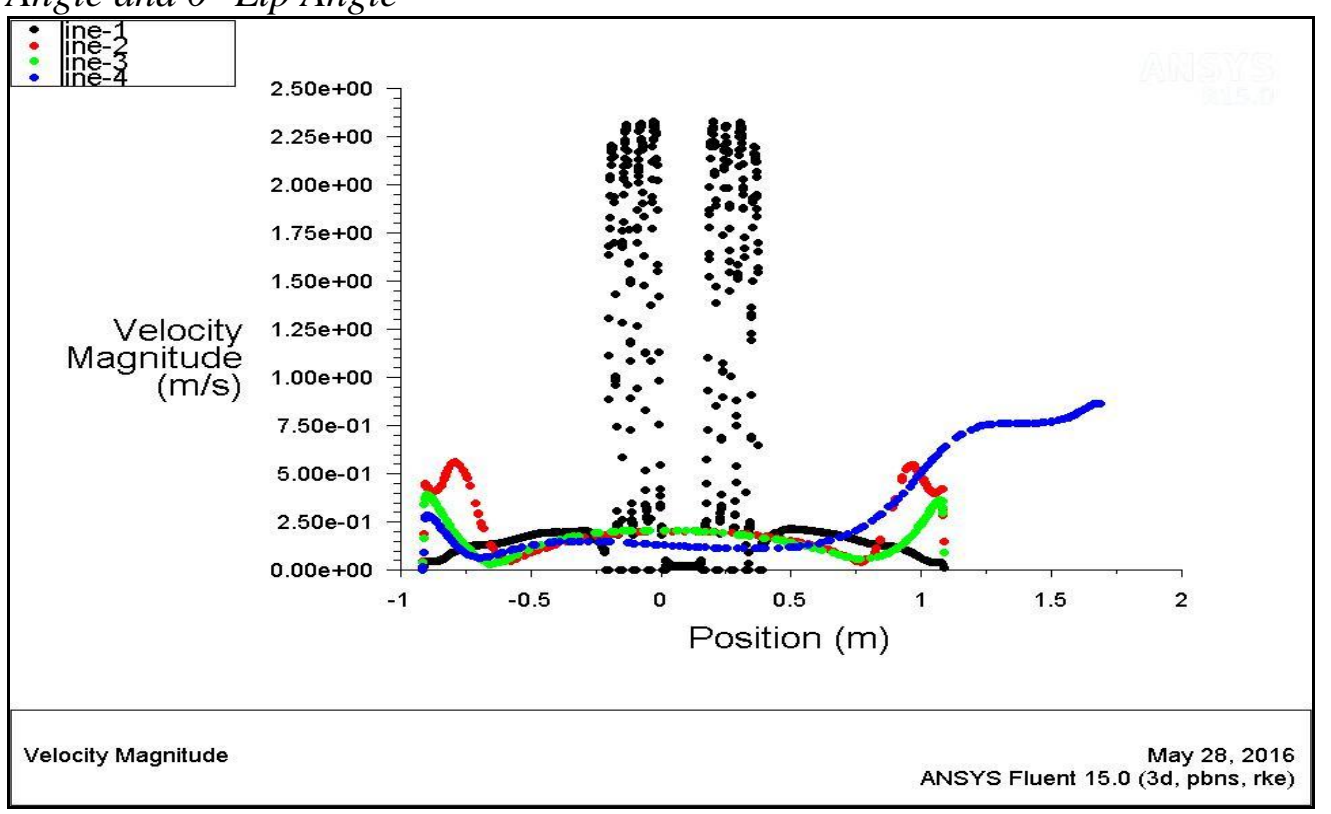

Figure 29 shows that the contour of $\mathrm{Y}$ velocity is relatively non uniform ($0.477-0.409 \mathrm{~m} / \mathrm{s}$ ) throughout the room as most of the distributed air was concentrated near the vertical walls up to the floor, which consistent with the results from Figure 27, and indicates that this model can be used in the room with larger height. In addition, Figure 30 shows that the XY plot for $\mathrm{Y}$ velocity at different lines (line 1 to 4 ), where the average airflow velocity inside the room for the lines 2 to 4 is within $0.20 \mathrm{~m} / \mathrm{s}$ and this consistent with the results from Figure 28.

Figure 29. Contour of $Y$ Velocity from the Diffuser with $45^{\circ}$ Blade Angle and $0^{\circ}$ Lip Angle

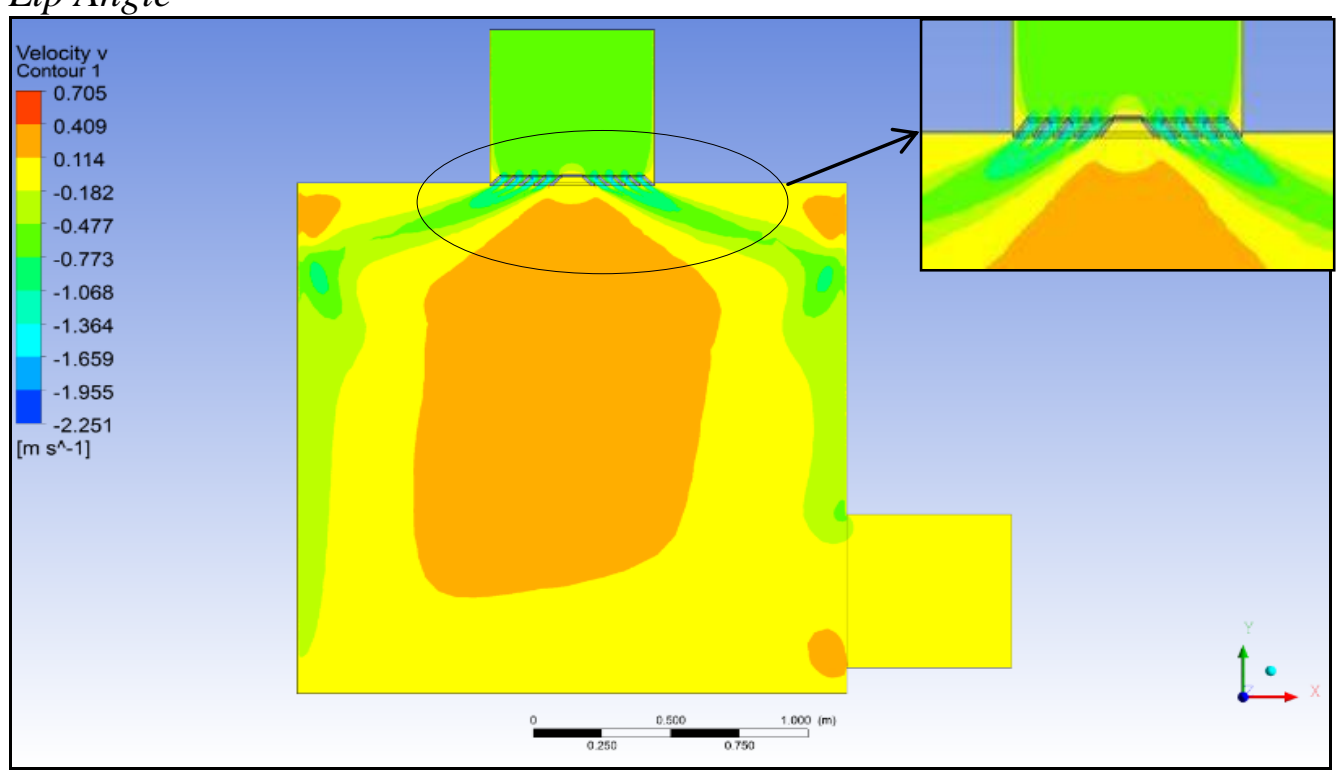


Figure 30. The XY Plot of Y Velocity from the Diffuser with $45^{\circ}$ Blade Angle and $0^{\circ}$ Lip Angle

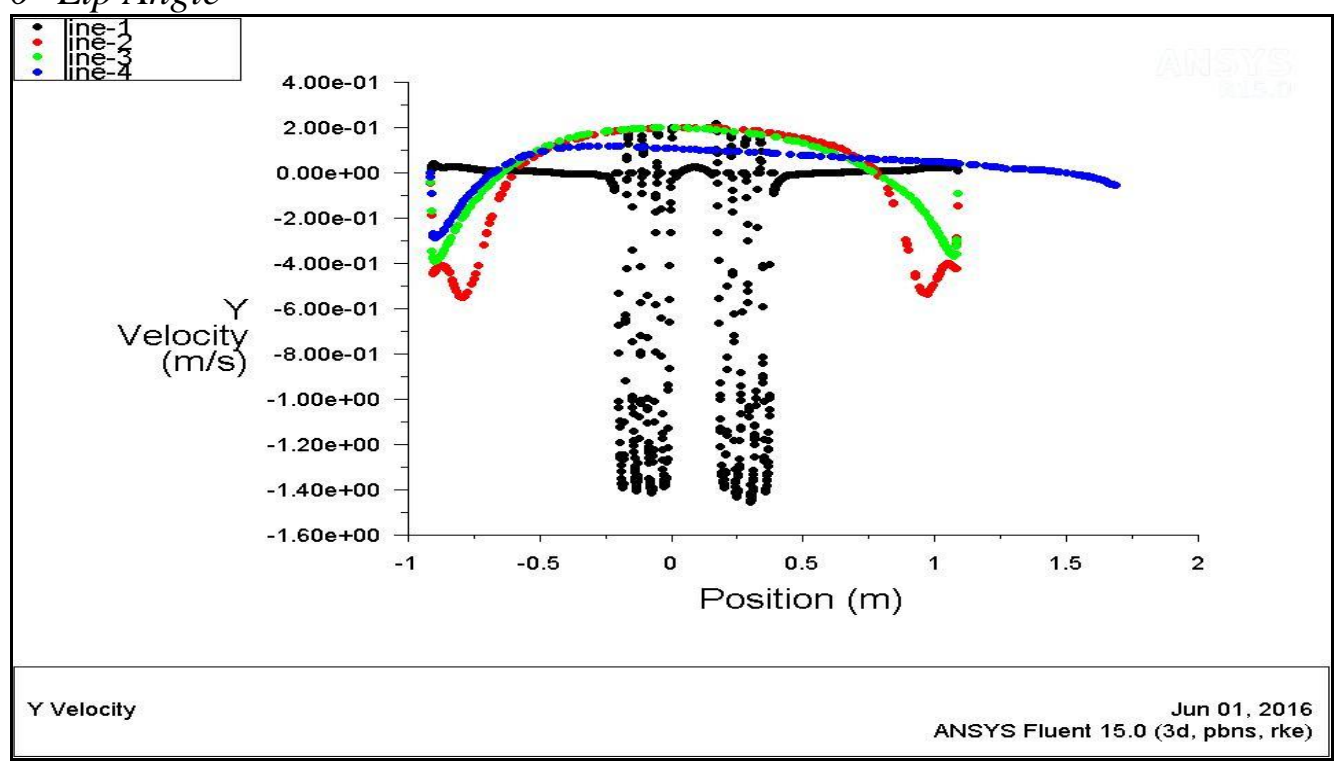

From Figure 31, the airflow temperature distribution from the ceiling diffuser is $(291.495-293.297 \mathrm{~K})$. In addition, Figure 32 shows the XY plot for static temperature at different lines, and Table 3 shows the average static temperature values at different lines. These indicate that the temperature gradient from line 2 to 4 is $1.950^{\circ} \mathrm{C}$ higher than the value with $60^{\circ}$ blade angle diffuser, and this value is acceptable according to the ASHRAE standard 55-2013 and the SMACNA standard (ASHRAE, 2013; SMACNA HVAC).

Furthermore, according to the distribution of airflow in a cone shape, the static temperature for line 2 in Figure 32 is shown below $290 \mathrm{~K}$ near the wall, while the static temperature at the same line but with a $60^{\circ}$ blade angle is presented above the $290 \mathrm{~K}$.

Figure 31. Contour of Temperature from the Diffuser with $45^{\circ}$ Blade Angle and $0^{\circ}$ Lip Angle

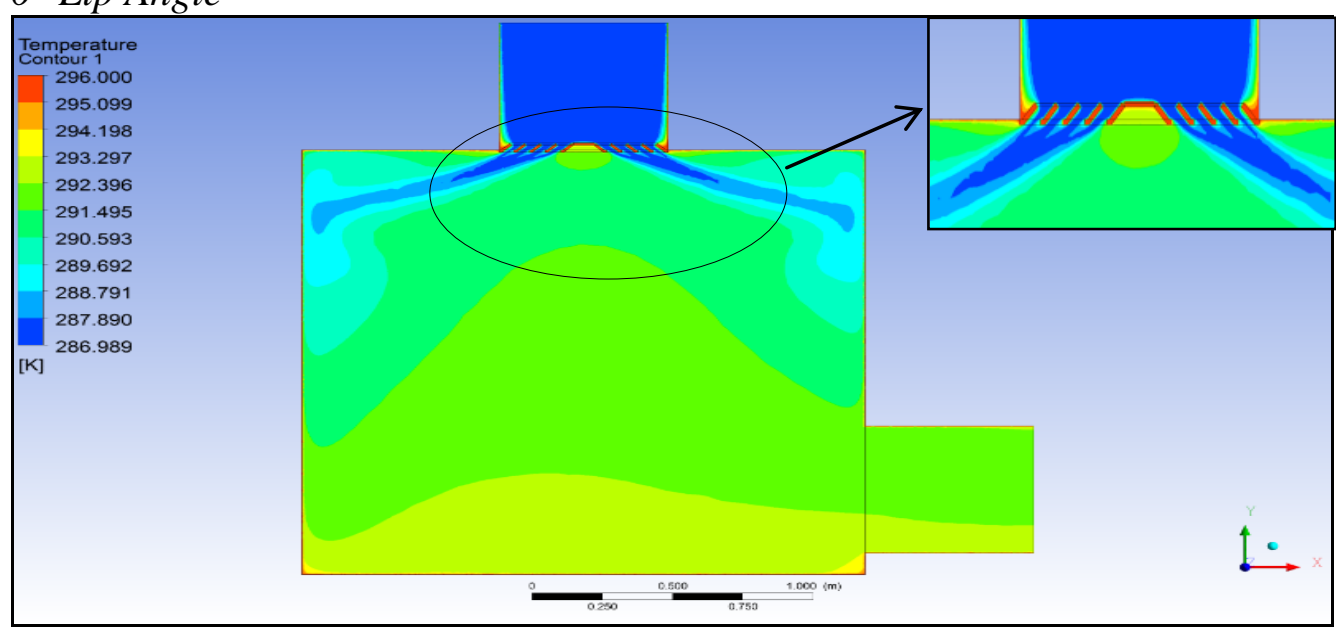


Figure 32. The XY Plot of Static Temperature from the Diffuser with $45^{\circ}$ Blade Angle and $0^{\circ}$ Lip Angle

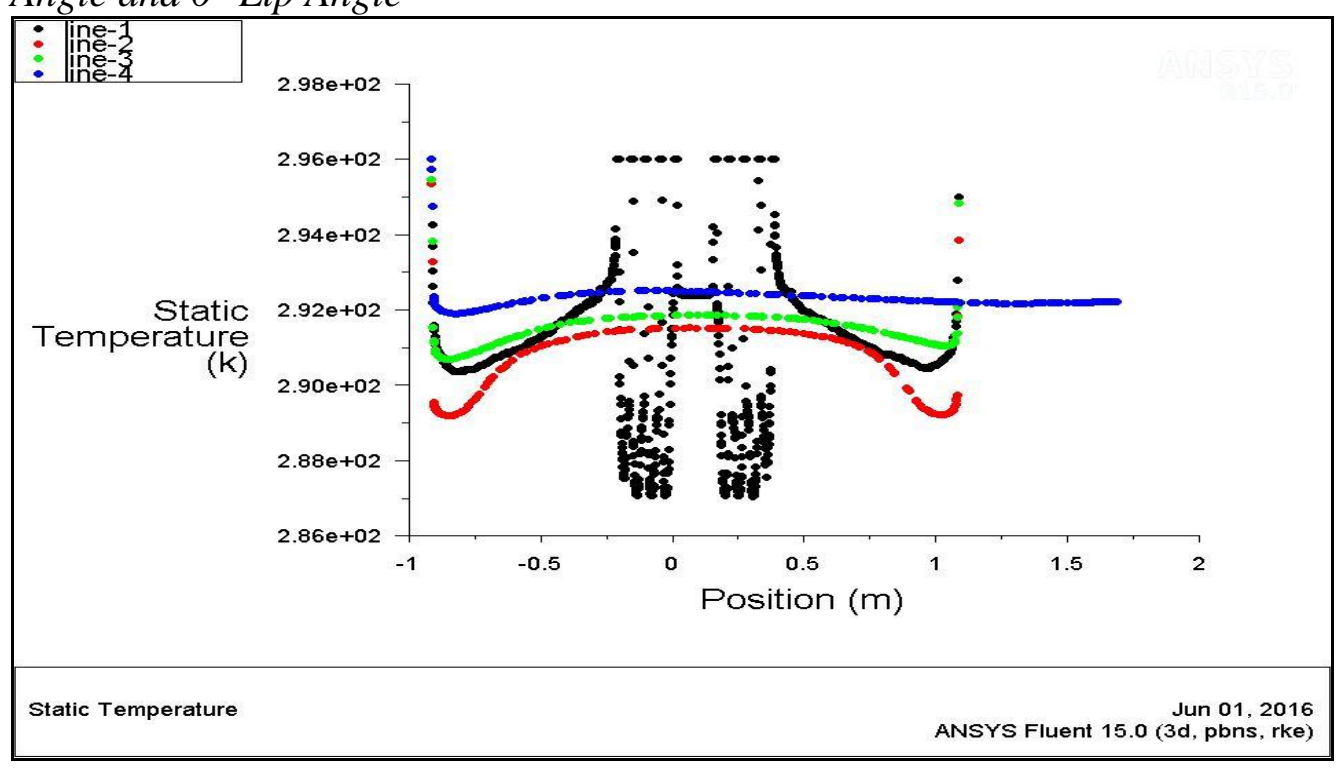

The diffuser shape with $45^{\circ}$ blade angle and $0^{\circ}$ lip angle inside the new room model with larger height $(2 \mathrm{~m}$ length $\times 2 \mathrm{~m}$ width $\times 3 \mathrm{~m}$ height $)$ is shown in Figure 33, with the same dimensions of supply and outlet air ducts from previous work $(0.6 \mathrm{~m}$ length $\times 0.6 \mathrm{~m}$ width $\times 0.6 \mathrm{~m}$ height $)$.

The airflow velocity contours from the diffuser with $45^{\circ}$ blade angle and with $0^{\circ}$ (horizontal) lip angle inside the new room model with larger height are shown in Figure 34. The jet velocity out from the diffuser within the range $(2.212-2.457 \mathrm{~m} / \mathrm{s})$ and the terminal velocity is noticed to be non harmonic $(0-$ $0.246 \mathrm{~m} / \mathrm{s}$ ) where the airflow velocity is higher near the wall due to airflow patterns of distribution. However, these values are relatively the same from the diffuser inside the small room.

In order to check the effect of the room height on the diffuser performance, Fig. 35 shows that the velocity magnitude at different lines located inside the occupied zone.

Figure 35 and Table 5 presented the average value for velocity magnitude at different levels inside both the small and large room. Inside the large room, the average values appeared within the range $(0.2-0.25 \mathrm{~m} / \mathrm{s})$ due to the airflow with high velocity near the wall. It represents the thermal comfort conditions inside the occupied zone, which is recommended by the ASHRAE standard 552013 (ASHRAE, 2013). However, near the room floor at line 7 the average velocity value is shown close to $0.1 \mathrm{~m} / \mathrm{s}$, the minimum value recommended by SMACNA (SMACNA HVAC). 
Figure 33. The 3D Room Geometry with New Height View with One Outlet near Right Hand Side Wall Bottom

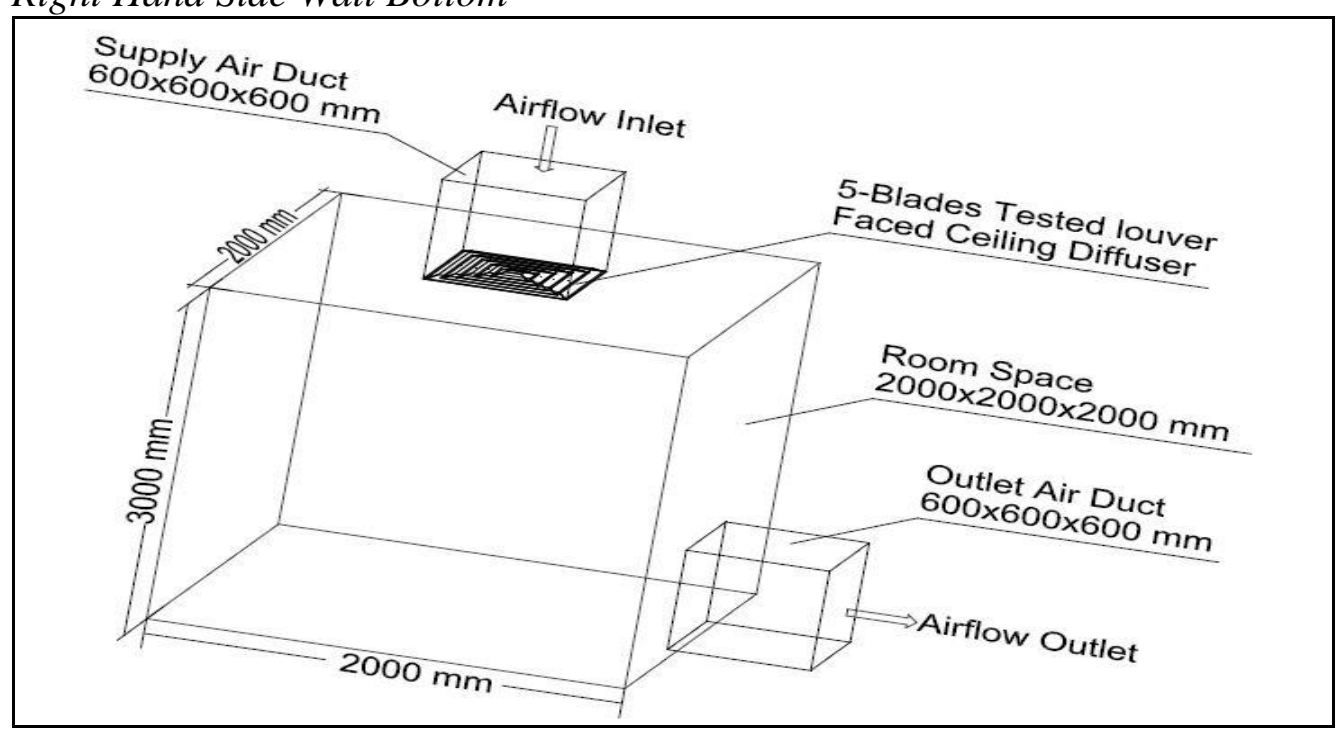

Figure 34. Contours of Airflow Velocity Distribution from the Diffuser with $45^{\circ}$ Blade Angle and $0^{\circ}$ Lip Angle inside the New Room Model

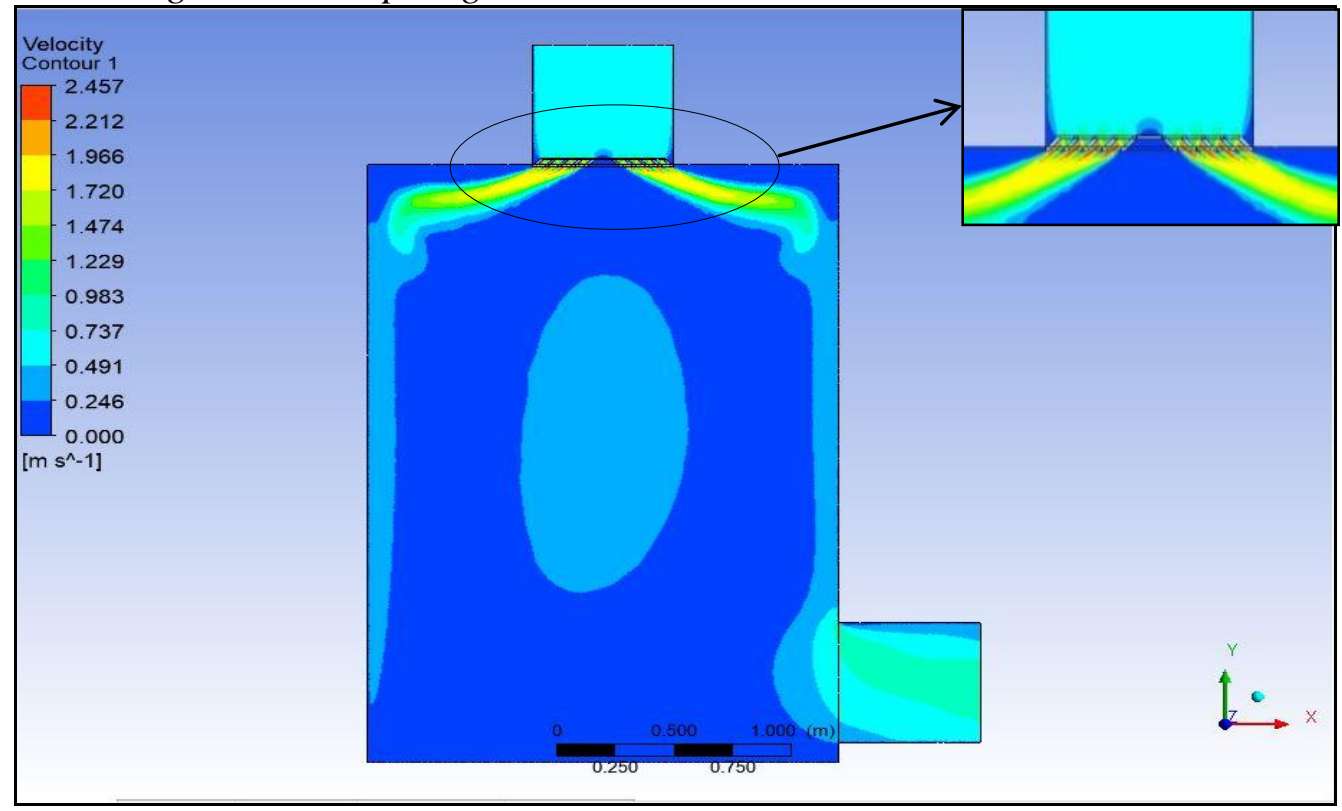


Table 5. Average Velocity Magnitude and Average Static Temperature Distribution from the Diffuser with $45^{\circ}$ Blade Angle and $0^{\circ}$ Lip Angle at Different Lines Location inside the Two Room Height Models

\begin{tabular}{|c|c|c|c|}
\hline Item & Line number & $\begin{array}{c}\text { Diffuser with } 45^{\circ} \\
\text { blade angle and } 0^{\circ} \text { lip } \\
\text { within the small room } \\
\text { height }\end{array}$ & $\begin{array}{l}\text { Diffuser with } 65^{\circ} \\
\text { blade angle and } 0^{\circ} \text { lip } \\
\text { within the large room } \\
\text { height }\end{array}$ \\
\hline \multirow{6}{*}{$\begin{array}{l}\text { Average velocity } \\
\text { magnitude }(\mathrm{m} / \mathrm{s})\end{array}$} & Line (2) & 0.298 & 0.263 \\
\hline & Line (3) & 0.204 & 0.242 \\
\hline & Line (4) & 0.404 & 0.240 \\
\hline & Line (5) & 0 & 0.224 \\
\hline & Line (6) & 0 & 0.231 \\
\hline & Line (7) & 0 & 0.085 \\
\hline \multirow{6}{*}{$\begin{array}{l}\text { Average static } \\
\text { temperature }(\mathrm{K})\end{array}$} & Line (2) & 290.273 & 290.697 \\
\hline & Line (3) & 291.309 & 291.747 \\
\hline & Line (4) & 292.228 & 292.458 \\
\hline & Line (5) & 0 & 292.799 \\
\hline & Line (6) & 0 & 293.160 \\
\hline & Line (7) & 0 & 293.507 \\
\hline
\end{tabular}

Figure 35. Velocity Magnitude from Louver Face Ceiling Diffuser with $45^{\circ}$ Blade Angle and $0^{\circ}$ Lip Angles at Different Lines inside the Different Room Height Models

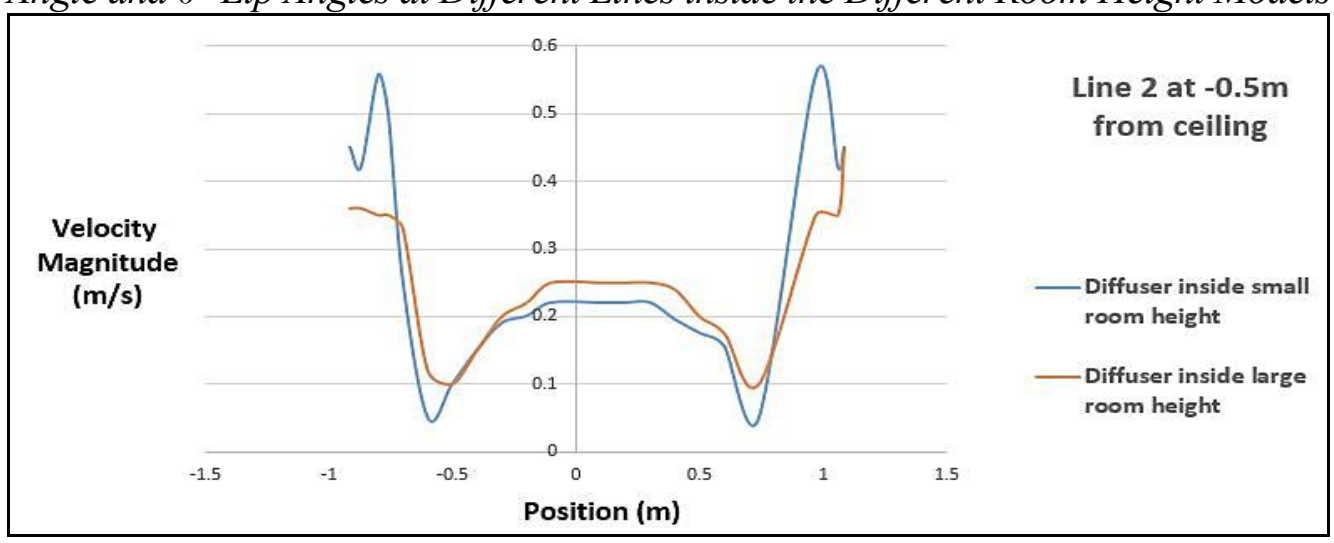

(a)

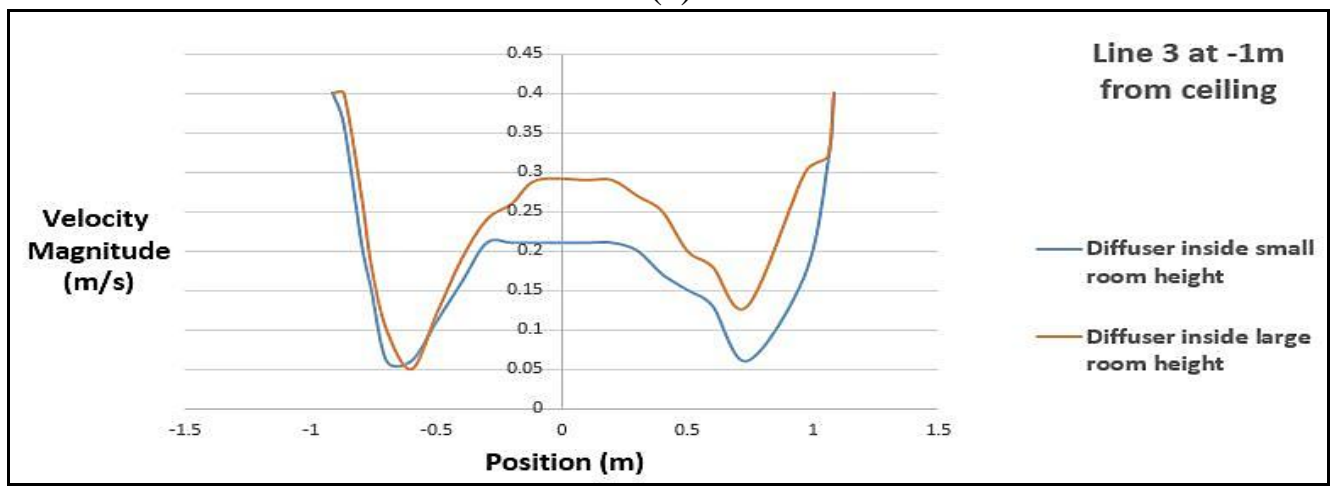

(b) 


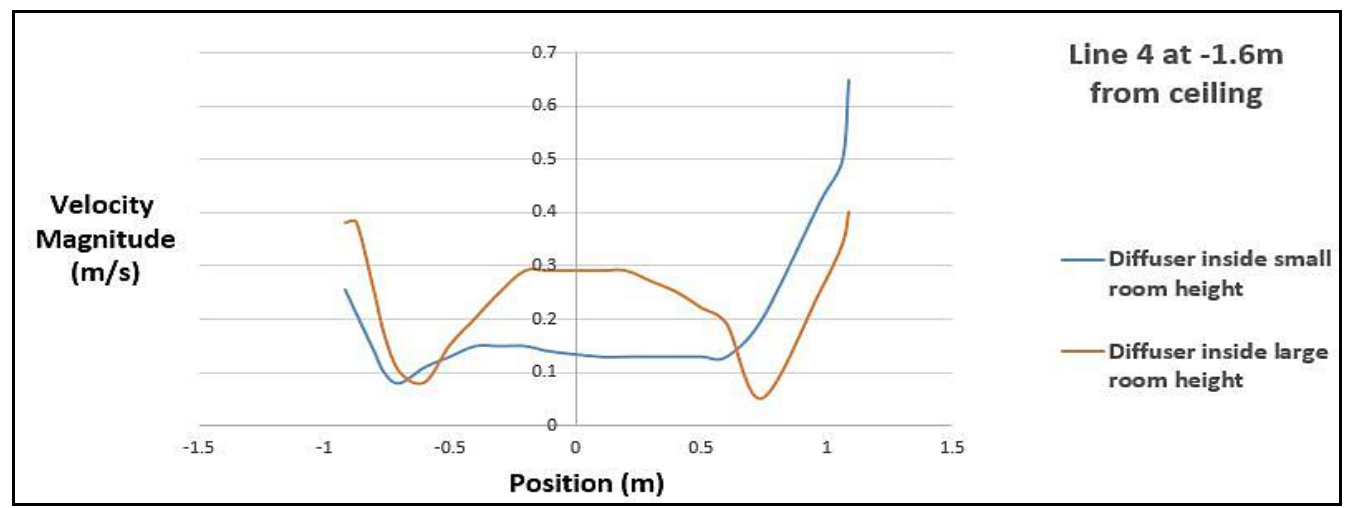

(c)

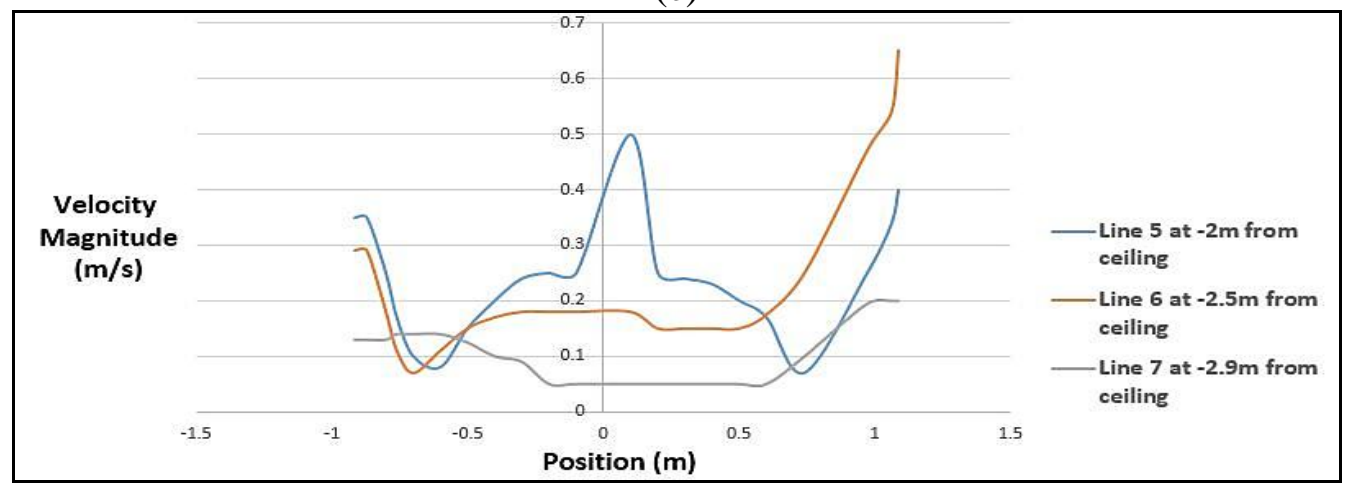

(d)

Figure 36 shows the contours of air temperature distribution from the diffuser with blade angle $45^{\circ}$ and horizontal lip angle throughout the new room model with larger height.

The airflow pattern distribution in a cone shape leads to some airflow patterns with low temperature reaching the lower parts of the room. However, near the floor the temperature distribution is within the range [293.292 - $294.195 \mathrm{~K}$ ].

Figure 37 and Table 5 presented the average values for temperature at different levels inside small and large room. It indicated that the temperature gradients between lines from the diffuser model inside the large room were $2.810^{\circ} \mathrm{C}$, more than that indicated from diffusers inside the small room $1.955^{\circ} \mathrm{C}$.

However, according to ASHRAE standard 55-2013, air temperature difference between head level and ankle level shall not exceed $3^{\circ} \mathrm{C}$ for seated occupants or $4^{\circ} \mathrm{C}$ for standing occupants (ASHRAE, 2013). Therefore, this diffuser model can be used inside the room with larger height. 
Figure 36. Contours of Airflow Temperature Distribution from the Diffuser with $45^{\circ}$ Blade Angle and $0^{\circ}$ Lip Angle inside the New Room Model with Larger Height

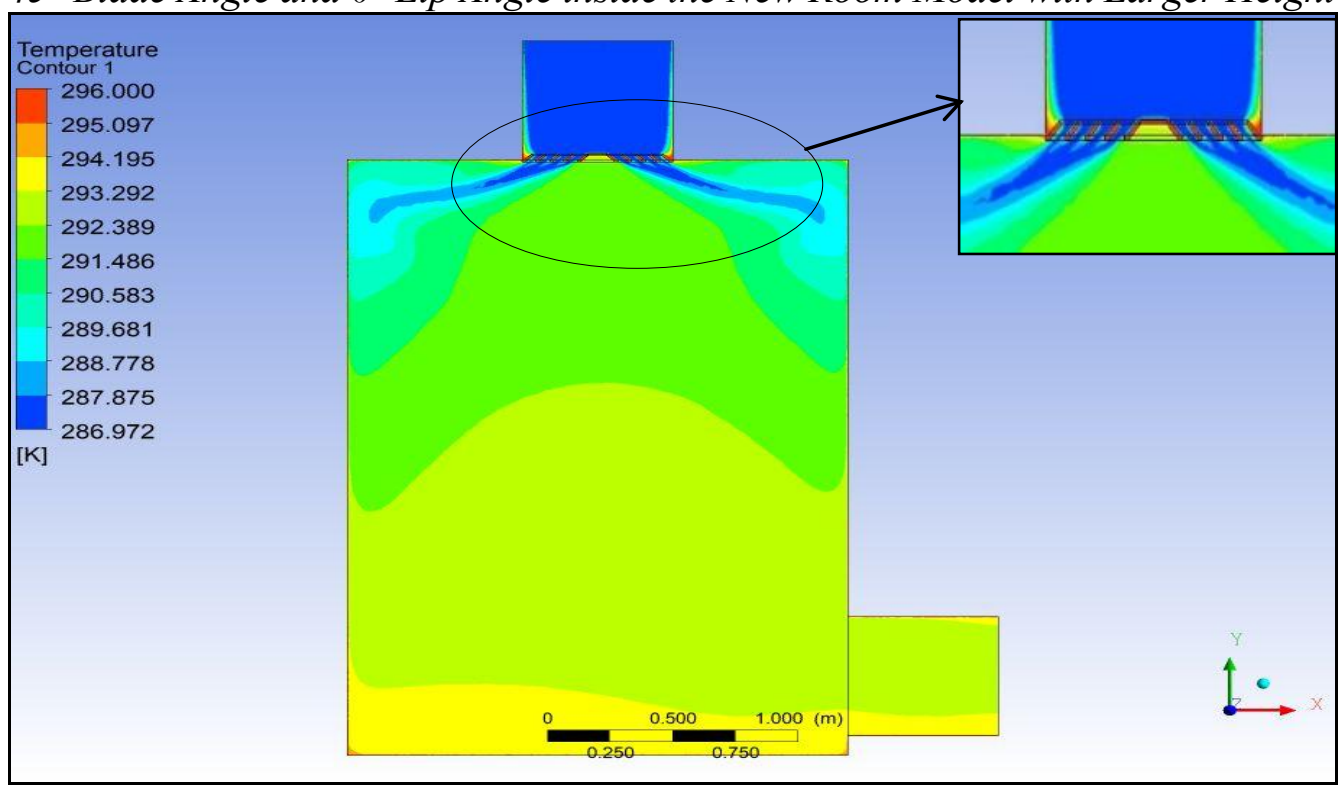

Figure 37. Static Temperature Distribution from Louver Face Ceiling Diffuser with $45^{\circ}$ Blade Angle and $0^{\circ}$ Lip Angles at Different Lines inside the Two Room Models

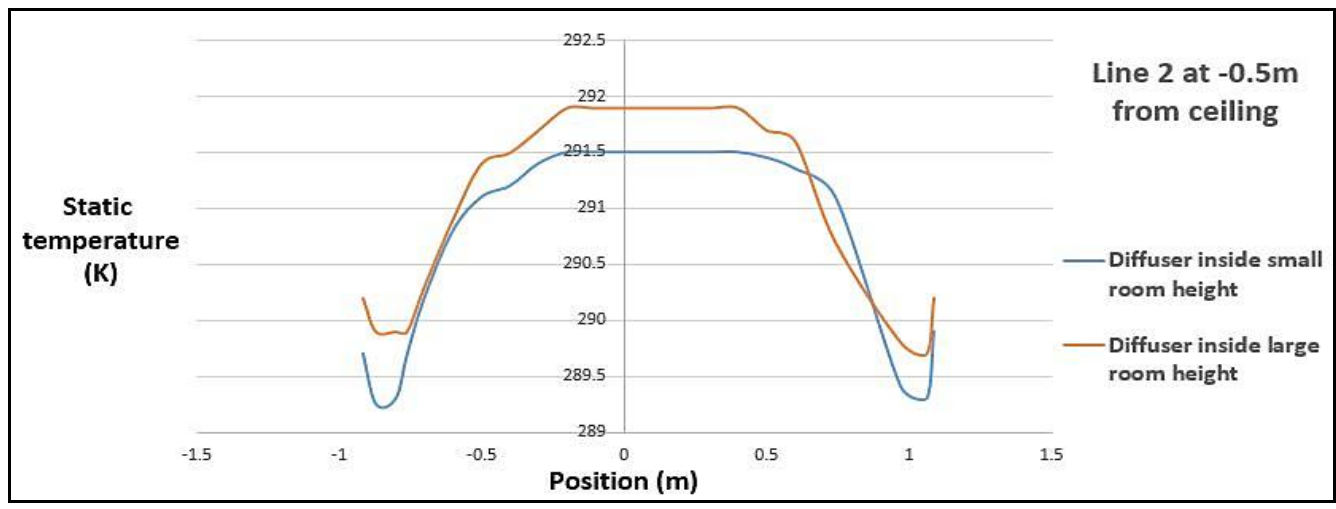

(a)

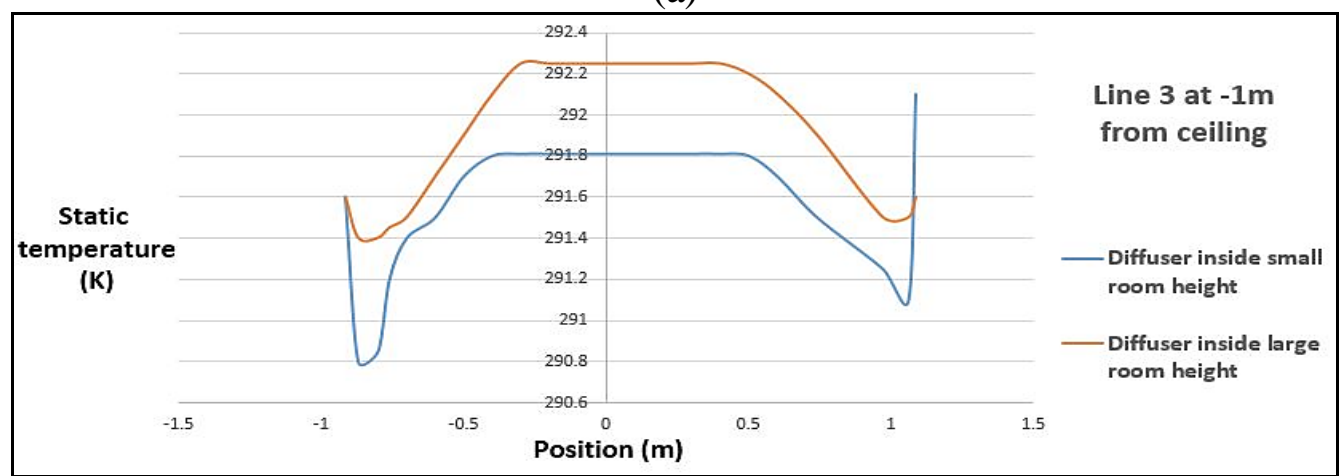

(b) 


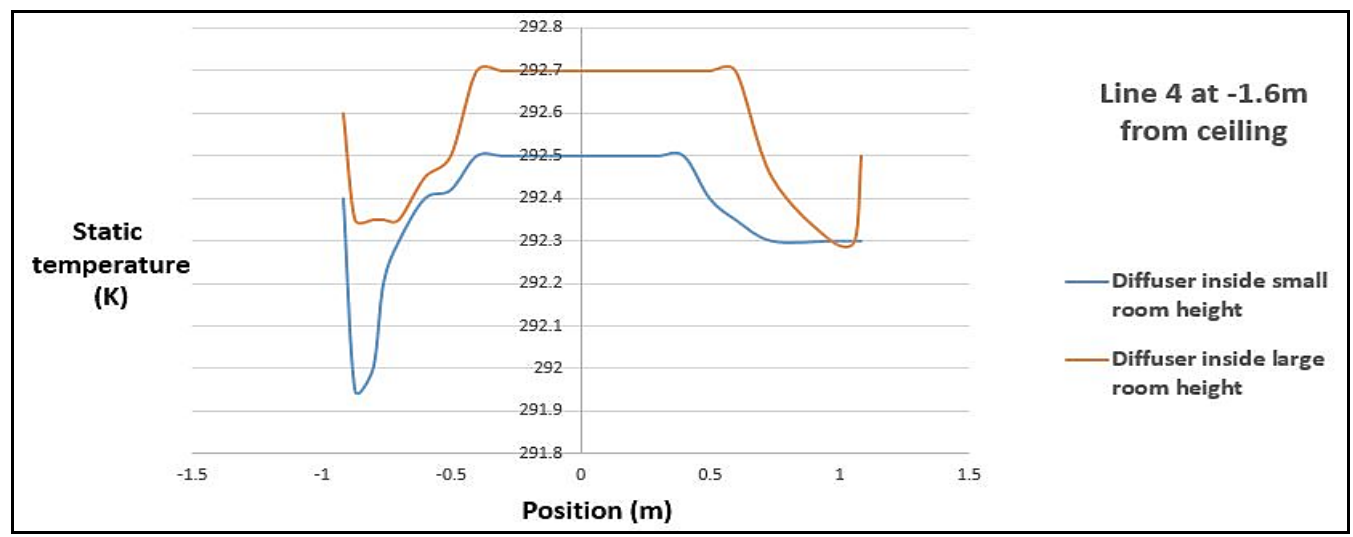

(c)

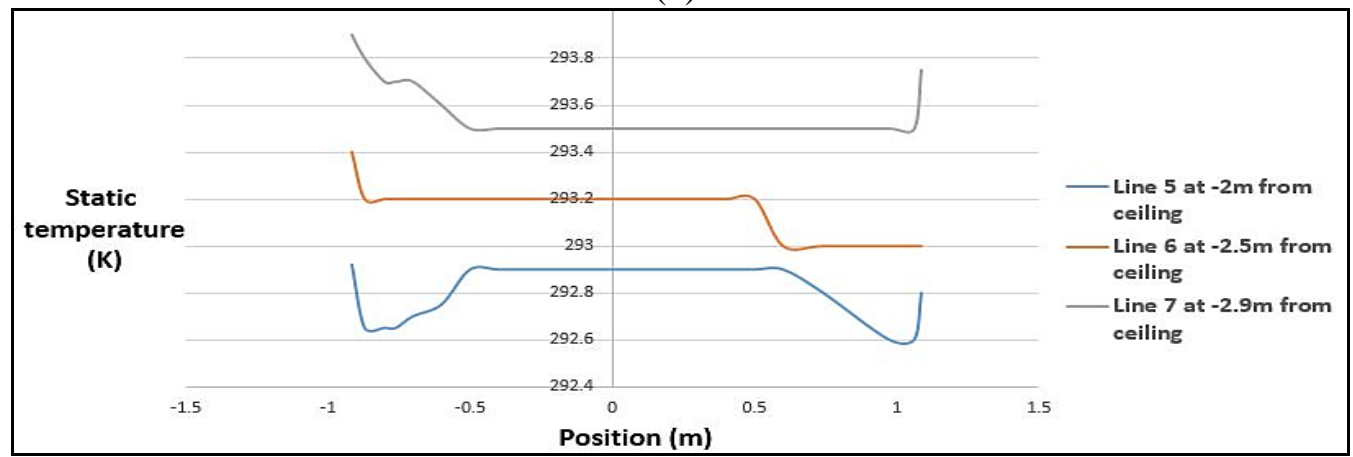

(d)

Louver Face Ceiling Diffuser with $60^{\circ}$ Blade Angle and Inclined $5^{\circ}$ Lip Angle

As shown in Figure 38, the contours of velocity from the diffuser with $5^{\circ}$ lip angle are very similar to the contours of velocity from the diffuser with $0^{\circ}$ horizontal lip angle. The surface (Coanda) effect of air distribution is noticed and the airflow patterns cling with the ceiling then turned downward before the airflow approached to the vertical walls. In addition, the airflow terminal velocities throughout the room are relatively uniform $(0-0.485 \mathrm{~m} / \mathrm{s})$ and are considered close in the case with $0^{\circ}$ lip angle $(0-0.467 \mathrm{~m} / \mathrm{s})$.

Figure 39 shows the XY plot for velocity magnitude at different lines inside the room shown in Figure 1. This figure proves that at lines 2 to 4 , the airflow velocity magnitude is higher near the walls (maximum $0.485 \mathrm{~m} / \mathrm{s}$ ) than the area away from the wall (average $0.25 \mathrm{~m} / \mathrm{s}$ ). Therefore, the occupants away from the walls will feel comfortable, and the results from diffuser with $5^{\circ}$ lip angle are very close to the results from diffuser with $0^{\circ}$ lip angle. 
Figure 38. Contour of Velocity Magnitude of the Diffuser with $60^{\circ}$ Blade Angle and $5^{\circ}$ Lip Angle

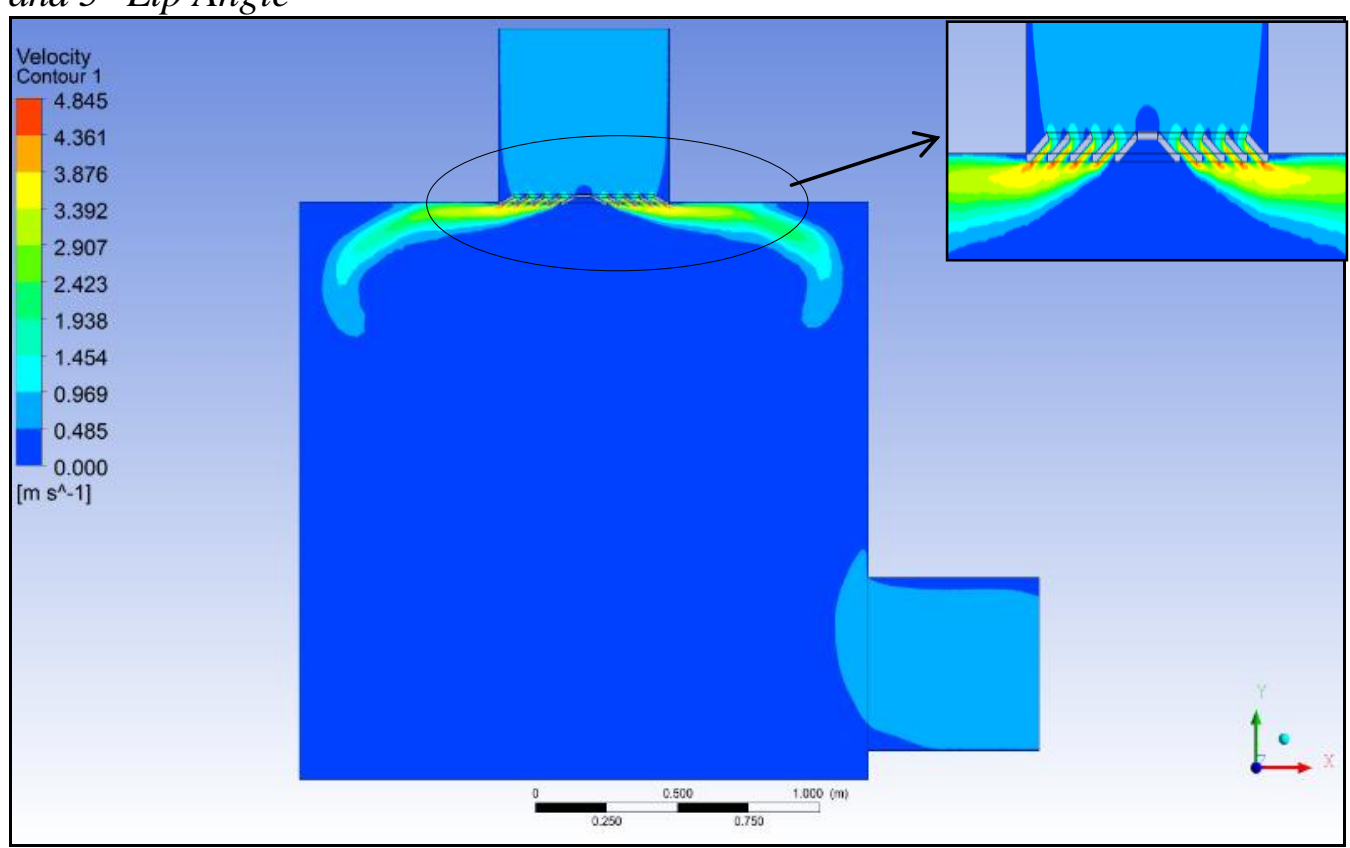

Figure 39. The XY Plot of Velocity Magnitude from the Diffuser with $60^{\circ}$ Blade Angle and $5^{\circ}$ Lip Angle

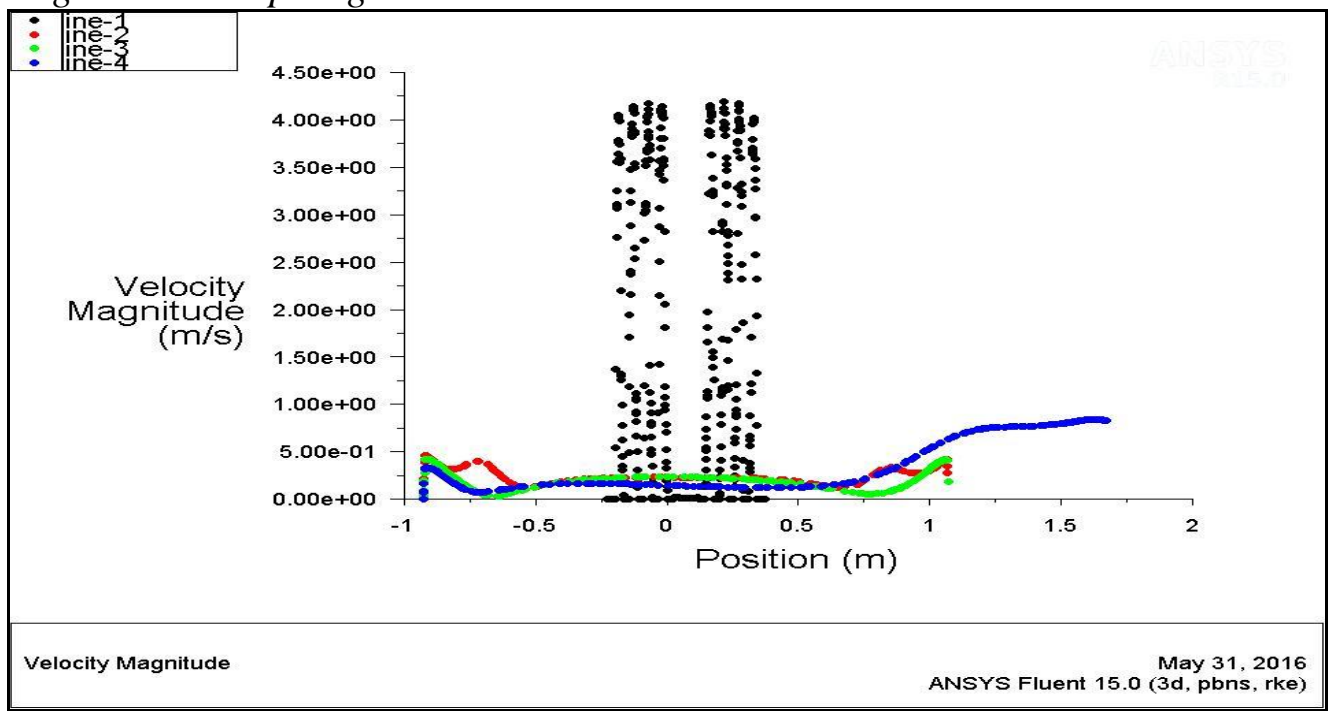

Figure 40 shows that the contour of $Y$ velocity is uniform $(-0.003-0.488 \mathrm{~m} / \mathrm{s})$ throughout the room, which is consistent with the results from Figure 38. In addition, Figure 41 shows that the XY plot for $\mathrm{Y}$ velocity at different lines, where the airflow velocity inside the room for the lines 2 to 4 is around $0.25 \mathrm{~m} / \mathrm{s}$ and this similar with the results from Figure 39. 
Figure 40. Contour of $Y$ Velocity from the Diffuser with $60^{\circ}$ Blade Angle and $5^{\circ}$

Lip Angle

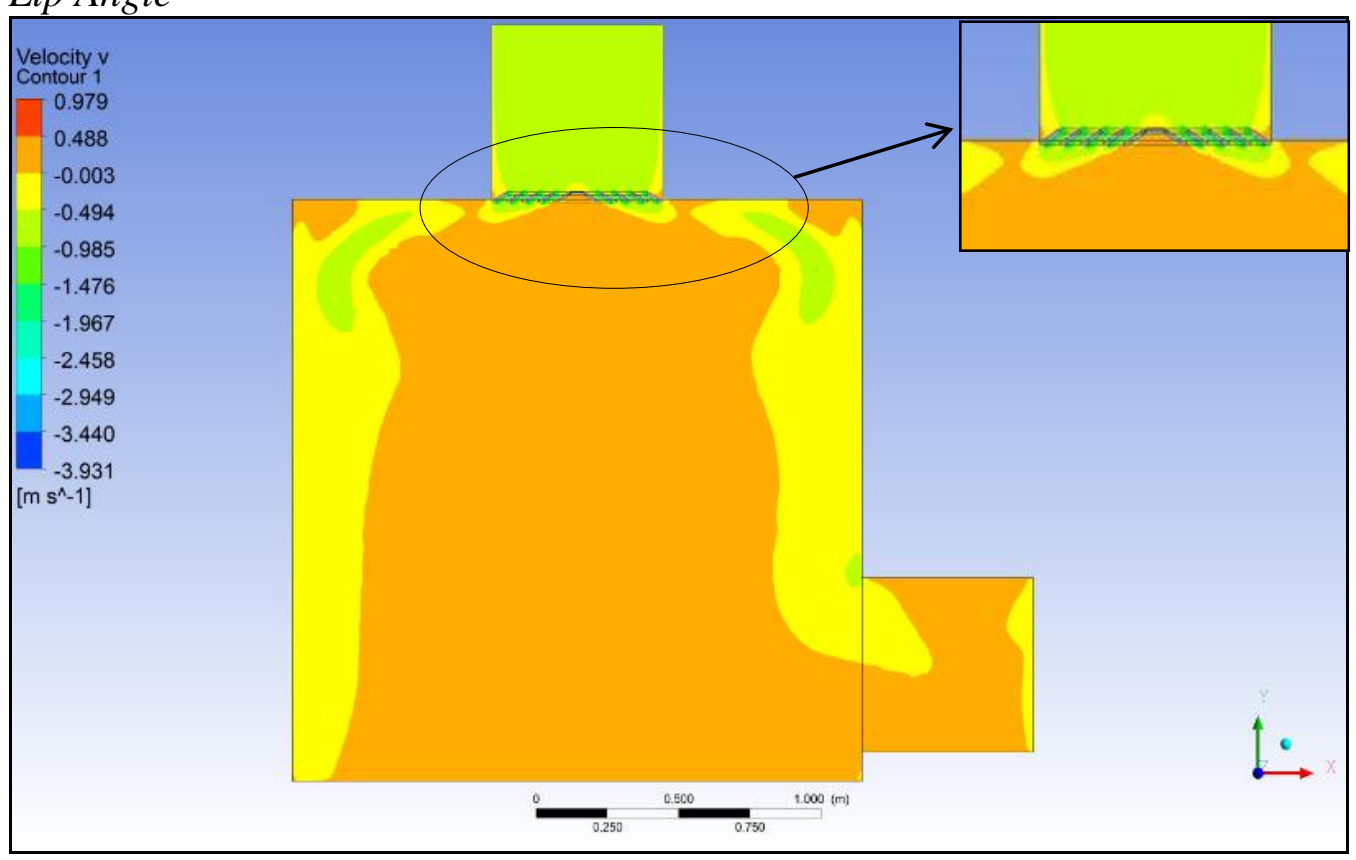

Figure 41. The $X Y$ Plot of $Y$ Velocity from the Diffuser with $60^{\circ}$ Blade Angle and $5^{\circ}$ Lip Angle

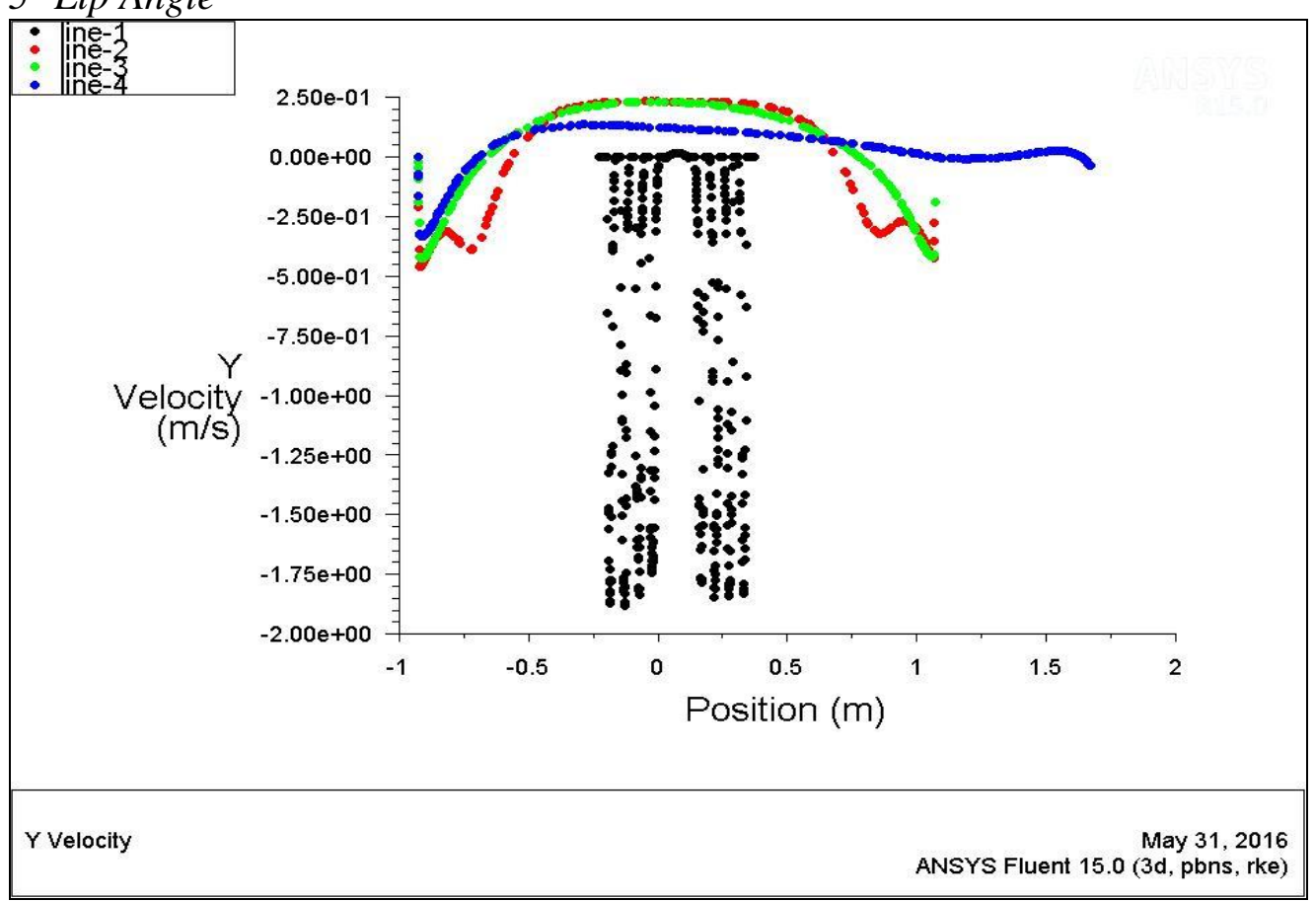

In Figure 42, the airflow temperature distribution from the ceiling diffuser is in range (291.486 - 293.292 K). In addition, Figure 43 shows the XY plot for static temperature at different lines (line 1 to 4 ) which similar with the results from diffuser with $0^{\circ}$ lip angle. Table 3 shows the average static temperature value 
at different lines, which indicates that the temperature gradients from line 2 to 4 is $\left(1.537^{\circ} \mathrm{C}\right)$ considered close to the case of $0^{\circ}$ lip, where this value is acceptable according to standards indicating the maximum temperature gradients value $\left(2^{\circ} \mathrm{C}\right)$.

Figure 42. Contour of Temperature from the Diffuser with $60^{\circ}$ Blade Angle and $5^{\circ}$ Lip Angle

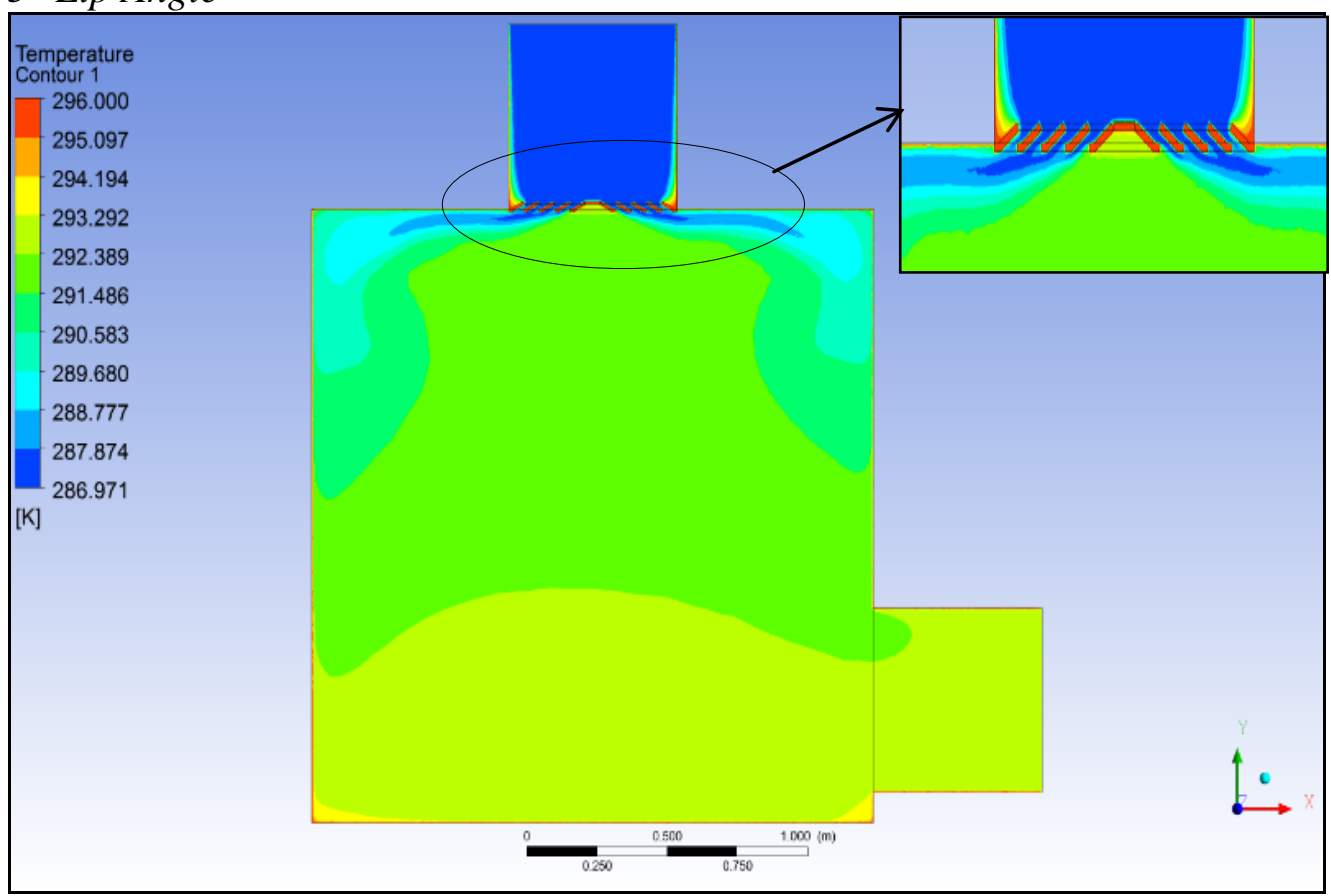

Figure 43. The XY Plot of Static Temperature from the Diffuser with $60^{\circ}$ Blade Angle and $5^{\circ}$ Lip Angle

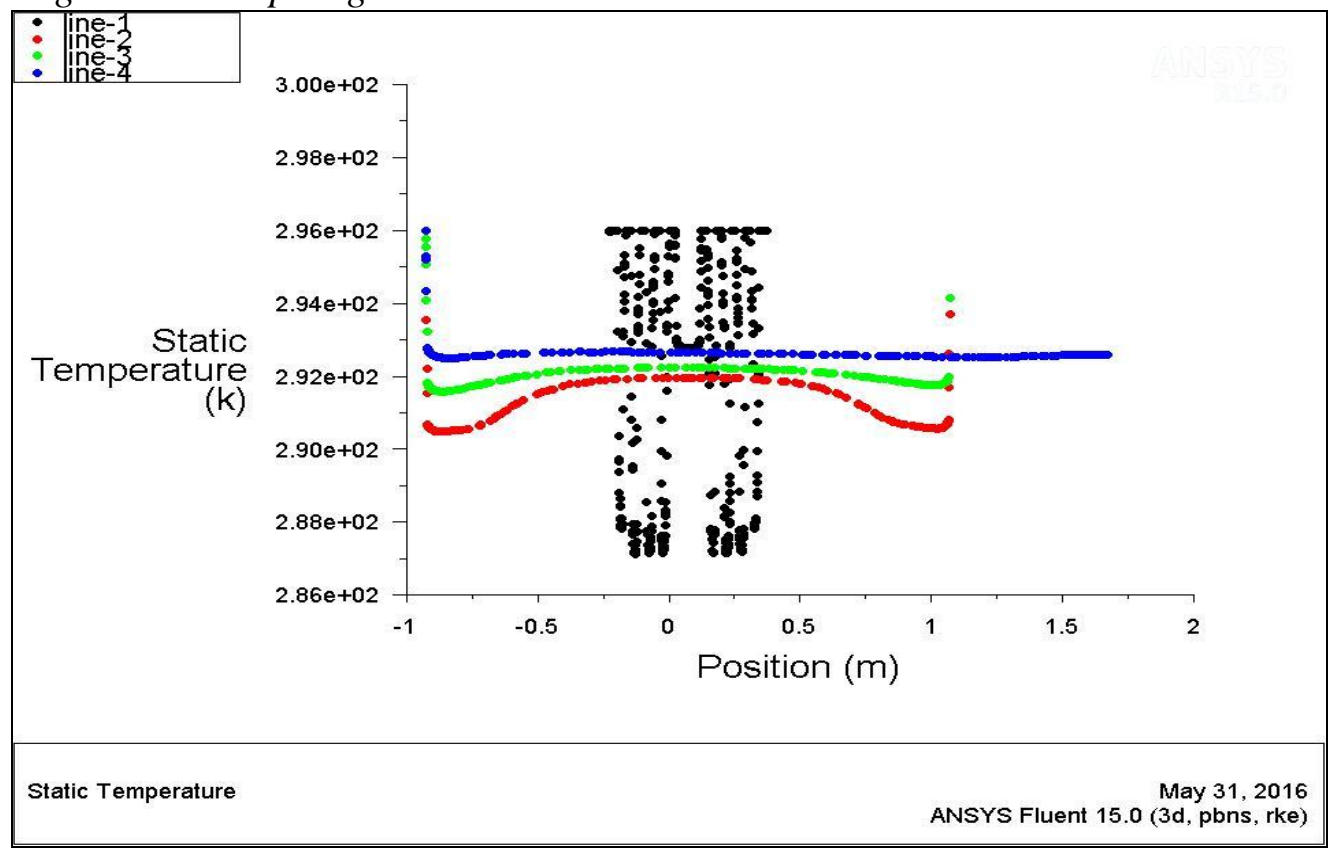




\section{Louver Face Ceiling Diffuser with $60^{\circ}$ Blade Angle and Inclined $10^{\circ}$ Lip Angle}

As shown in Figure 44, increasing the diffuser lip angle leads to decreasing the jet velocity out from the diffuser $(3.835-4.261 \mathrm{~m} / \mathrm{s})$ less than the jet velocity from $0^{\circ}$ lip angle $(4.205-4.672 \mathrm{~m} / \mathrm{s})$. The airflow distribution patterns throughout the room are relatively uniform $(0-0.426 \mathrm{~m} / \mathrm{s})$ and relatively less than the diffuser with $0^{\circ}$ lip angle $(0-0.467 \mathrm{~m} / \mathrm{s})$, where the surface (Coanda) effect of air distribution is noticed.

Figure 45 shows the XY plot for velocity magnitude at different lines: from lines 2 to 4 the airflow velocity magnitude was higher near the walls (maximum $0.462 \mathrm{~m} / \mathrm{s}$ ) than the area away from the wall (average $0.21 \mathrm{~m} / \mathrm{s}$ ).

Figure 44. Contour of Velocity Magnitude of the Diffuser with $60^{\circ}$ Blade Angle and $10^{\circ}$ Lip Angle

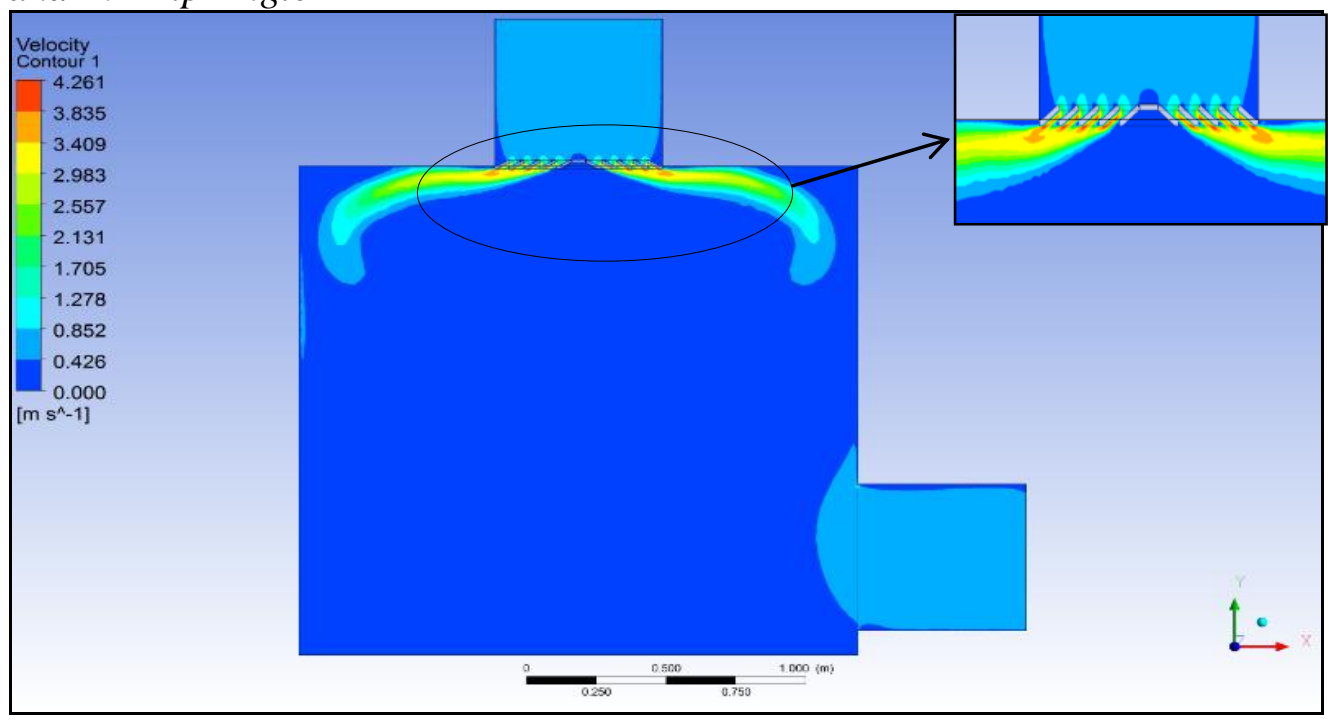

Figure 45. The XY Plot of Velocity Magnitude from the Diffuser with $60^{\circ}$ Blade Angle and $10^{\circ}$ Lip Angle

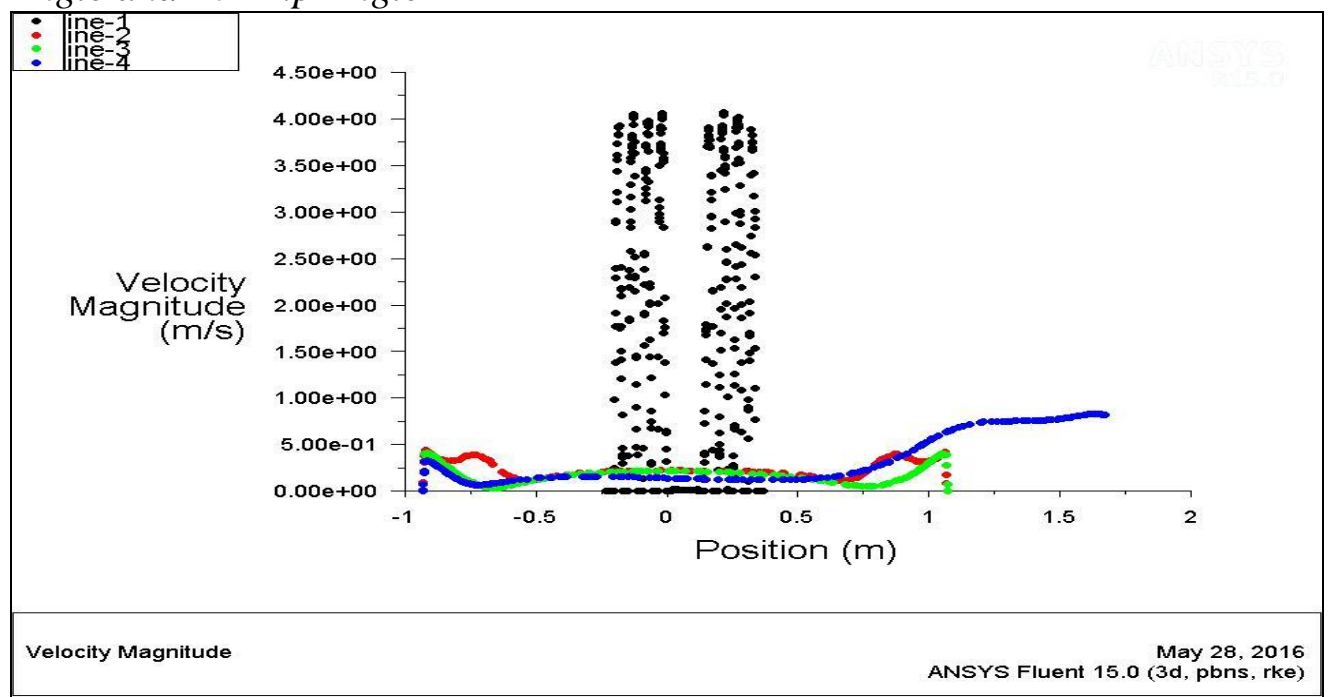


Figure 46 shows that the contour of $\mathrm{Y}$ velocity is relatively non-uniform ($0.351-0.570 \mathrm{~m} / \mathrm{s}$ ) throughout the room. Most of the airflow is concentrated near the vertical walls up to the floor, which is relatively similar to the results from the diffuser with $45^{\circ}$ blade angle and horizontal lip. In addition, Figure 47 shows the XY plot for Y velocity at different lines, where the airflow velocity inside the room for the lines 2 to 4 is within average $0.21 \mathrm{~m} / \mathrm{s}$. This is consistent with the results from Figure 46.

Figure 46. Contour of $Y$ Velocity from the Diffuser with $60^{\circ}$ Blade Angle and $10^{\circ}$ Lip Angle

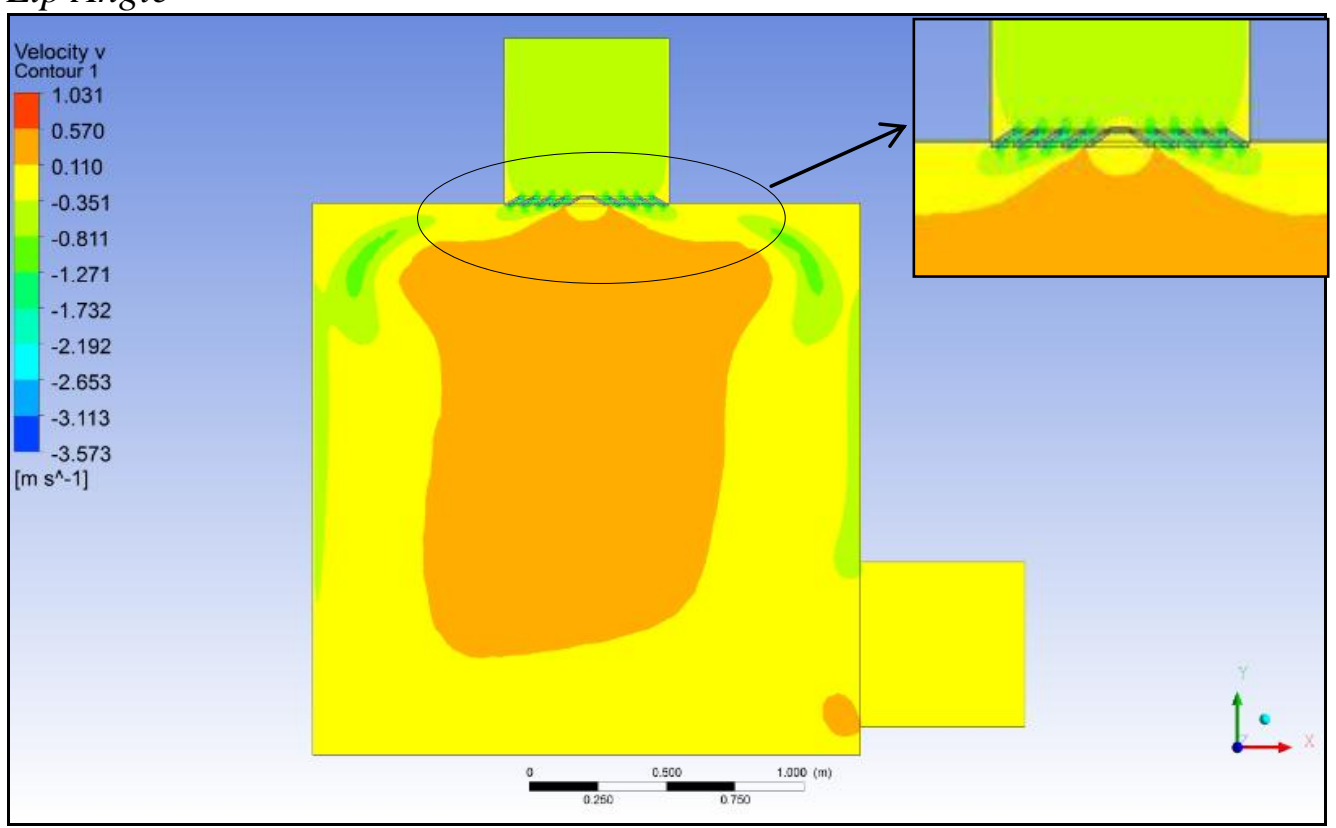

Figure 47. The $X Y$ Plot of $Y$ Velocity from the Diffuser with $60^{\circ}$ Blade Angle and $10^{\circ}$ Lip Angle

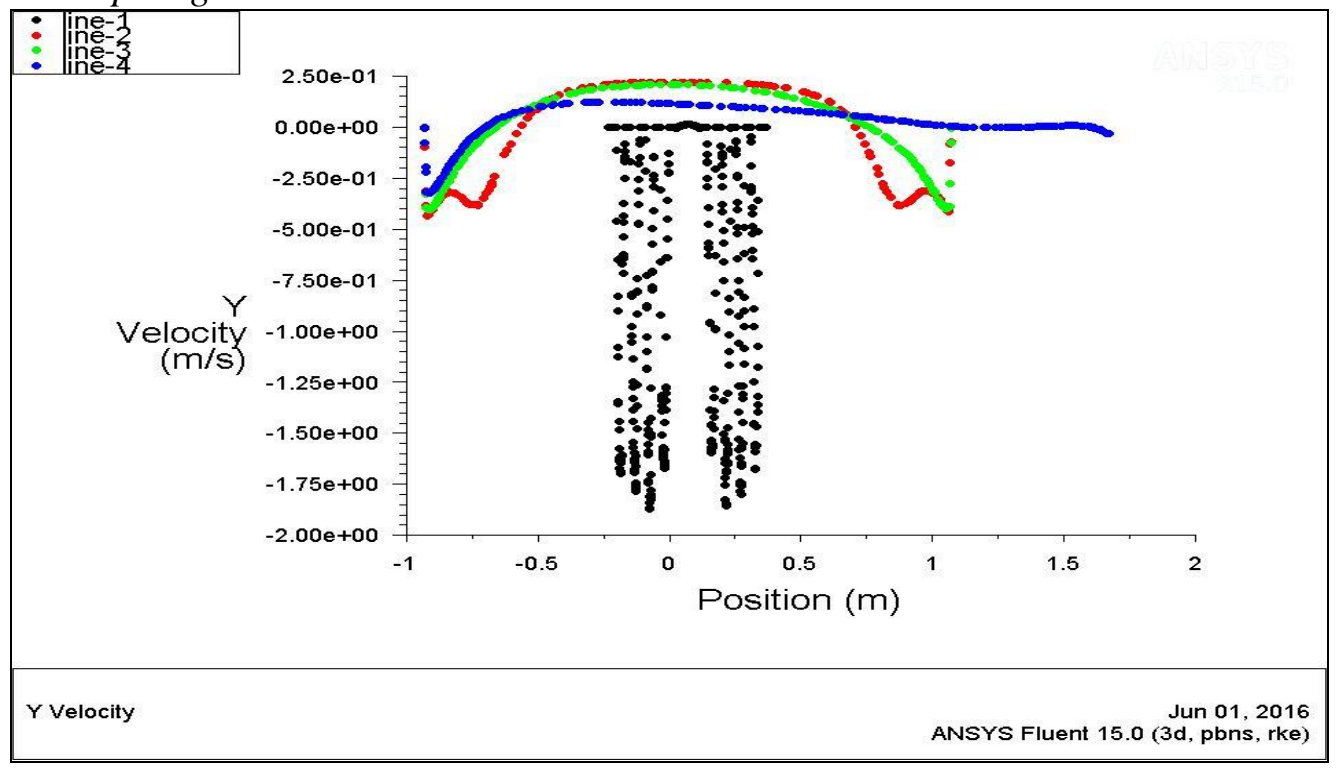


The airflow temperature distribution from the ceiling diffuser is in range (291.482 - 293.289 K) as shown in Figure 48. In addition, Figure 49 shows that the XY plot for static temperature at different lines is close with the results from the diffuser with $0^{\circ}$ and $5^{\circ}$ lip angle. Table 3 shows the average static temperature value at different lines, which indicates that the temperature gradient from line 2 to 4 is $1.562^{\circ} \mathrm{C}$.

Figure 48. Contour of Temperature from the Diffuser with $60^{\circ}$ Blade Angle and $10^{\circ}$ Lip Angle

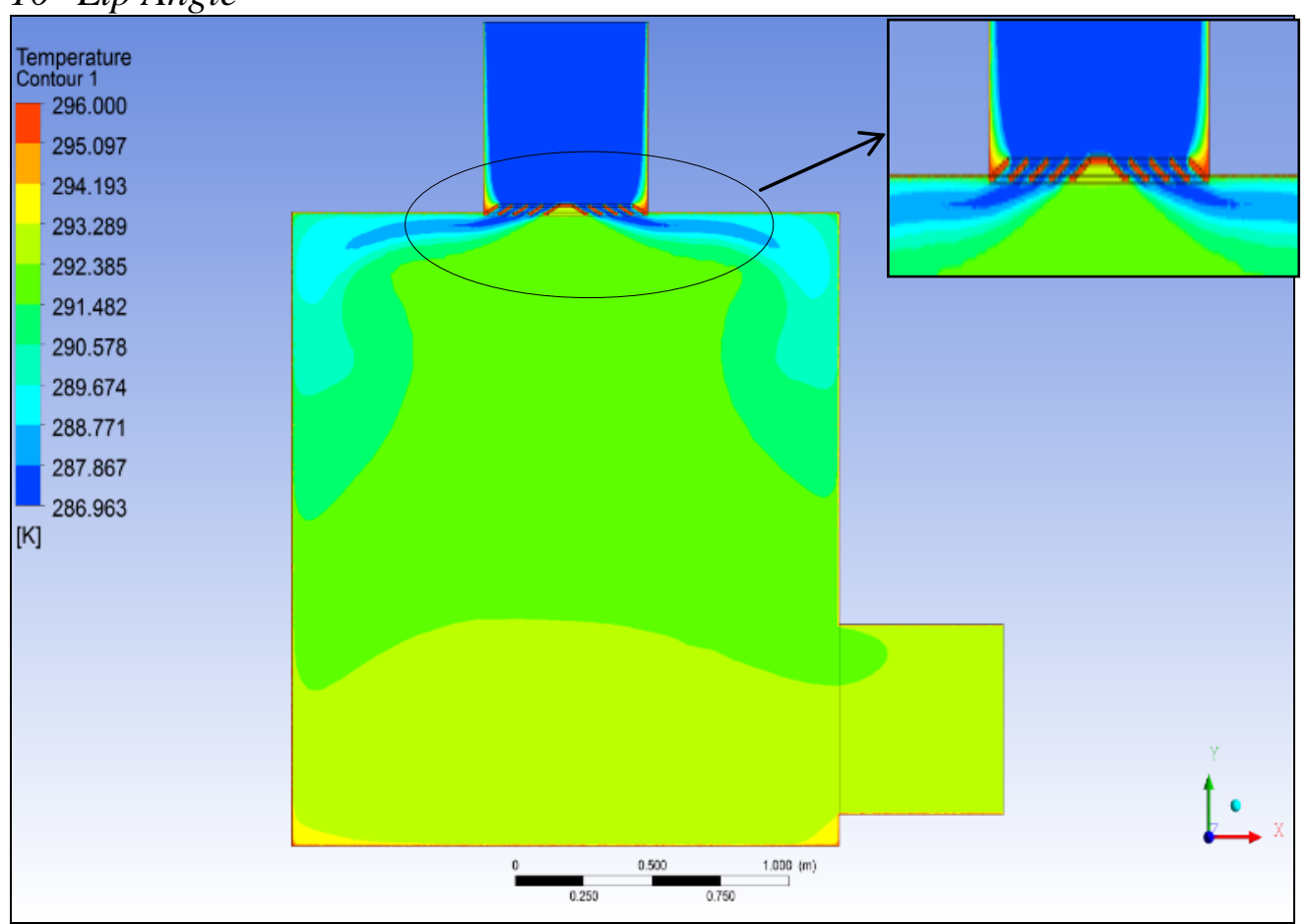

Figure 49. The XY Plot of Static Temperature from the Diffuser with $60^{\circ}$ Blade Angle and $10^{\circ}$ Lip Angle

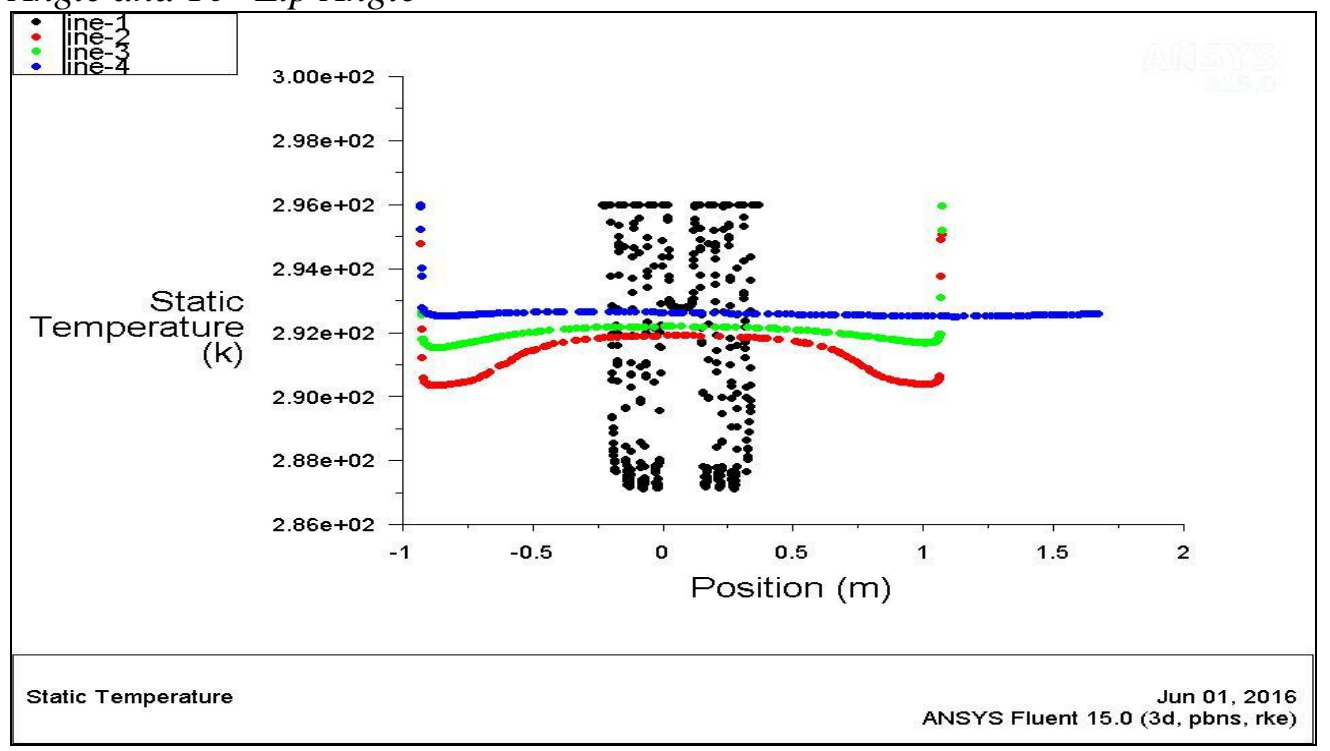




\section{Louver Face Ceiling Diffuser with $60^{\circ}$ Blade Angle and Inclined $15^{\circ}$ Lip Angle}

As shown in Figure 50, increasing the diffuser lip angle $15^{\circ}$ leads to increasing the passage distance and decreasing the jet velocity out from the diffuser $(3.648-4.053 \mathrm{~m} / \mathrm{s})$ less than the jet velocity from $0^{\circ}$ lip angle $(4.205$ $4.672 \mathrm{~m} / \mathrm{s})$ and $10^{\circ}$ lip angle $(3.835-4.261 \mathrm{~m} / \mathrm{s})$. The airflow distribution patterns throughout the room are relatively uniform $(0-0.405 \mathrm{~m} / \mathrm{s})$. The surface (Coanda) effect of air distribution is noticed where the airflow patterns cling to the ceiling and the airflow approaches the vertical walls then turns downward.

Figure 51 proves that the XY plot for velocity magnitude at different lines where the airflow velocity magnitude appeared to be higher near the walls.

Figure 50. Contour of Velocity Magnitude of the Diffuser with $60^{\circ}$ Blade Angle and $15^{\circ}$ Lip Angle

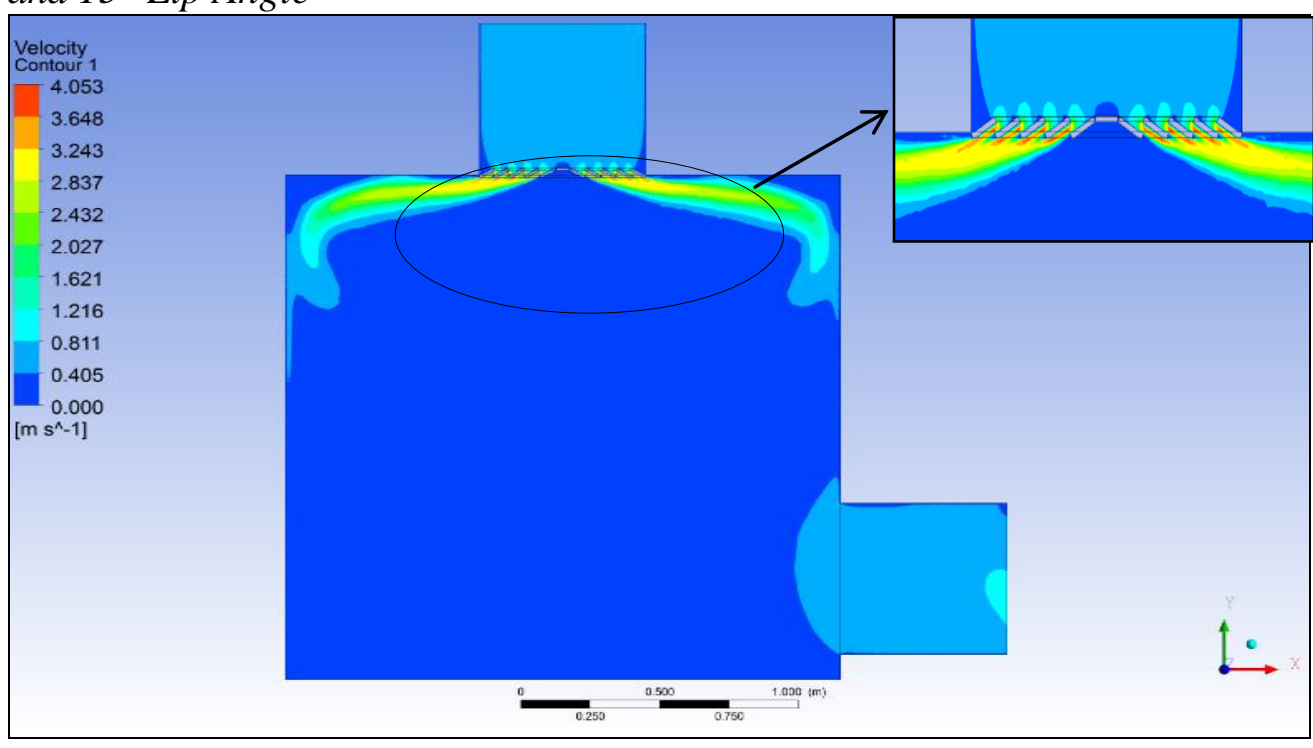

Figure 51. The XY Plot of Velocity Magnitude from the Diffuser with $60^{\circ}$ Blade Angle and $15^{\circ}$ Lip Angle

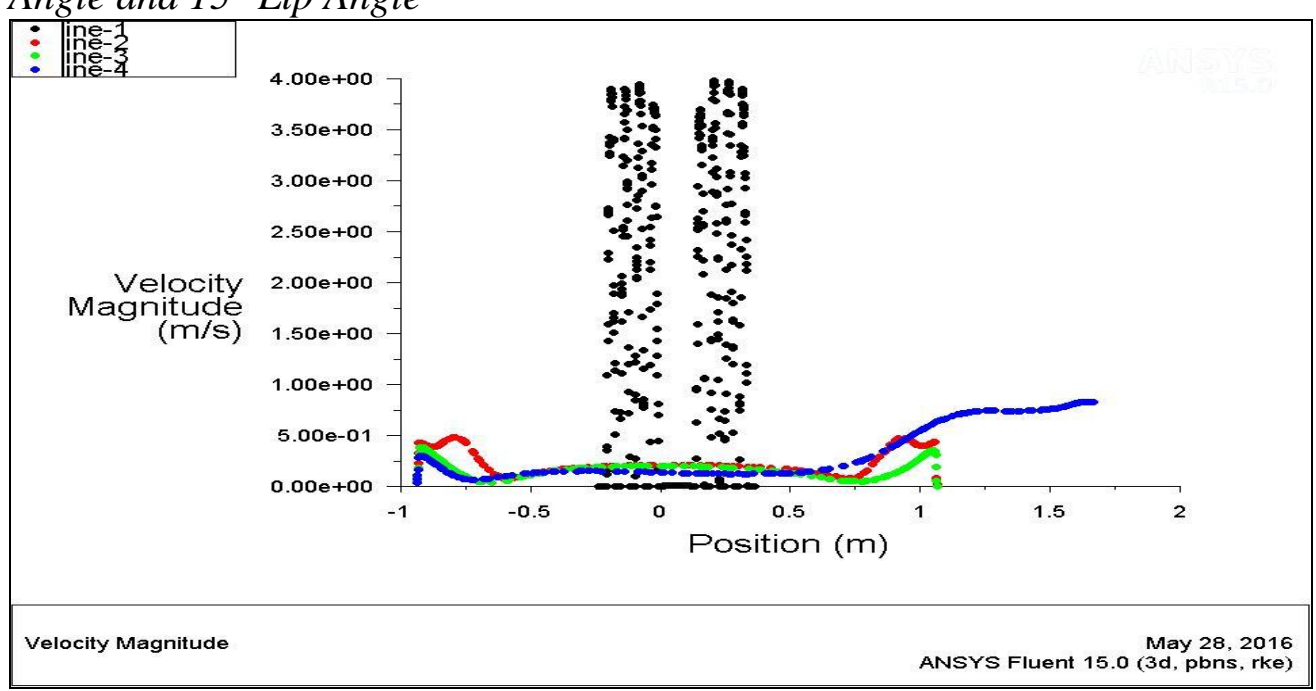


Figure 52 shows that the contour of $\mathrm{Y}$ velocity is relatively non uniform ($0.298-0.583 \mathrm{~m} / \mathrm{s}$ ) throughout the room. The $15^{\circ}$ lip angle forced airflow patterns to leave the ceiling and reach the vertical walls more than $5^{\circ}$ and $10^{\circ}$. Therefore, this model can be used in rooms with larger height.

The XY plot for Y velocity at different lines from the diffuser model with $15^{\circ}$ lip angle is shown in Figure 53, where the airflow velocity inside the room from line 2 to 4 is within average $0.20 \mathrm{~m} / \mathrm{s}$, consistent with the results from Figure 52.

Figure 52. Contour of $Y$ Velocity from the Diffuser with $60^{\circ}$ Blade Angle and $15^{\circ}$ Lip Angle

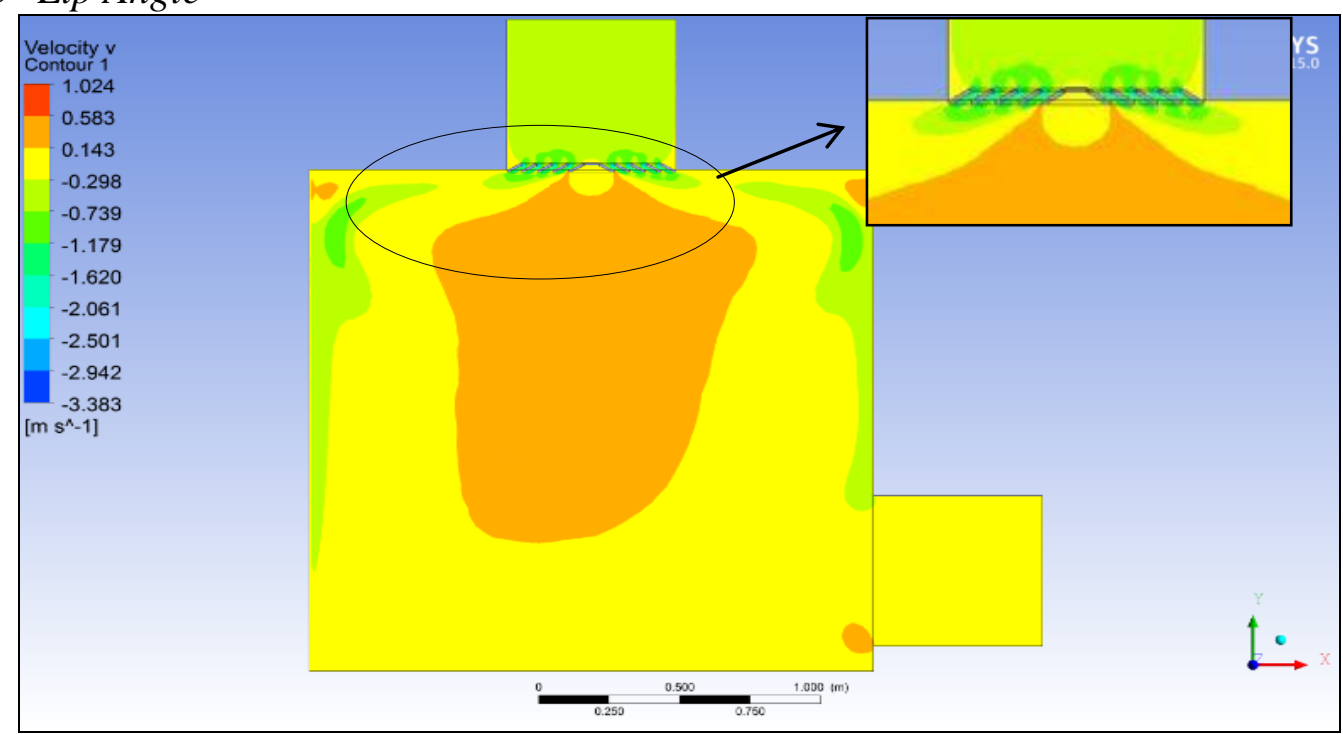

Figure 53. The $X Y$ Plot of $Y$ Velocity from the Diffuser with $60^{\circ}$ Blade Angle and $15^{\circ}$ Lip Angle

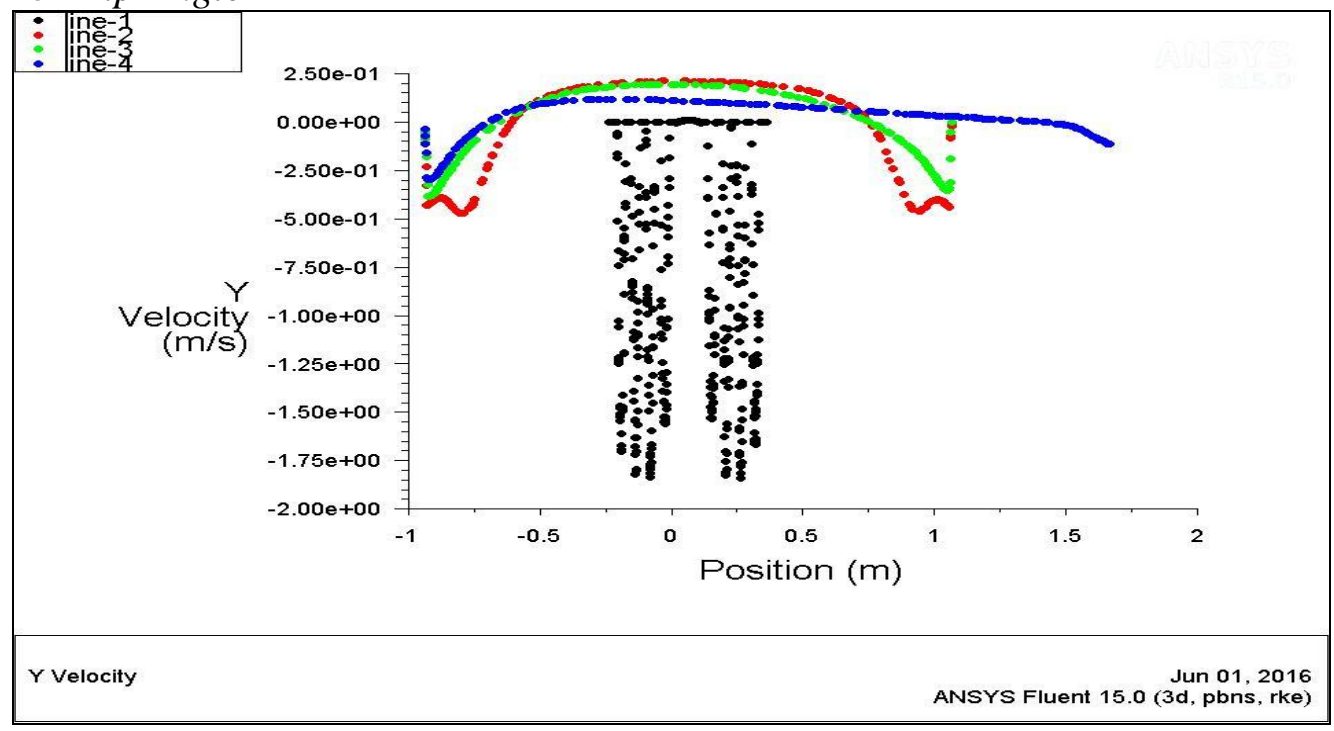


In Figure 54, the airflow temperature distribution from the ceiling diffuser is in range (291.493 - 293.296 K). In addition, Figure 55 shows the XY plot for static temperature at different lines, which validates and consistent with the results from Figure 54. Table 3 also shows the average static temperature value at different lines, which indicates that the temperature gradient from inside the occupied zone is $1.589^{\circ} \mathrm{C}$, and this value is acceptable according to the ASHRAE standard 55-2013 and the SMACNA standard (ASHRAE, 2013; SMACNA HVAC).

The average values appeared within the range $(0.2-0.32 \mathrm{~m} / \mathrm{s})$. However, near the room floor at line 6 the average velocity value was shown above $0.1 \mathrm{~m} / \mathrm{s}$. Therefore, the diffuser model with $15^{\circ}$ can be used inside rooms with larger dimensions.

Figure 54. Contour of Temperature from the Diffuser with $60^{\circ}$ Blade Angle and $15^{\circ}$ Lip Angle

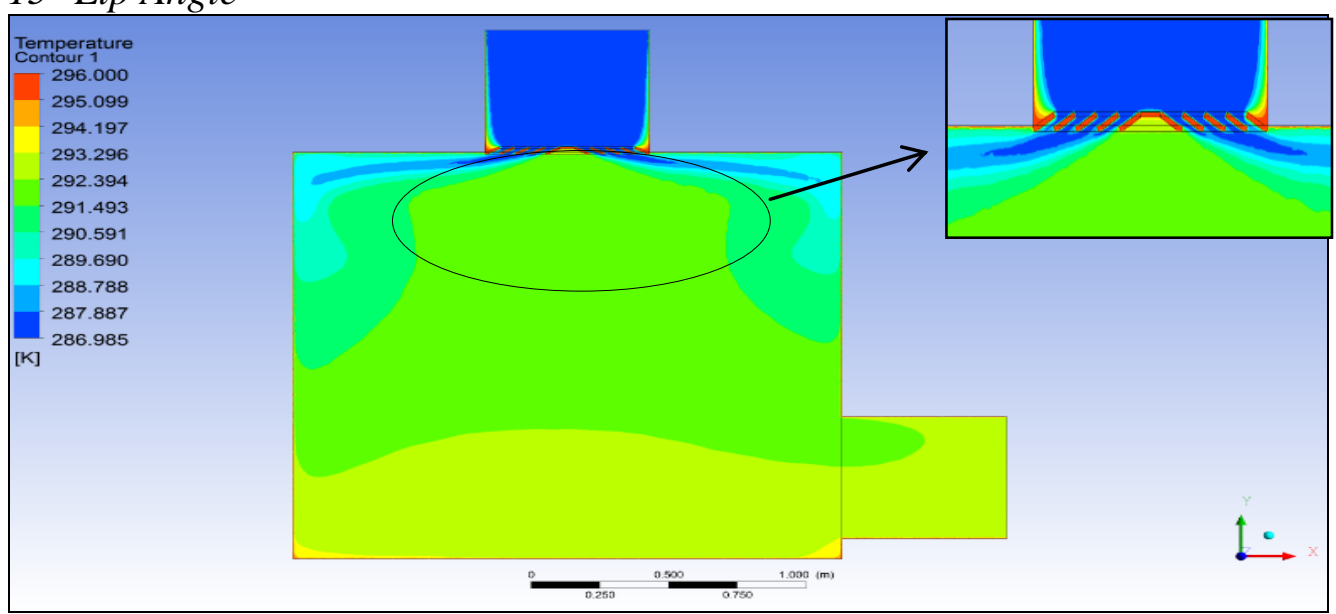

Figure 55. The XY Plot of Static Temperature from the Diffuser with $60^{\circ}$ Blade Angle and $15^{\circ}$ Lip Angle

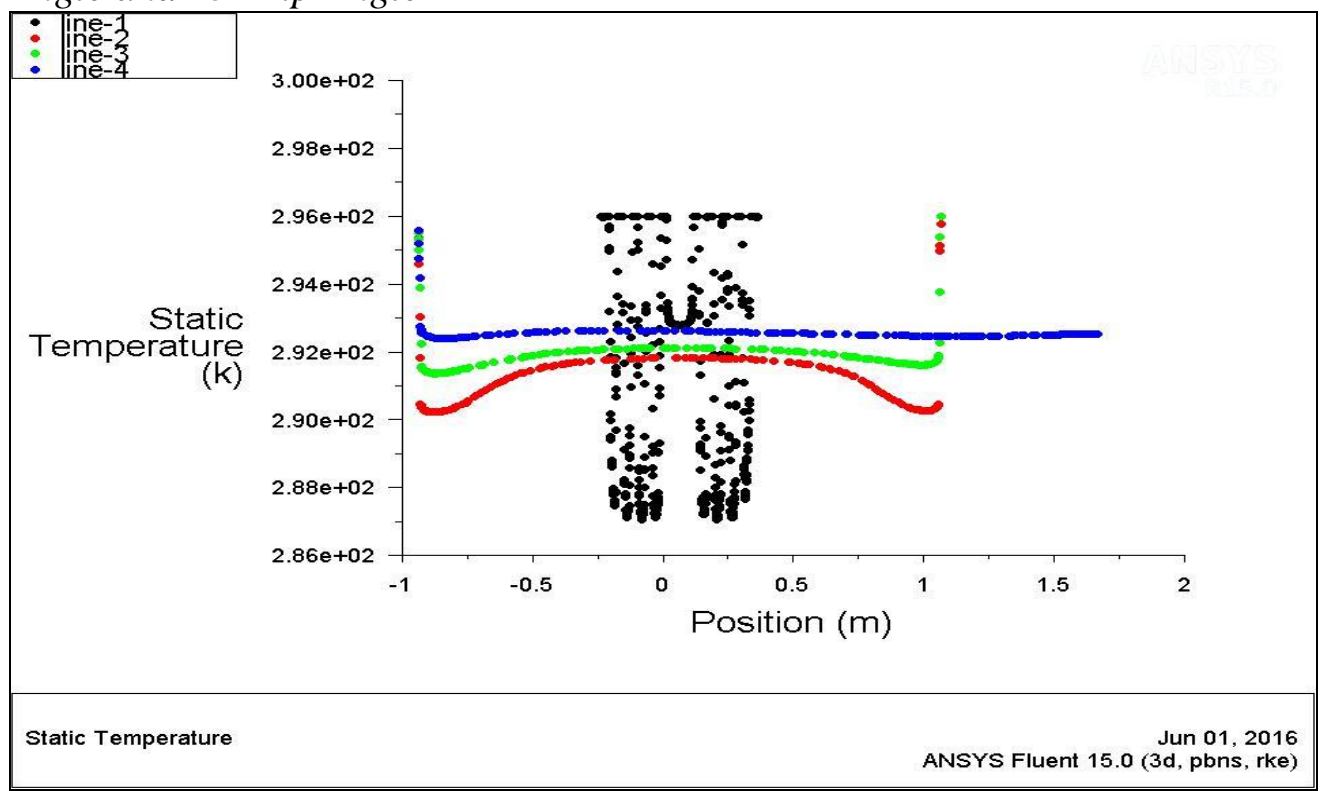


Figure 56 shows the contours of airflow velocity from the diffuser with blade angle $60^{\circ}$ and $15^{\circ}$ lip angle throughout the new room model. Increasing the diffuser lip angle to $15^{\circ}$ leads to decreasing the jet velocities out from the diffuser $(3.633-4.037 \mathrm{~m} / \mathrm{s})$ and the terminal velocity of airflow throughout the room $(0-0.404 \mathrm{~m} / \mathrm{s})$. These velocity values are consistent with the values from the diffuser model inside the small room $(3.648-4.053 \mathrm{~m} / \mathrm{s})$ and $(0-0.405 \mathrm{~m} / \mathrm{s})$, respectively.

In addition, increasing the lip angle to $15^{\circ}$ resulted in the airflow patterns attaching to the ceiling and therefore the surface (Coanda) effect is noticed where the airflow approached the walls then turned downward.

Figure 57 proves that the velocity magnitude at different lines located inside the occupied zone of the small and large room models. In addition, Table 6 shows that the average value for velocity magnitude at different levels inside small and large room.

Figure 56. Contours of Airflow Velocity Distribution from the Diffuser with $60^{\circ}$ Blade Angle and $15^{\circ}$ Lip Angle inside the New Room Model with Larger Height

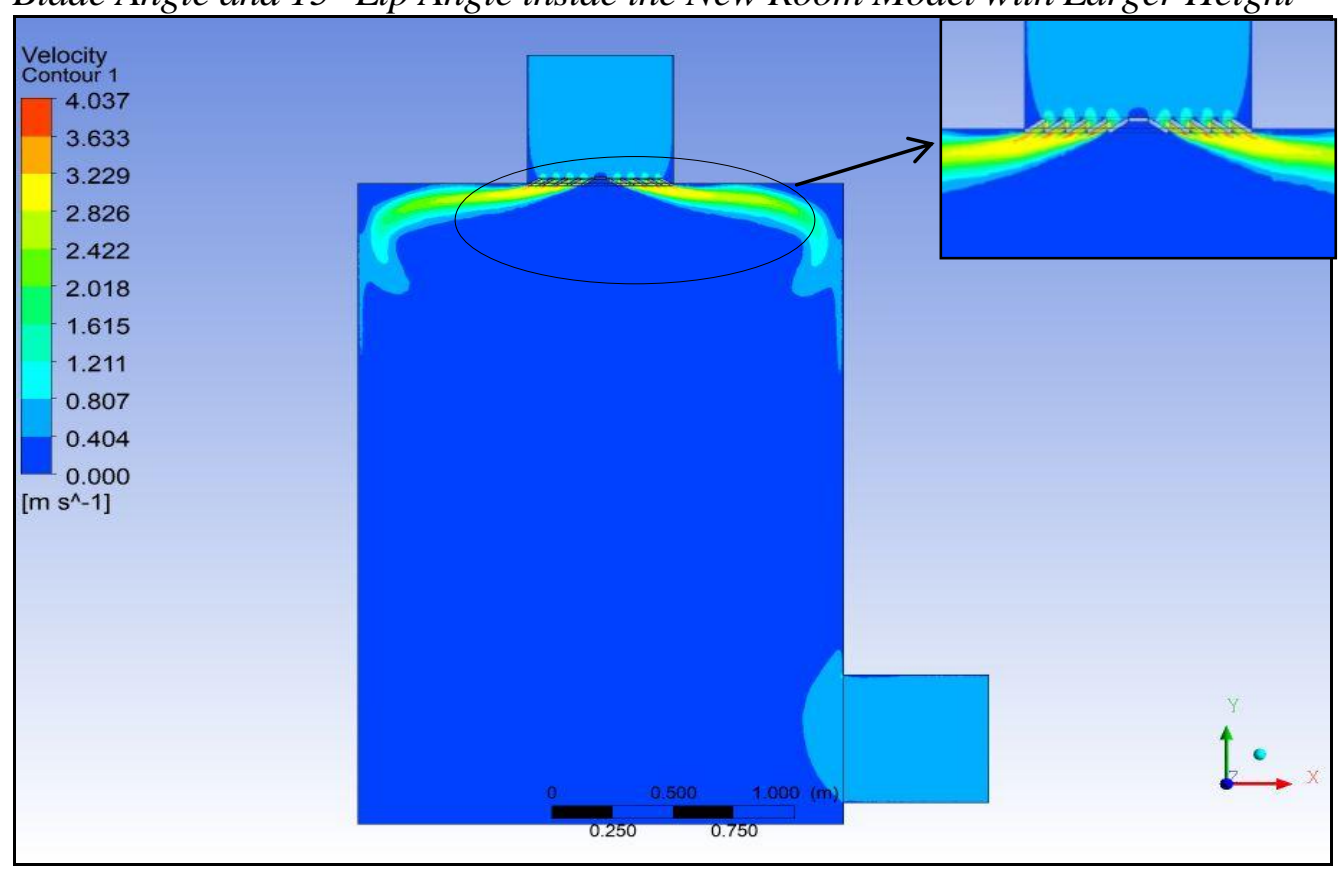


Figure 57. Velocity Magnitude from Louver Face Ceiling Diffuser with $60^{\circ}$ Blade Angle and $15^{\circ}$ Lip Angles at Different Lines inside the Two Room Models

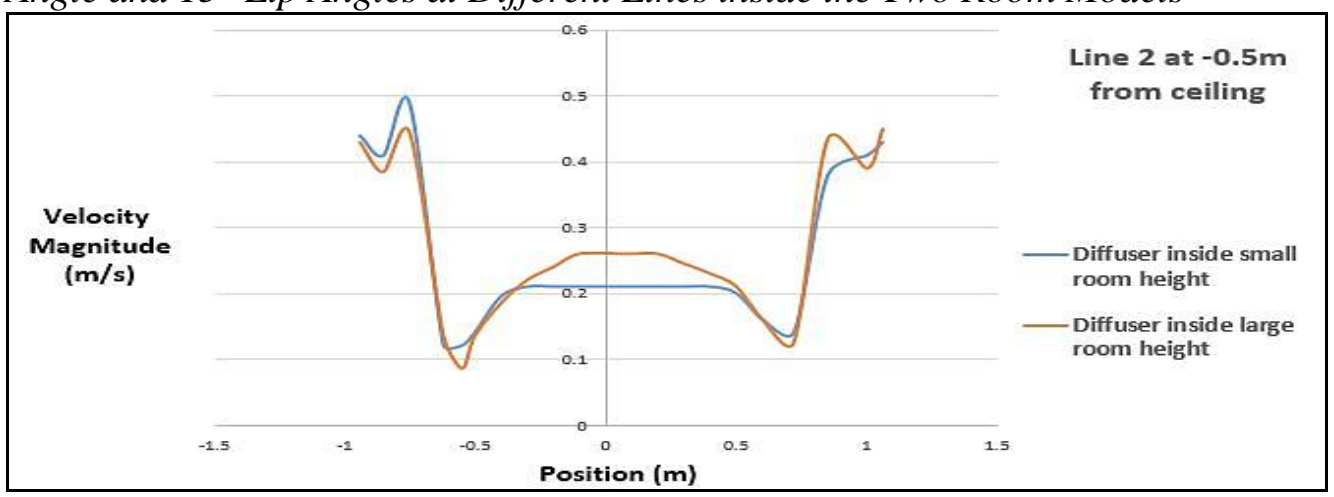

(a)

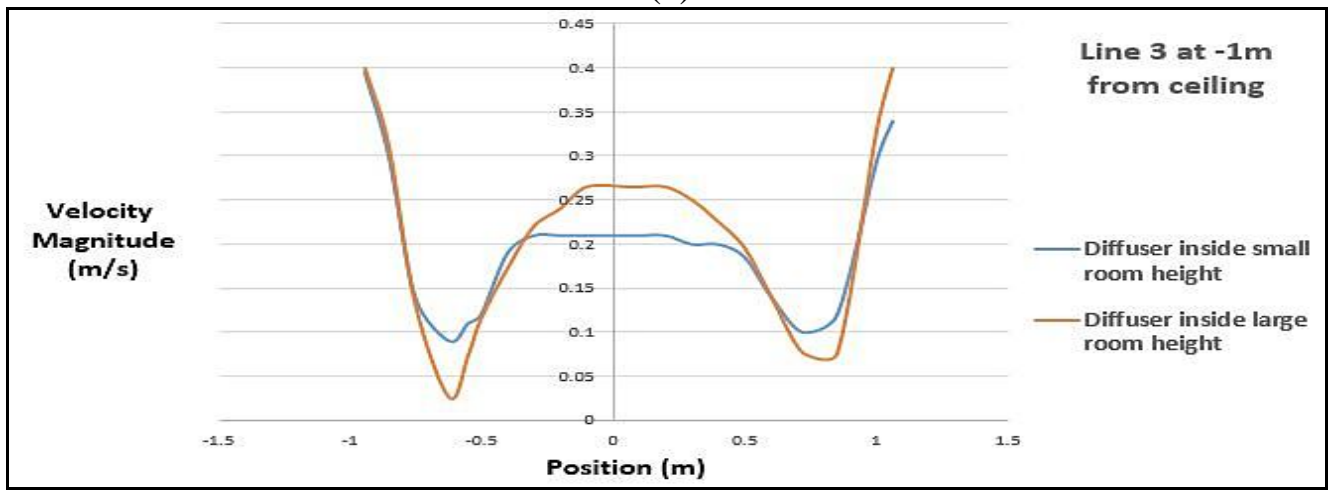

(b)

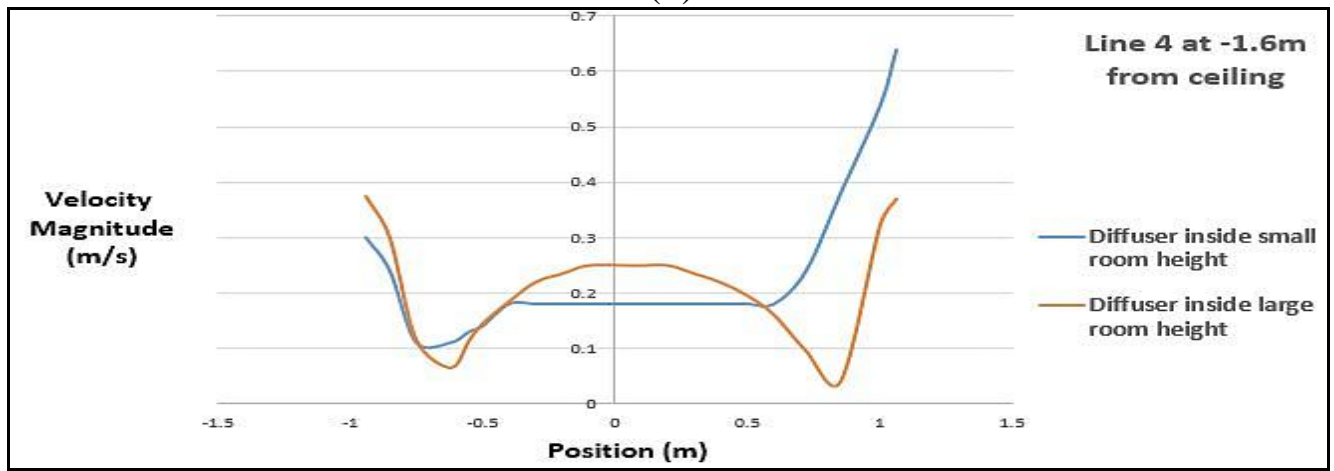

(c)

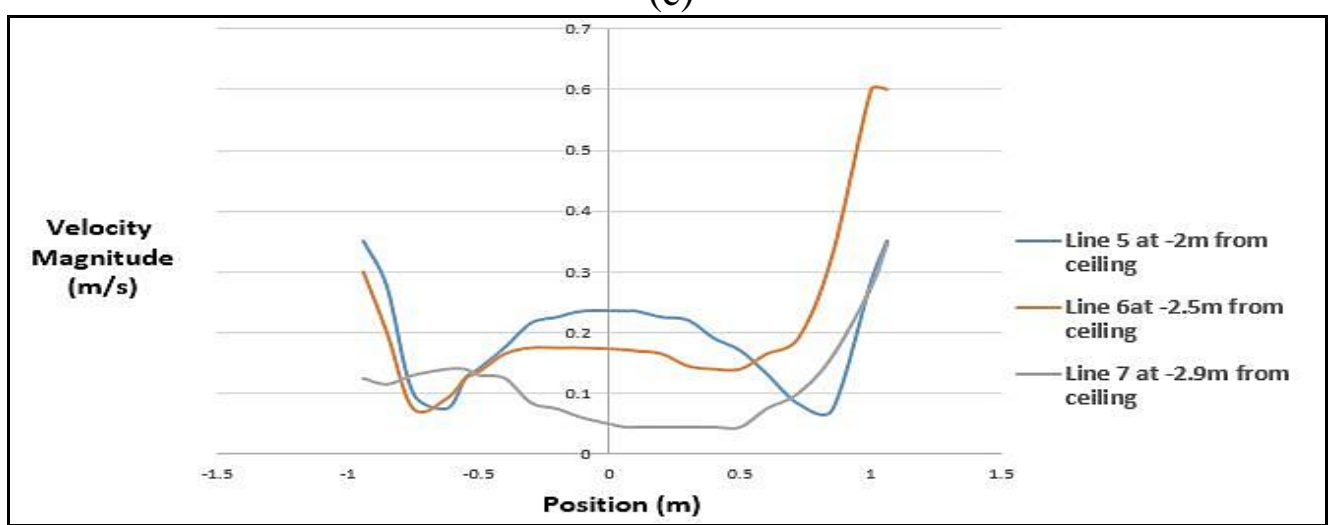

(d) 
Table 6. Average Velocity Magnitude and Average Static Temperature Distribution from the Diffuser with $60^{\circ}$ Blade Angle and $15^{\circ}$ Lip Angle at Different Lines Location inside the Two Room Models

\begin{tabular}{|c|c|c|c|}
\hline Item & Line number & $\begin{array}{l}\text { Diffuser with } 65^{\circ} \\
\text { blade angle and } 0^{\circ} \text { lip } \\
\text { within the small } \\
\text { room }\end{array}$ & $\begin{array}{l}\text { Diffuser with } 65^{\circ} \\
\text { blade angle and } 0^{\circ} \\
\text { lip within the large } \\
\text { room }\end{array}$ \\
\hline \multirow{6}{*}{$\begin{array}{l}\text { Average velocity } \\
\text { magnitude }(\mathrm{m} / \mathrm{s})\end{array}$} & Line (2) & 0.305 & 0.322 \\
\hline & Line (3) & 0.200 & 0.227 \\
\hline & Line (4) & 0.412 & 0.217 \\
\hline & Line (5) & 0 & 0.212 \\
\hline & Line (6) & 0 & 0.234 \\
\hline & Line (7) & 0 & 0.111 \\
\hline \multirow{6}{*}{$\begin{array}{l}\text { Average static } \\
\text { temperature }(\mathrm{K})\end{array}$} & Line (2) & 290.928 & 291.097 \\
\hline & Line (3) & 291.757 & 291.910 \\
\hline & Line (4) & 292.517 & 292.585 \\
\hline & Line (5) & 0 & 292.921 \\
\hline & Line (6) & 0 & 293.237 \\
\hline & Line (7) & 0 & 293.558 \\
\hline
\end{tabular}

The contours of air temperature distribution from the diffuser with blade angle $60^{\circ}$ and $15^{\circ}$ lip angle throughout the new room model with larger height are shown in Figure 58.

Increasing the diffuser lip angle leads to relatively reducing the cling or attachment of airflow patterns with the ceiling, which reduces the heat transfer process (friction) between the airflow and ceiling. Therefore, the static temperature near the walls in the case of $15^{\circ}$ is low. However, near the floor the temperature distribution within the range [293.294 - 294.196 K].

Figure 59 and Table 6 present the average values for temperature at different levels inside both the small and large rooms. These indicated that the temperature gradients between lines from the diffuser model inside the large room was $2.461^{\circ} \mathrm{C}$, which is more than that indicated from the diffuser inside the small room, or $1.589^{\circ} \mathrm{C}$. However, the temperature gradients from this diffuser model are less than the values from the diffuser with $45^{\circ}$ blade angle and the value indicated by the ASHRAE standard 55-2013 (ASHRAE, 2013). 
Figure 58. Contours of Airflow Temperature Distribution from the Diffuser with $60^{\circ}$ Blade Angle and $15^{\circ}$ Lip Angle inside the New Room Model with Larger Height

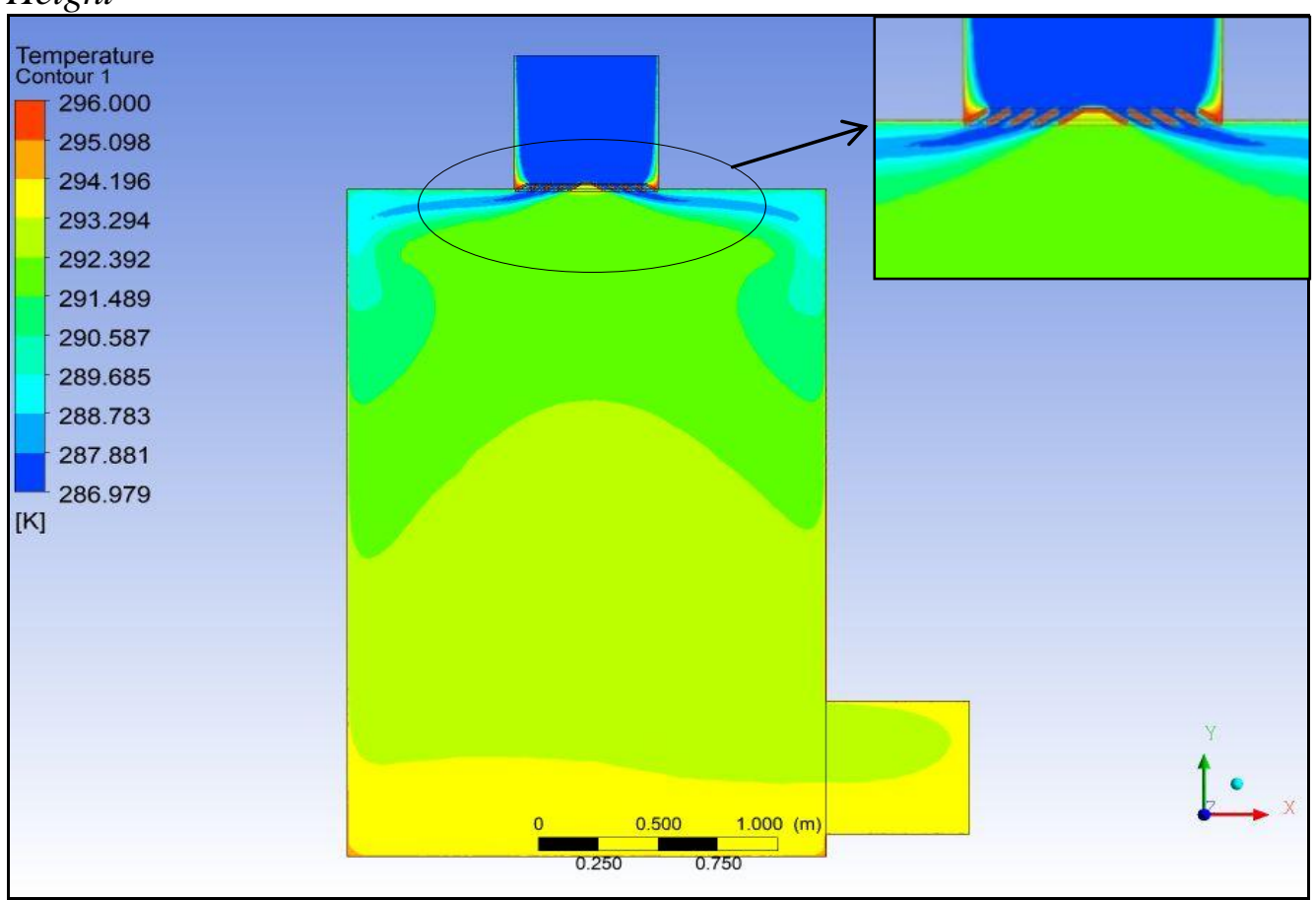

Figure 59. Static Temperature Distribution from Louver Face Ceiling Diffuser with $60^{\circ}$ Blade Angle and $15^{\circ}$ Lip Angles at Different Lines inside the Two Room Models

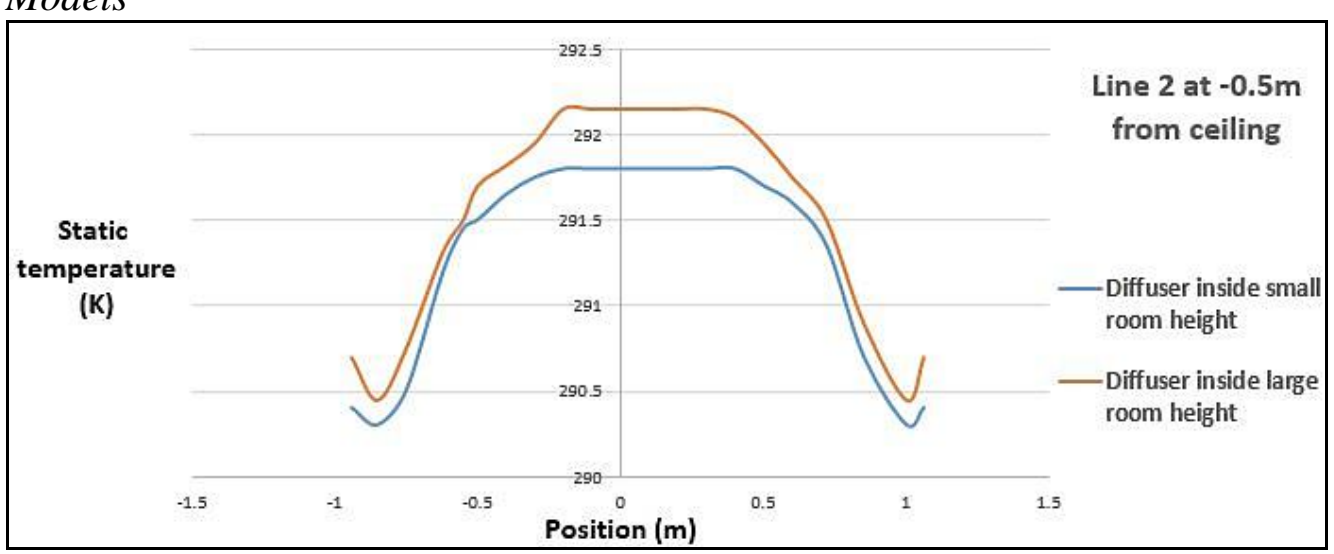

(a) 


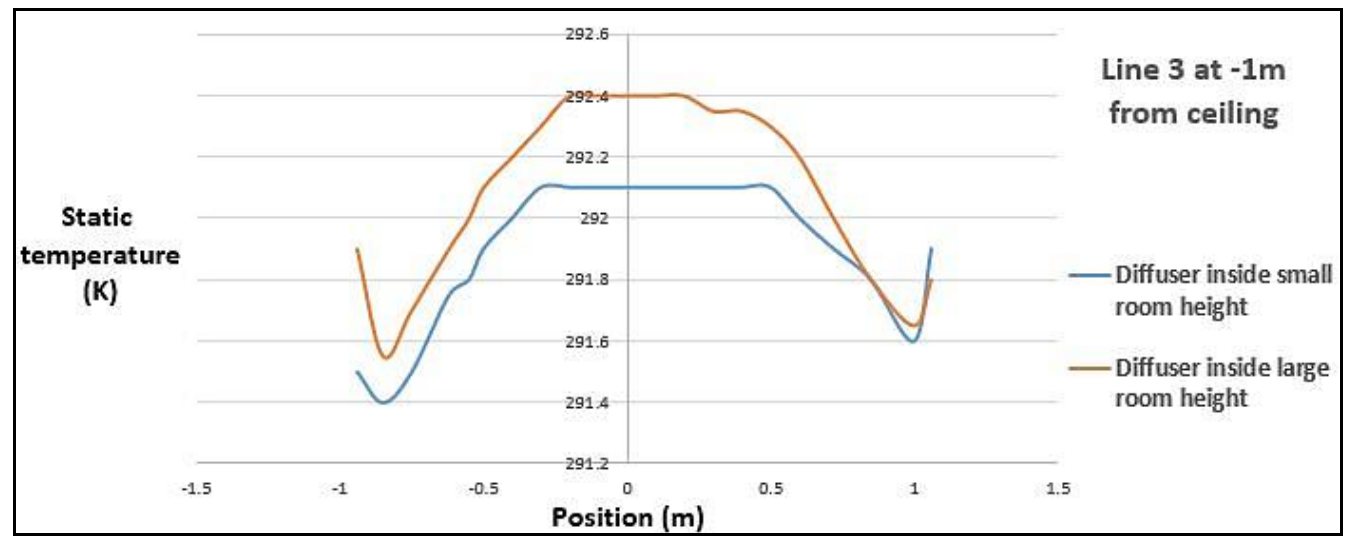

(b)

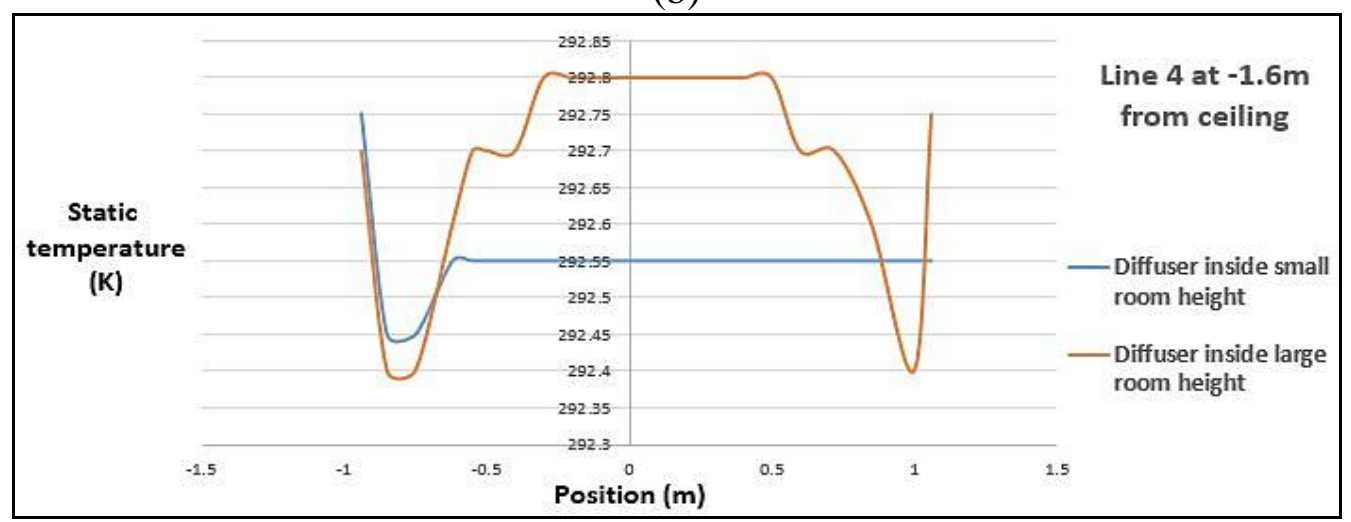

(c)

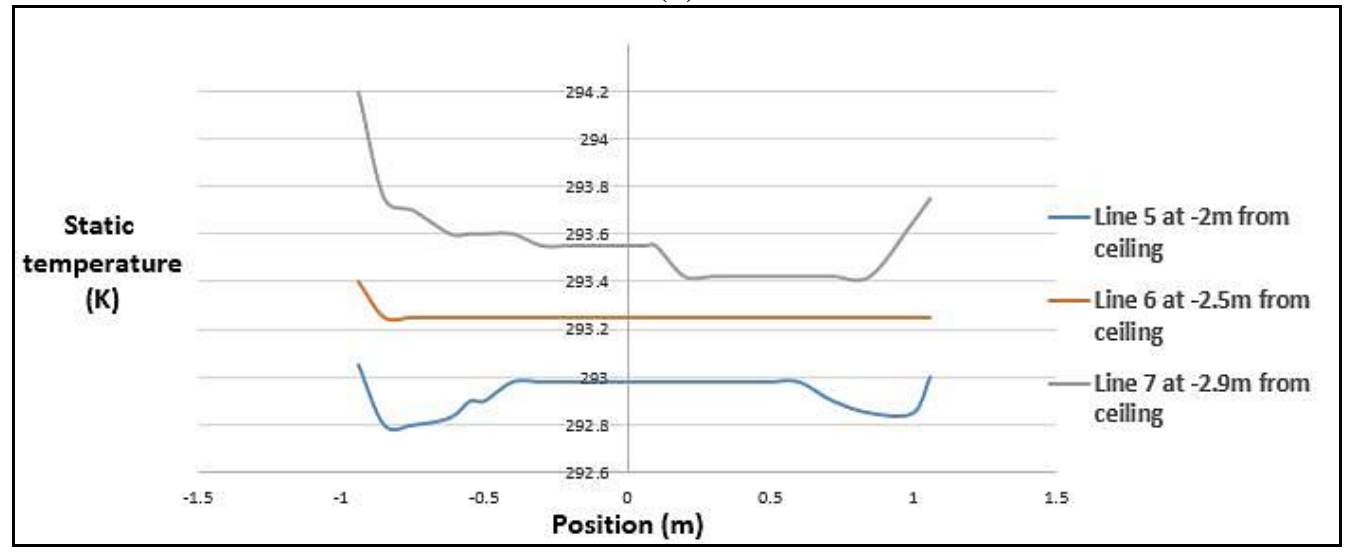

(d)

\section{Conclusions}

In the present study, the performance of square louver face ceiling diffusers within a room have been presented for several diffuser models with different blade and lip angles. The effects of different diffuser shapes on the airflow characteristics throughout the room and occupants' thermal comfort are presented. 


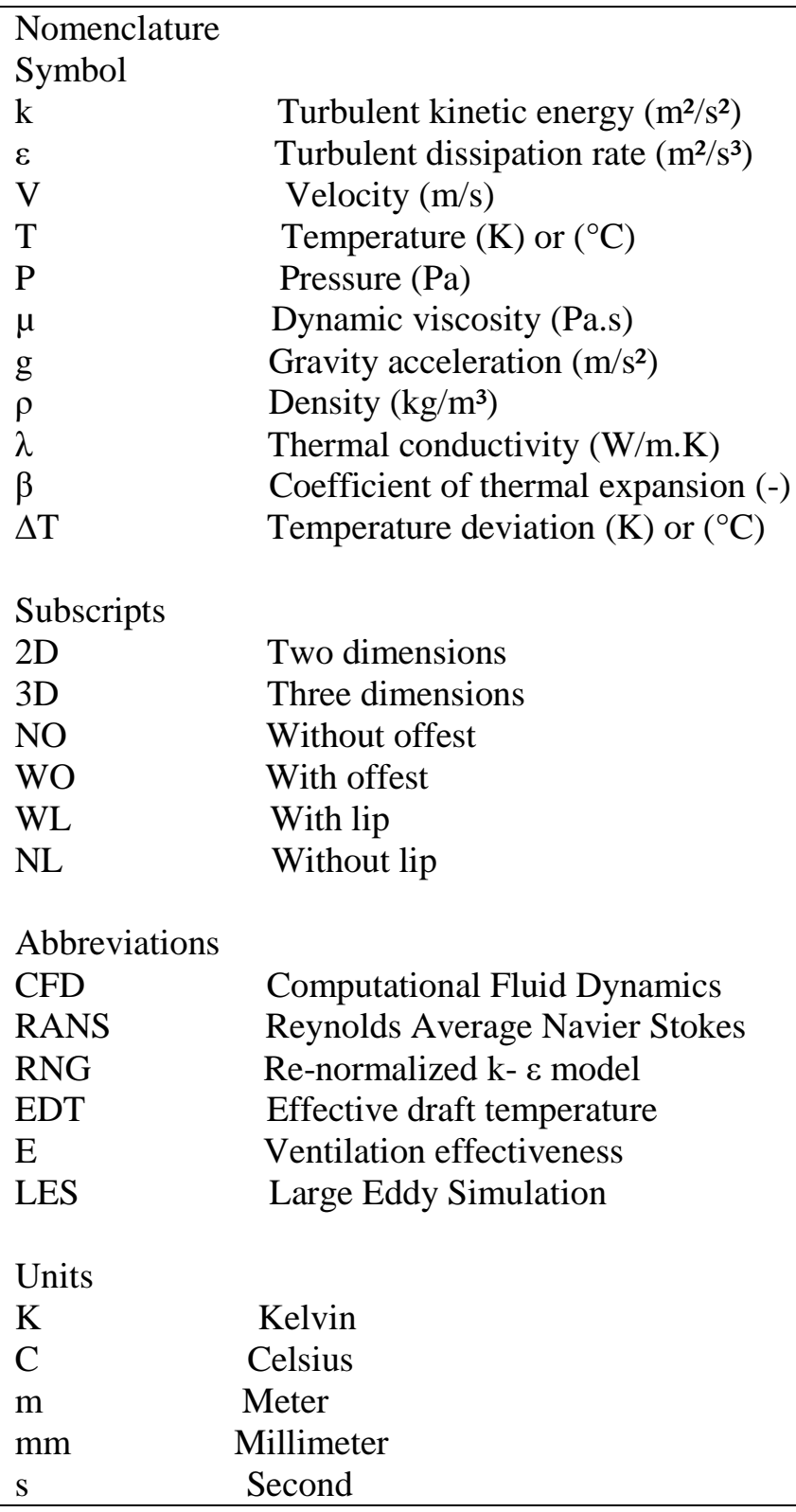

- The diffuser model with $65^{\circ}$ blade angle and $0^{\circ}$ lip angle leads to an increase in the jet velocity out from the diffuser, while the Coanda effect was noticed with higher throw than $60^{\circ}$ blade angle.

- The terminal velocity distribution in the occupied zone is noticed above $0.25 \mathrm{~m} / \mathrm{s}$ causing occupants discomfort. In addition, the maximum temperature gradient throughout the occupied zone is $1.427^{\circ} \mathrm{C}$.

- The diffuser model with blade angle at $65^{\circ}$ blade angle and $0^{\circ}$ lip angle can be used in larger spaces. Therefore, the number of diffusers distributed inside the large space, the amount of ductwork required, and installation cost will be reduced. 
- The diffuser model with $45^{\circ}$ blade angle and $0^{\circ}$ lip angle leads to the airflow going throughout the room in a cone shape and forced air to reach to the vertical walls with high velocity.

- The terminal velocity distribution in the occupied zone below $0.25 \mathrm{~m} / \mathrm{s}$ and above $0.20 \mathrm{~m} / \mathrm{s}$ causes occupants comfort. Moreover, the maximum temperature gradient throughout the occupied zone is $1.950^{\circ} \mathrm{C}$. Therefore, this model can be used in spaces with larger height.

- Increasing the diffuser lip angle to $15^{\circ}$ leads to an increase in the airflow passage distance, which decreases the jet from the diffuser similar to $45^{\circ}$ blade angle diffuser but with airflow clinging to the ceiling (Coanda effect).

- The terminal velocity distribution in the occupied zone within the range $0.22-0.25 \mathrm{~m} / \mathrm{s}$ which causes occupant's thermal comfort.

- In addition, the maximum temperature gradients throughout the occupied zone were $1.589^{\circ} \mathrm{C}$. Therefore, the diffuser with $60^{\circ}$ blade angle and $15^{\circ}$ lip angle can be used in spaces with larger heights better than the $45^{\circ}$ blade angle and $0^{\circ}$ lip angle.

\section{References}

Abanto, J., Barrero, D., Reggio, M., Ozell, B. Airflow modelling in a computer room, Building and Environment 39 (2004), 1393-1402.

AIR MASTER Engineering Guide. Retrieved May 20, 2016, from AIR MASTER website: http://bit.ly/2kgaNtp, last accessed at June-2016.

ANSYS Inc., ANSYS FLUENT user's guide release 15.0, November 2013.

ASHRAE Handbook Fundamentals 2013. Chapter 20, Space Air Diffusion. ASHRAE Standard 55-2013. Thermal Environmental Conditions for Human Occupancy.

Aziz, M. A., Gad, I.A.M., Mohammed, E.S.F.A., Mohammed, R.H. Experimental and numerical study of influence of air ceiling diffusers on room air flow characteristics, Energy and Buildings 55 (2012), 738-746.

Djunaedy, E. and Cheong, K. W. D. Development of a simplified technique of modelling four-way ceiling Air supply diffuser, Building and Environment 37 (2002), 393-403.

Fan, J., Hviid, C. A., Yang, H. Performance analysis of a new design of office diffuse ceiling ventilation system, Energy and Buildings 59 (2013), 73-81.

Fontanini, A., Olsen, M. G., Ganapathysubramanian, B. Thermal comparison between ceiling diffusers and fabric ductwork diffusers for green buildings, Energy and Building 43 (2011), 2973-2987.

GAMMA LINE INTERNATIONAL. Retrieved May 20, 2016, from GAMMA LINE international web site: http://www.gammaline.com/products.htm.

Heschl, C., Inthavong, K., Sanz, W., Tu, J. Evaluation and improvements of RANS turbulence models for linear diffuser flows. Computers \& Fluids 71 (2013), 272-282.

Lu, W., Howarth, A . T., Nor, A., Riffat, S . B. Modeling and measurement of airflow and aerosol particle distribution in a ventilated two-zone chamber. Building and Environment 31 (1996), 417-23.

Mohammed, R. H. A simplified method for modeling of round and square ceiling diffusers, Energy and Building 64 (2013), 473-482. 
PRICE Air Distribution Engineering Guide. Retrieved May 20, 2016, from Price web site: http://bit.ly/2xLb0ua, last accessed at June-2016.

Posner, J. D., Buchanan, C. R., Dunn-rankin, D. Measurement and prediction of indoor air flow in a model room, Energy and Building 35 (2003), 515-526.

Rees, S. J., and Haves, P. An experimental study of air flow and temperature distribution in a room with displacement ventilation and a chilled ceiling, Building and Environment 59 (2013), 358-368.

Rees, S., McGuirk, J., Haves, P. Numerical investigation of transient buoyant flow in a room with a displacement ventilation and chilled ceiling system. Int. J. of Heat Mass Transfer 44 (2001), 3067-3080.

SMACNA HVAC system - duct design, chapter 3 - room air distribution.

Sun, Y. and Smith, F. Air flow characteristics of a room with square cone diffusers, Building and Environment 40 (2005), 589-600.

Tina, Z. F., Tu, J. Y., Yeoh, G. H., Yuen, R. K. K. On the numerical study of contaminant particle concentration in indoor airflow, Building and Environment 41 (2006), 1504-1514.

Tina, Z. F., Tu, J. Y., Yeoh, G. H., Yuen, R. K. K. Numerical studies of indoor airflow and particle dispersion by large eddy simulation, Building and Environment 42 (2007), 3483-3492.

Wang, X. and Lin, Z. An experimental investigation into the pull-down performances with different air distributions, Applied Thermal Engineering 91 (2015), 151-162.

ZAMZAM Air Quality Products. Retrieved May 20, 2016, from Zamzam engineering industries web site: http://www.zamzam-eg.com/outlets/outlet1.htm.

Zhao, B., Li, X., Yan, Q. A simplified system for indoor airflow simulation, Building and Environment 38 (2003), 543-552. 